\title{
Gaze processing in chimpanzees and humans
}

Citation for published version (APA):

Okamoto-Barth, S. (2005). Gaze processing in chimpanzees and humans. [Doctoral Thesis, Maastricht University]. Universitaire Pers Maastricht. https://doi.org/10.26481/dis.20050609so

Document status and date:

Published: 01/01/2005

DOI:

10.26481/dis.20050609so

Document Version:

Publisher's PDF, also known as Version of record

\section{Please check the document version of this publication:}

- A submitted manuscript is the version of the article upon submission and before peer-review. There can be important differences between the submitted version and the official published version of record.

People interested in the research are advised to contact the author for the final version of the publication, or visit the DOI to the publisher's website.

- The final author version and the galley proof are versions of the publication after peer review.

- The final published version features the final layout of the paper including the volume, issue and page numbers.

Link to publication

\footnotetext{
General rights rights.

- You may freely distribute the URL identifying the publication in the public portal. please follow below link for the End User Agreement:

www.umlib.nl/taverne-license

Take down policy

If you believe that this document breaches copyright please contact us at:

repository@maastrichtuniversity.nl

providing details and we will investigate your claim.
}

Copyright and moral rights for the publications made accessible in the public portal are retained by the authors and/or other copyright owners and it is a condition of accessing publications that users recognise and abide by the legal requirements associated with these

- Users may download and print one copy of any publication from the public portal for the purpose of private study or research.

- You may not further distribute the material or use it for any profit-making activity or commercial gain

If the publication is distributed under the terms of Article $25 \mathrm{fa}$ of the Dutch Copyright Act, indicated by the "Taverne" license above, 
GAZE PROCESSING

IN CHIMPANZEES AND HUMANS 
ISBN 90-5278-468-X

Production: Datawyse / Universitaire Pers Maastricht

Coverdesign: Annett Gericke 


\section{GAZE PROCESSING IN CHIMPANZEES AND HUMANS}

\section{PROEFSCHRIFT}

ter verkrijging van de graad van doctor aan de Universiteit Maastricht, op gezag van de Rector Magnificus, Prof. mr. G.P.M.F. Mols, volgens het besluit van het College van Decanen,

in het openbaar te verdedigen op donderdag 9 juni 2005 om 14.00 uur

door

SANAE OKAMOTO-BARTH

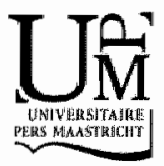


Promotor

Prof. dr. R. Goebel

Co-Promotor

Dr. W.G.M. Raaijmakers

Beoordelingscommissie

Prof. dr. W. J. Riedel (voorzitter)

Prof. dr. J.A.R.A.M. van Hooff (Universiteit Utrecht)

Prof. dr. C. Kemner

Prof. dr. C. Moore (University of Toronto)

Dr. J. E. A. Stauder

The research reported in chapters 1, 2, and 3 was conducted at the Primate Research Institute, Kyoto University in Aichi, Japan under the supervision of Prof. dr. Tetsuro Matsuzawa, Dr. Masaki Tomonaga, and Dr. Masayuki Tanaka. The research reported in chapter 4 was conducted at Nagoya University, Cognitive Informatics Unit under the supervision of Dr. Nobuyuki Kawai. The general continuous supervision and support by Prof. dr. Kiyoshi Ishii at Nagoya University is greatly appreciated. 


\section{CONTENTS}

Chapter 1: Development of Visual Interaction

Looking compensates for the distance between mother and infant chimpanzee.

Chapter 2: Development of Gaze Following I

An infant chimpanzee (Pan troglodytes) follows

human gaze.

Chapter 3: Development of Gaze Following II

Looking back:

the 'representational mechanism' of joint attention in an infant chimpanzee (Pan troglodytes).

Chapter 4: Facilitation Effect by a Gaze-cue

The role of attention in the facilitation effect and Another "Inhibition of Return"

General Discussion

Summary

Samenvatting

Dankwoord

Curriculum vitae

Publications 
s. 


\section{GENERAL INTRODUCTION}




\section{DEVELOPMENTAL ASPECTS OF GAZE PROCESSING - GAZE PERCEPTION AND EYE CONTACT}

Gaze is defined as looking steadily, intently, and with fixed attention, and is an important component of social interaction. Humans are highly sensitive to the gaze of others. For instance, humans use gaze to signal turns in conversation and to communicate interpersonal attitudes (Kleinke, 1986). Eyes per se have long held special interest to humans. They are, arguably, the most important components of the face and are often described as the "window to the soul" (Baron-Cohen, 1995), providing information about emotional and mental states.

Our species' interest in eyes appear early in development. They are the first points of contact between infants and their mothers (Haith, Bergman, \& Moore, 1977). The ability to perceive eyes and eye-like stimuli appears to develop very early in humans. By 2 months of age, human infants prefer looking at eyes than at any feature of the face (Hainline, 1978; Haith, Bergman, \& Moore, 1977; Maurer, 1985). Two-day old infants discriminate between pictures of adults face with eyes open versus eyes closed (Batki, Baron-Cohen, Wheelwright, Connellan, \& Ahluwalia, 2000). Similarly, newborn infants (2- to 5 -days old) prefer to look at faces that are looking at them than faces that are looking away from them. Consistent with these results are studies showing enhanced neural activity when looking at forward facing eyes from 4 months of age (Farroni, Csibra, Simion, \& Johnson, 2002).

This preference for eyes is important for the mother-infant bond. By 5 months of age, infants look longer at a face showing direct eye contact (Lasky \& Klein, 1979). Robson (1967) was among the first to report on the developmental significance of eye contact between mother and infant in the first 6 months of life. In a variety of ways, eye contact facilitates mother-infant attachment (Ainsworth, 1963; Bowlby, 1969; 1973). Additionally, previous research has also shown that eye contact between mother and infant serves to initiate and structure their interaction, leading to an increase in an infant's smiles and vocalizations (Bruner, 1975; Stern, 1974).

Specifically, mutual gaze, which is defined as eye contact between social partners while in a face-to-face position, between a mother and her infant may be the foundation of attachment, and sets the occasion for communicative exchanges (e.g., Bullowa, 1979, Trevarthen \& Aitken, 2001). Other studies reported that mutual gaze between mother and infant is a consequence of breaking physical contact, and that early communication can rely on the tactile mode (Stack, 2001; Sorenson, 1979). These investigators have suggested that a loss of physical contact early in life when the infant is still very dependent on the mother creates a need for mutual gaze. In this instance, mutual gaze serves as a means to re-establish the mother-infant bond. Infants develop the emotional bond with their mother via the interaction physically and visually from early infancy. As mutual gaze is necessary to re-establish mother-infant bonds, looking at each other even when it does not occur at the same moment may also compensate for the physical distance between mother and infant. 


\section{PHYLOGENTIC ASPECTS OF GAZE PROCESSING - GAZE PERCEPTION AND EYE CONTACT}

Non-human primates are also attracted to eyes. They gather information from eyes and appear to use their own eyes for the purposes of communication, for example, warning others of their emotional disposition (threatening or submissive). Schematic drawings of eyes are perceived as eyes in a number of species and appear to be a part of a rapid predator detection system (e.g., wild house mice; Topal \& Csanyi, 1994, birds; Scaife, 1976a, b; Jones, 1980, lemurs; Coss, 1978). Keating and Keating (1982) investigated the eye movement responses of two rhesus monkeys while they viewed different primate' (i.e. rhesus monkey, chimpanzee, and human) and schematic faces. They reported that the subjects showed an extreme bias of looking at the eyes and the small region surrounding the eyes compared with other parts of the face (e.g., nose, mouth) regardless of species and stimulus. Similar results have been reported in baboons (Kyes \& Candland, 1987).

In contrast to humans, many animals react to eyes with avoidance and fear. For example, macaques look less at photographic slides of faces that make eye contact than slides of faces that make no eye contact (Keating and Keating, 1982). Mendelson, Haith, and Goldman-Rakic (1982) reported that infant macaques ( 3 weeks of age) showed more emotional disturbance when confronted by a picture of a full face making eye contact than by a picture of a face turned away in profile with gaze averted. Perret and Mistlin (1991) also demonstrated that submissive gestures by macaques are controlled by gaze angle and head postures. In their study, subjects showed more submissive gestures when a human face was looking directly at them than when a human face was tilted backward.

Among monkeys and apes, mutual gaze (in this case, it is more like staring) is a component of threatening displays (e.g., baboon; Hall \& Devore, 1965, gorillas; Schaller, 1964, macaques; Altmann, 1967, and a number of other old world monkeys and apes; van Hooff, 1962). Autonomic physiological changes in monkeys have been reported to accompany the detection of eye contact, suggesting that eye gaze is an emotive stimulus (Wada, 1961). However, in certain contexts, another individual's gaze directed at you is not always a threat. For instance, in many nonhuman primates, the gazing interaction between mother and infant has been observed in captive and and wild populations (e.g., macaques, Ehardt \& Blount, 1984; squirrel monkeys; Biben, 1994; chimpanzees; Bard, 1994; van Lawick-Goodall, 1968). Linnankoski, Gronroos, and Pertovaara (1993) reported that only when eye contact was established between a male and a female macaque, subsequent mating was successful. In fact, monkeys and apes regularly make eye contact when engaged in grooming bouts, when greeting partners and when initiating play behavior(s) (van Hooff, 1962). Argyle and Cook (1976) suggested that primates are unique in their use of gaze as both an affiliative and aggressive cue. However, Emery (2000) suggested that monkeys do not appear to make the subtle distinction between direct staring and mutual eye contact that some great apes and humans make (however, Linnankoski et al. [1993] suggested 
that macaques might occasionally make this distinction). From the evolutional perspective, this suggestion has some considerable meanings. This distinction may have evolutionary significance.

The ability of non-human primates, especially chimpanzees, to process gaze has recently received much attention in developmental psychology. To understand the evolutionary and developmental background of gaze processing in primates including humans, the data from chimpanzee infants is essential component. Chimpanzee infants are also sensitive to faces that are looking at them (e.g., Tomonaga, Okamoto, Myowa-Yamakoshi, \& Yamaguchi, 2002). Moreover, chimpanzee mothers and infants, as early as 2 weeks of age, spend a significant amount of time engaged in mutual gaze (Bard, 1994). As noted earlier, mutual gaze in humans is necessary to re-establish the mother-infant bond, when that bond has been broken. The same may be true in chimpanzees (Bard, in press) When a mother and an infant look at one another, even when this doesn't occur simultaneously, is it to compensate for the distance between them? In order to answer this question we must measure the visual interaction of mothers and infants over time.

However, gaze is not limited to information from the eyes as simple stimuli. Gaze is one cue that is often used to determine the focus of another individual's direction of attention. Of course, eye-gaze is not the only attentional cue. The orientation of the whole head, body, and hand (especially pointing) are similarly good indicators of attention and interest and are used in our daily interactions with others. The ability to follow gaze to specific objects, events and individuals develops early in human development. This ability is also present in other primate species such as macaques and the other great apes.

\section{GAZE DIRECTION, GAZE FOLLOWING AND JOINT ATTENTION}

Humans are highly sensitive to the direction of gaze. Determining the precise direction of another's attention is an important ability. Gaze shifts provide salient information about the location of objects, but may also function in complex forms of social cognition (Whiten, 1997).

In our daily lives, a great deal of information is communicated by means of following other individual's gaze to specific objects and events. This behavioral sequence is called gaze following or joint attention. Gaze following/Joint Attention is characterized by one individual $(X)$ following the direction of another individual $(Y$ )'s attention to an object $(Z)$ (an object of joint focus; see Figure from Emery, 2000). These terms are used interchangeably by researchers. Emery, Lorincz, Perrett, Oram, \& Baker, (1997) suggested that gaze following and joint attention are different, yet intimately related abilities (probably with different developmental and phylogenetic time courses). They defined gaze following as the ability of $X$ to follow the direction of the gaze of $Y$ to a position in space (not an object). Joint attention has the additional requirement that $X$ follows the direction of $Y$ 's gaze to the object $Z$ that is the focus of $Y$ 's attention. Joint attention thus requires extra computation to process the object of attention not just the direction of gaze. 

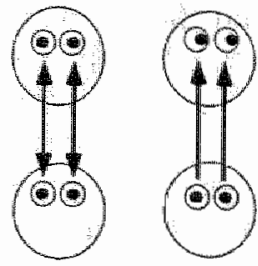

A. Mutuall versus Averted Gaze

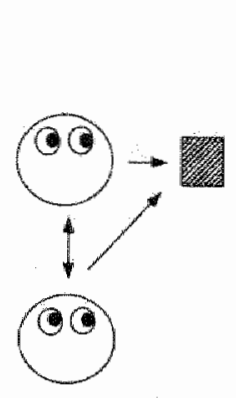

D. Shared Attention

D. Shared Atention

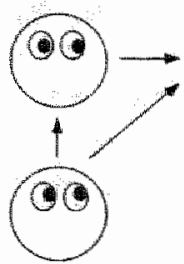

Q. Gaze Following

E "Theory of Mind"

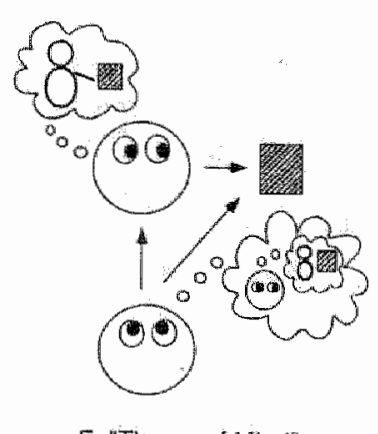

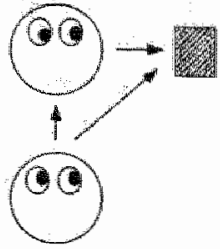

G. Joint Attention

Figure Gaze direction provides a number of potential social cues which may be utilized by an individual to learn about the external (other individuals, objects, events, etc.) or internal (emotional and intentional) states. A. Mutual gaze is where the attention of individuals $A$ and $B$ is directed to one another. Averted gaze is where individual A is looking at B, but the foeus of their attention is elsewhere. $B$. Gaze following is where individual A detects that B's gaze is not directed towards them, and follows the line of sight of B onto a point in space. C. Joint Attention is the same as Gaze Following except that there is a focus of attention (such as an object), so individuals $A$ and $B$ are looking at the same object. D. Shared Attention is a combination of Mutual Attention and Joint Attention, where the focus of individual A and $\mathrm{B}$ s attention is on the object of joint foeus and each other (i.e "I know you"re looking at $X$, and you know that I'm looking at $X$ "). E. Mental state attribution or theory of mind, probably uses a combination of the previous A-D attentional processes, and higher-order cognitive strategies (including experience and empathy) to determine that an individual is attending to a particular stimulus because they intend to do something with the object, or believe something about the object. (from Emery, 2000)

Emery (2000) similarly argued that there are subtle differences between joint attention and shared attention (see also Perrett \& Emery, 1994). Nevertheless, these two terms are also used interchangeably in the literature. Emery (2000) defined shared attention as a more complex form of communication than joint attention. Shared attention requires that individuals $\mathrm{X}$ and $Y$ each have knowledge of the directions of the other individual's attention (or a method for checking that what the other individual is looking at is the same as what they are looking at).

Determining the direction of another individual's attention is easier to establish from larger visual cues, such as head or body orientation. Attentional 
cues or social gaze, are not only provided by the eyes. Perrett and his colleagues have suggested that the direction of the head and the orientation of the body may also provide important indicators of attention, when the eyes are obscured or not clear, or when the eyes are used for other purposes (Perrett, Hietanen, Oram, \& Benson, 1992; Perrett \& Emery, 1994). When all cues are available for processing, a hierarchy of importance exists, whereby the eyes provide more important cues than the head and the head is a more important cue than the body.

Research with human infants suggests that sensitivity to gaze shifts occurs very early in infancy. From 3 months of age, infants are able to discriminate changes in an adult's eye direction (Hains \& Muir, 1996). The ability to follow gaze has been demonstrated most successfully in laboratory studies of human infants. In most of those experiments, the general procedure involves the experimenter (or the mother of the infant) sitting face-to-face with the infant. After making eye contact, the experimenter shifts her gaze to a particular location or object. Infant's responses in this task have a specific developmental trajectory. However, the age at which an infant first follows another's gaze is controversial, ranging from 3 months to 18 months (e.g., Scaife \& Bruner, 1975; Butterworth \& Cochran, 1980; Butterwort \& Jarrett, 1991; Corkum \& Moore, 1995; D'Entremont, Hains, \& Muir, 1997). These conflicting results may be due to methodological, conceptual, or definitional differences. Before 12 months of age, human infants follow their mother's gaze, but do not direct their attention to the object of her attention. At around 12 months, infants begin to follow their mother's gaze towards particular objects in their visual field and at around 18 months they can direct their attention to objects outside of their visual field.

Joint attention is considered an early social cognitive ability leading to later developments associated with mental-state attribution (e.g., theory of mind, deception, perspective taking; of. Baron-Cohen, 1995; Tomasello, 1995). However, there are some accounts which do not need to attribute understanding other's mental states that apply to young infants. Young infants are primed from an early age to look in the direction that others are looking (cf. D'Entremont; et.al., 1997). When they do so, they often see interesting (and rewarding) objects and events. Hence, infants may learn to use gaze direction as a cue to where such rewarding events are located (Corkum \& Moore, 1995, 1998; Moore, 1999). In this view, gaze is merely a discriminative stimulus for the general direction in which an attractive event might be encountered, and, once encountered, search should presumably cease. Butterworth's account of gaze following stressed the innate properties of this behavior. He suggests that young infants are hard-wired to follow the gaze direction of others. They are held to terminate search at the first salient object in their scan path (Butterworth \& Cochran, 1980; Butterworth \& Jarrett, 1991). Unlike Moore's conception (1999), there is no learning on the infant's part and no expectation of finding an event.

Although previous studies have suggested that infants are innately sensitive to eye gaze and gaze direction, it is still an open question whether gaze 
following (or joint attention) is, in fact, an innate ability or a learning effect from daily experience.

\section{GAZE FOLLOWING AND JOINT ATTENTION IN NON-HUMAN PRIMATES}

Gaze following is also found in a number of nonhuman primates. The use of gaze shifts as a social cue has various evolutionary advantages. For instance, gaze shifts may index the location of predators, potential mates or food sources. Several field studies suggest that primates can follow the gaze of conspecifics (e.g., Chance, 1967; Menzel \& Halperin, 1975; Whiten \& Byrne, 1988). However, in field studies, it is difficult to identify which object or event is looked by two individuals by means of gaze following. For instance, individuals may come to fixate on the same object because the object is inherently interesting even if they do not follow gaze. Such interpretational confounds can be effectively excluded in laboratory studies. In fact, various studies have demonstrated that many primate species follow the gaze direction of conspecifics to objects (e.g., chimpanzees, mangabeys, and macaques; Emery et al. 1997; Tomasello Call, \& Hare, 1998; Tomonaga, 1999). The general procedure in the primate studies is the same as in the studies with humans (see above). Furthermore, primates (especially apes) follow gaze of non-conspecific individuals (e.g., a human experimenter). They do this even when the target is located above and/or behind them (Itakura, 1996; Povinelli \& Eddy, 1996b; 1997). Itakura (1996) studied the ability of various species of prosimians, monkeys and apes to follow a human experimenter's gaze. Only the ape (orangutan and chimpanzee) responded above chance levels. Neither Old nor New World Monkeys (i.e., brown lemur, black lemur, squirrel monkey, brown capuchin, whiteface capuchin, stump-tailed macaque, rhesus macaque, pig-tailed macaque, and tonkean macaque) responded above chance levels.

The clearest evidence for the ability to follow gaze in non-human primates comes from laboratory work on great apes, in particular, studies with chimpanzees. But while these studies have shed some light on the topic, they have left many questions unanswered. For instance, how do chimpanzees follow the other's gaze? Which cues are important for gaze following? Why do chimpanzees follow other's gaze? And when do chimpanzees start to follow other's gaze?

Previous studies have investigated how chimpanzees follow the other"s gaze. Povinelli and Eddy (1996b), for exámple, installed an opaque barrier in a testing room in order to obstruct the chimpanzee subjects" line of sight. In cases where the experimenter looked to an object next to the barrier (outside the immediate line of sight of the subject), chimpanzees followed the experimenter's line of sight around the barrier to the unseen object. This ability may be important when trying to extrapolate information from other"s attention, specifically, when the focus of attention is out of sight. In another paradigm using a distracter in the subjects' visual field, Emery et al. (1997) reported that the monkeys bypassed looking at the first interesting object in their line of sight 
and followed the demonstrator's to the target object; following gaze geometrically Tomasello, Hare, \& Agnetta, (1999) have reported similar results in chimpanzees. These results suggest that subjects do not reflexively follow gaze to the first available object within their view, but actively track the gaze of others geometrically to localize objects or locations the others are attending to.

A number of other studies have demonstrated that primates use a variety of cues to track the focus of other's attention (e.g., pointing, head orienting, gazing without head orientation). For example, in one study, Perrett and his colleagues investigated which cue(s) primates use to direct their own attention by measuring eye movements of monkeys during presentation of head and body cues, and head only and head with eyes cues (Lorincz, Baker, \& Perrett, 1999). They found that the subjects used the information from the head more readily than the body. They also appeared to follow gaze cues when the demonstrator's head was oriented towards the subjects.

Povinelli and his colleagues $(1996 \mathrm{a} ; 1996 \mathrm{~b} ; 1996 \mathrm{c} ; 1997)$ in a series of experiments have investigated why chimpanzees follow the experimenter's gaze. The main question is whether they attribute mental states to other individuals when they follow their gaze direction (not automatically). They suggested that chimpanzees can follow a human experimenter's gaze, but do not use that information to learn about objects in the world or about the "mental state" of the individual providing the gaze cues. As with human infants, it is still an open question where chimpanzees use gaze as an indicators of mental states (as mentioned above, however, the question for human infants is at what age do they start to attribute mental states to another individuals' gaze).

Previous studies, however, have tested adult (or juvenile) subjects and described the ability to follow gaze. A longitudinal study of infant chimpanzees that measures the frequency of gaze following in the course of development may yield important clues as to the ontogeny and evolution of this behavior. Such a study would, in principle, address the question of when (e.g., a developmental time course) infant chimpanzees start to follow others' gaze. In this dissertation a series of longitudinal experiments evaluated the development of gaze processing in an infant chimpanzee in order to address this important question in both human and chimpanzee development.

\section{REFLEXIVE SHIFTS TRIGGERED BY GAZE DIRECTION}

As mentioned above, the ability to follow and use another's gaze is an important skill used daily in the social life of humans and present early in infancy. Previous studies found, by using a cueing paradigm (Posner, 1980) that in human adults this ability occurs "automatically" and is called reflexive visual orienting.

Reflexive visual orienting is typically demonstrated and studied by using the cueing paradigm introduced by Posner (e.g., Posner, 1980). In experiments of this kind, subjects are asked to make a simple key-press response to the onset of a visual target which can appear at one of several locations in a display. Before the onset of the target stimulus, the subjects' attention is directed 
to one of several possible target locations by some kind of cue, such as an arrow in the center of the screen, or a flash of light in the periphery. The typical finding is that target detection is faster at the location indicated by the cue, relative to the un-cued locations (e.g., Posner, 1980; Rafal, Calabresi, Brennan, \& Sciolto, 1989). Not only does this cueing facilitation effect occur when subjects make an overt orienting response by moving their eyes in the direction of the cue (e.g., Posner, 1980), but also when subjects are instructed not to move their eyes, or when the interval between the offset of the cue and onset of the target is too brief to allow the programming and execution of a saccadio eye movement (e.g., Posner, 1980; Posner, Snyder, \& Davidson, 1980). The advantage for cued over non-cued locations in the absence of eye movements is usually attributed to a shift in covert visual attention.

This facilitation effect has also been found with the gaze direction cue, even when the subjects are asked to try to ignore these cues (e.g., try to fixate their eyes to the center fixation position), or when the gazed-at direction does not predict the location of the target (e.g., the subjects are told that the cue does not predict target location), and with eye-like stimuli of a schematic face (Friesen \& Kingstone, 1998; Driver et al., 1999; Langton \& Bruce, 1999). These findings support the conclusion that humans are highly sensitive to the eyes. As early as 2 to 3 months of age, infants look preferentially at the eyes of a schematic face (Maurer, 1985), and three-month old infants also turn their eyes to a given target more rapidly when the location of that target had been previously cued by an adult's gaze direction (Hood, Willen, \& Driver, 1998).

The facilitation for a gazed-at target location might result from participants shifting covert attention to the target location by volitionally planning or moving their eyes to the gazed-at location. This facilitation effect may be due to small saccades subjects make in response to the cue (e.g., Langton \& Bruce, 1999). These saccades could bring the subjects closer to the congruent location of the cued targets. Only a few studies have monitored the subjects' eye movements during the experiments by means of an eye tracking device. Mansfield, Farroni, \& Johnson (2003), however, ruled out cue-driven saccades as a significant contributor to the facilitation effect observed in previous studies (e.g., Friesen \& Kingstone, 1998). Their procedure, however, differs from previous studies that used a standard detection task. Instead, they required eye movements as a detection response to a peripheral target.

The cueing paradigm has also been used to test whether non-human primates evidence gaze facilitation. Fagot and Deruelle (2002) found that there was no reliable effect of eye gaze on discrimination speed, using either schematic gazes or pictures of real gazes. However, only the condition in which gaze cues were perfect predictors of target location, gaze cues facilitated target detection. They suggested that baboons do not spontaneously process gaze direction but can learn to do so if the gaze has a predictive value. Tomonaga (2004) also has tested the facilitation effect with chimpanzees. In a series of experiments, chimpanzee subjects did not show the facilitation effect demonstrated in human participants. This result is consistent with other research 
that has suggested an essential difference between chimpanzees' and humans' ability to process gaze cues.

\section{OUTLINE OF THE DISSERTATION}

In this dissertation, the sensitivity to particular behaviors (e.g., gaze following, gaze direction and visual interaction) was investigated from a comparative, developmental, evolutionary and cognitive science perspective. These different behaviors have been defined as components of gaze processing. The studies focused on the developmental aspects of gaze processing in an infant chimpanzee (e.g., Chapter 1: vistal interaction and Chapter 2 and 3: gaze following) using a comparative perspective. A cognitive science perspective was used to address reflexive shifts in gaze processing triggered by gaze direction in human adults (Chapter 4).

The main part of this dissertation (Chapter I, 2 and 3) consists of a longitudinal study measuring the development of gaze processing (visual interaction and gaze following) in an infant chimpanzee that is reared by his mother. This method has not been used in any previous study because of the difficulties associated with monitoring and measuring subtle behaviors such as gaze following early in infancy. Such a study is particularly difficult to do with infant chimpanzees because infant chimpanzees are held by their mothers throughout infancy. This feature of the chimpanzee mother-infant relationship makes is especially difficult to check the gaze behavior of infants and to test them directly. Moreover, testing chimpanzees that are reared by their biological mothers brings us data from the natural development of gaze interaction and processing. Chimpanzees raised by humans in a nursery setting might show a different developmental pattern (e.g., enculturation). Fortunately, I had the opportunity to study the development of several chimpanzee infants born in the Primate Research Institute, Kyoto University (PRI) and reared by their biological mothers since birth.

In 2000, investigators in PRI began a project for the longitudinal studies of chimpanzee development (Matsuzawa, 2002, 2003; Tanaka, Tomonaga, \& Matsuzawa, 2002; Tomonaga, Tanaka, \& Matsuzawa, 2003). Necessary conditions (e.g., enriched environment, community) for natural development of chimpanzees were in place, and 3 infants were born in 2000. Three mothers living in social groups successfully reared their babies (Tomonaga, et. al., in press). The studies reported in this dissertation were among other comparative developmental studies with infant chimpanzees (cf. Tomonaga, Tanaka, \& Matsuzawa, 2003).

Unfortunately, only a single subject or single chimpanzee mother-infant pair was amenable for studies reported here. The others could not participate in the study due to unavoidable circumstances (e.g., mothers became anxious at the presence of the experimenter and did not make their infants available). Thus, tests with more mother-reared subjects are needed to verify the generality of these findings. Nevertheless, the findings present a very unique case and may have a number of significant implications for developmental research on gaze 
processing from a eomparative perspective:

Chapter 4 focused on the visual reflexive attention to gaze in human adults from a cognitive science aspeet. Prewious studies have confirmed the importance of cues from the direction of gaze. Such cues cannot be ignored even when they are irrelevant to the task in hand and can create reflexive shifts in visual attention. However, in previous research, eye movements were not measured. Moreover, like in the gaze following task (chapter 3), this experiment controlled for the presence of a target and investigated how expectancy of a target (or the absence of a target) affects attention to the gaze direction cue.

\section{REFERENCES}

Ainsworth, M. D: S. (1963). The development of infant-mother interaction among the Ganda. In B. M. Foss (Ed.), Determinants of infant behawion (Vol. 2; pp. 67-112). New York: Willey.

Altmann, S. (1967). Social communication among primates. Chicago: University of Chicago Press:

Argyle, M., Cook, M: (1976). Gaze and mutual gaze. Cambridge, England: Cambridge University Press.

Baiki, A., Baron-Cohen, S., Wheelwright, S., Connellan, J., \& Ahluwalia, J. (2000), Is there an innate gaze module? Evidence from human neonates. Infant Behavior \& Development, 23, 223-229.

Baron-Cohen, S. (1995). Mindblindness: An Essay on Autism and Theory of Mind, MIT Press.

Bard, K. A. (1994). Evolutionary roots of intuitive parenting: Maternal competence in chimpanzees Early Development and Parenting, 3, 19-28.

Bard, K. A., Myowa-Yamakoshi, M., Tomonaga, M., Tanaka, M. Quinn, J., Costall, A., \& Matsuzawa, T. (in press). Group differences in the mutual gaze of chimpanzees (Pan iroglodyres). Developmental Psychology:

Biben, M. (1994). Eye contact and vocal responsiveness in squirrel monkey infants and their caregivers. Early Development and Parenting, 3, 29-36.

Bowlby, J. (1969). Attachment and Loss: Nol. 1. Attachment. New York: Basic Books.

Bowlby, J. (1973) Attachment and Loss: Vol 2. Separation. New York: Basic Books.

Bruner, J. S. (1975). The ontogenesis of speech acts. Jownal of Child Language, 2, 1-19.

Bullowa $a_{*}$. (1979). Introduction: Prelinguistic communication: a field for scientific research. lis Bullowa, M. (Ed), Before speech: The beginning of interpersonal communcation. (pp. 1-62). New York: Cambridge University Press.

Butterworth, G, \& Cochran, E. (1980). Towards a mechanism of joint visual attention in human infaincy. International Soumal of Behavioral Development, 3, 253-272.

Butterworth, G, \& Jarrett. N. (1991). What minds have in common is space: spatial mechanisms serving joint visual attention in infancy. British Jowrnal of Developwentol Psychology, 9, 55-72.

Chance, M. R. A. (1967). Attention structure as a basis of primate rank orders. Mam, 2, 503-5॥8.

Coss, R. G. (1978). Perceptual determinants of gaze aversion by the lesser mouse lemur (Microcerbus Morinus). The role of two facing eyes. Behowior, 64, 248-267.

Corkum, V., \& Moore, C. (1995). The development of joint attention in infants. In C. Moore \& P. J. Dunham (Eds.). Joint Atrention: Its prigins and vole in development. (pp. 61-85). Hillsdalle, NJ: Lawrence. Erlbaum Associates; Tinc.

Corkum, V., \& Moore, C. (1998). The origins of joint visual attention iti intants. Developmental Psychology, 34, 28-38.

D'Entremont, B., Hains, S. M. J., \& Muir, D. W. (1997). A demonstration of gaze following in 3. to 6-month-olds. Infant Behavior \& Development, 20,569-572. 
Driver, J., Davis, G, Riceiardell, P. Kidd, P. Maxwell, E, \& Baron-Cohen, S. (1999). Gaze perception triggers reflexive wisuospatial orienting. Visual Cognition, 6, 509-540.

Whardt, C. L, Blount, B. G. (1984). Mother-infant visuall interaction in Japanese macaques. Developinental Psychobiology: 17,391-405.

Emery, N. $\mathrm{J}(2000)$. The eyes have it the neuroethology, function and evolution of social Gaze. Newrosclence and Biobehavioral Reviews, $24,581-604$

Emery, N. J, Lornes, E. N. Perret, D. I., Oram, M. W. \& Baker, C. I. (1997). Gaze following and joint attention in thesus monkeys (Macaca mulatta). Joumal of Comparative Psychology, 111, 286-293.

faggt, J, \& Deruelle, C. (2002). Perception of picturial eye gaze by baboons (Papio papio). Journal of Experimental Psychology. Animal Behavior Processes, 28, 298-308.

Farroni, T. Csilbra, G. Simion, F., \& Johnson, M. H. (2002). Eye contact detection in humans from birth. Proceedings of the National Academy of Sciences of the United States of America, 99, 9602-9605.

Freedle, R., \& Lewis, M. (1977). Prelinguistic conversations. In M. Lewis \& L. Rpsenblum (Eds.), Interaction, Conversation, and the Development of Langage. (pp. 157-185). New York: Wiley.

Friesen, C.K., K Kingstone, A. (1998). The eye have it!: Reflexive orienting is triggered by nonpredictive gaze. Psychonomic Bulletin and Review, 5, 490-495.

Haith, M. M., Bergman, T., \& Moore, M. J. (1977). Eye contact and face scanning in early infancy. Scrence, $198,853-855$.

Hainline, L. (1978), Developmental changes in visual scanning of face and non-face patterns by infants. Journal of Experimental Child Psychology, 25, 90-115.

Hains, S. M. J., \& Muir, D. W. (1996). Infant sensitivity to adult eye direction. Child Development, 67, 1940-1951.

Hall, K., \& Devore, I. (1965). Baboon social behavior. In: I. Devore (Ed.), Primate Behavior. New York: Holt, Rinehart \& Winston.

Hood, B. M., Willen, J. D., \& Driwer, J. (1998). Adult's eyes trigger shifts of visual attention in human irifants. Psychological Science, 9, 131-134.

Itakura, S. (1996). An exploratory study of gaze-monitoring in non-human primates. Japanese psychological research, 38, 174-180.

Jones, R. B. (1980). Reactions of male domestic chicks to two-dimensional eye-like shapes. Animai Behowour, 28, 212-218.

Keating C. F, \& Keating, E. G. (1982). Visual scan patterns of thesus monkeys wiewing faces. Pereprion, 11, 211-219.

Kleinke, C.L. (1986). Gaze and eye contact: a research review. Psychological Review, 100, $78-100$.

Kyes, R. C., Candland, D. K. (1987). Baboon (Papio hamadryas) visual preferences for regions of the face Jourmal of Comparative Pyychology, 101, 345-348.

Langton, $S . R . H$. \& Bruce, V. (1999). Reflexive visual orienting in response to the social attention of others. Vistal Cognition, 6, 54l-567.

Lasky, R., \& Klein, R. (1979). The reactions of 5 month old infarits to eye contact of the mother and a shanger (Vol. 25), Quarterly.

Linnankoski, 1, Gronroos, M., \& Pertovara, A. (1993). Eye contact as a trigger of male sexual arousal in stump-tailed macaques (Macaca arctordes). Folia Primatologica, 60, 181-184.

Lotince, E. N., Baker, C. 1., \& Perrett, D. I. (1999). Visual cues for attention following in rhesus monkeys. Cahiers de Psychologie Cognirive, 18, 973-1003.

Mansfield, E. M., Farroni, T., \& Johnson, M. H. (2003). Does gaze perception facilitate overt orienting? Wswal Cognition, 10, 7-14. 
Matsuzawa, T. (2002). Chimpanzee Ai and her son Ayumis: An episode of education by master-apprenticeship. In M. Bekofr, $\mathrm{C}$. Alen, $\mathrm{G}$ M. Gondon (Bds,), the cogmitive animal. (pp. 190-195). Cambridge, MA: MTT Press.

Matsuzawa, T. (2003). The Ai project: historical and eoological contexts. Anmal Cogmiton, 6 , 199-211.

Maurer, D. (1985). Infants' perception of facedness. In T. M. Field \& N. A. Fox (Eds.), Social perception in infants (pp. 73-1.00). Norwood, $\mathrm{NJ}^{2}$ Ablex.

Mendelson, M. J., Haith, M. M., \& Goldman-Rakic, P. S. (1982). Face scanning and responsiveness to sociall cues in infant rhesus monkeys. Developmental Psychology, 18, 222-228.

Menzel, E. W., \& Halperin, S. (1975). Purposive behavior as a basis for objective communication between chimpanzees. Science, 189, 652-654.

Moore, C. (1999). Gaze following and the control of attention. In P. Roshat (Ed.), Early social cognition. (pp. 241-256). Mahwah, NI: Lawrence Erlbaum Associates, Inc.

Perrett, D. I., \& Emery, N. J. (1994). Understanding the intentions of others from visual signals: neurophysiological evidence. Cahiers de Psychologie Cognitive, 13, 683-694.

Perret, D. 1., \& Mistlin, A. J. (1991). Perception of facial characteristics by monkeys. In: W. C. Stebbins \& M. A. Berkley (Eds.), Comparative Perception. (pp. 187-215). New York: John Willey.

Perrett, D. L., Hiatanen, J. K., Oram, M. W., \& Benson, P. J. (1992). Organization and functions of cells responsive to faces in the temporal cortex. Philosophical Tramssactions: Biological Sciences, $335,23-30$.

Posner, M. L. (1980) Orienting of attention. Quarterly Journal of Experimental Psychology, Part $A_{\text {, }}$ $32,3-25$.

Posner, M. I., Snyder, C. R. R., \& Davidson, B. J. (1980). Attention and the detection of signals. Journal af Experimental Psychology: General, 109, 160-174.

Povineli, D. J., \& Eddy; T. J. (1996a). Factors influencing young chimpanzees' (Pan troglodytes) recognition of attention, Journal of Comparative Psychology, 110, 336-345.

Povinelli, D. J., \& Eddy, T. J. (1996b). Chimpanzees: joint visual attention. Psychological Science, $7,129-135$.

Povinelli, D. J., \& Eddy, T. J. (1996c). What young chimpanzees know about seeing. Monographs of the Saciety for Research in Child Development, 61, 247.

Povinelli, D. J., \& Eddy, T. J. (1997). Specificity of gaze-following in young chimpanzees. British jowrnal of Developmental Psychology, 15, 213-222.

Rafal, R. D., Calabresi, P., Brennan, C., \& Sciolto, T. (1989). Saccade preparation inhibils reorienting to recently attended locations. Journal of Experimernal Psychology: Human Perceprion \& Performance, $15,673-685$.

Robson, K. S. (1967). The role of eye-to-eye contact in matemal-infant attachment. Jowthat of Child Psychology \& Psychiaty \& Allied Disciplines. 8, 13-25.

Scaife, M., \& Bruner, J.S. (1975). The capacity for joint visual attention in the infant. Nature, 253, 265-266.

Scaife, M. (1976a). The response to eye-like shapes by birds. I: the effect of context: a predator and a strange bird. Animal Behaviour, 24, 195-199.

Scaife, M. (1976b). The response to eye-like shapes by birds. HI: the importance of staring, pairedness and shape. Animal Behaviour, 24, 200-206.

Schaller, G. (1964). The mowntain gorilla. Chicago: Chicago University Press.

Sorenson, E. R. (1979). Early tactile communication and the patterning of humbitn organization; a New Guinea carse study. In Bullowa, M. (Ed.), Before speech: The beginning of interpersonal communication. (pp. 289-306). New York: Cambridge University Press.

Stack, D. M. (2001). The salience of touch and physical contact during infancy: Unraveling some 
of the nystertes of the somestixetic sense. Bremner, $\mathrm{G}$ (Ed), Fogel. A (Ed). Blachwell handbook of infont development. Hondbooks of developmental psychology: (pp: 351-378). Maldern, MA, US: Blackwell Fublishers.

Sten, D. N. (1974). Mother and infant at play: The dyadic interaction involving facial, vocal, and gaze behavions. In $M$ Lewis and $\mathrm{L}$. Rosenblum (Eds), The Effect of the infont on its Caregive (pp $187-213$ ). New York. Wley.

Tanaka, M. Tomonaga, M, Matsuizawa, $\mathrm{T}$ (2002). A developmental research project witli three mother-infant chimpanzee pairs: $A$ new apwroach to comparative developmental seience. Japanese Psychological Rewiew; 45, 296-308. (Japanese text)

Tomasello, M. (1965). Joint attention as social cognition. In C. Moore \& P J. Dunham (Eds.). Joint Antention: Its origins and role in development. (pp 61-85). Hillsdalie, NI: Lawrence Entlbaum Associates, Inc.

Tomasello, M., Hare, B., \& Agnetla, B. (1999). Chimpanzees. Pan troglodytes, follow gaze difrection geometrieally. Animal Behewiow, 58,769-777.

Tomasello, M, Call, J, \& Hare; B. (1998). Five prinate species follow the wisual gaze of conspeethes: Animal Behawiour, 55, 1063-106\%.

Tomonagy, M. (1999): Attending to the others' attention in macaques" joint attention or not? Primate Research, 15, 425. (Japanese text)

Tomonaga, M. (2004). Perceptiat Basis of Social Cognition: Compararive-Cognitive. Unpublished research repont of guant-in-aid for scientific research 2001-2003. (Japanese text)

Tomonaga, M., Okwmoto, S., Myowa-Yamakoshi, M., \& Yamaguchi, M. (2002). Recognition of foce and gaze in infant chimpanzees (Pan troglodyles). Paper presented at the Second international symposium on compatative cognitive science; "Social transmission of knowledge", Inyuma, Japan.

Tomonaga, M, Tanaka, M. \& Matskzawa, T. (Eds.) (2003). Cognitive and behavioral development in chimpanzees: A camparative approach. Kyote; Japan: Kyoto University Press: (Japanese text)

Tomonaga, M., Myowa-Yamakoshi, M., Mizune, Y., OKamoto, S., Yamaguchi, M. K., Kasugi, D., Bard, K. A., Tanaka, M. \& Matsuzawa, T. (in press). Chimpanzee social cognition in early life: Comparatiwe-developmental perspective: In E. A. Wasserman \& T. R. Zentall (Eds.), Compatative cogmition: Expermental explorations of ammal intelligence. Oxford University Press: New York.

Topal, I, Csangi, V. (1994). The effect of eye-like sehema on shuttling activity of wild house mice (Ming musculas domesticur): Context-dependent threatening aspects of the eyespot patterns. Amimal Learwing and Behawion, 22,96-102.

Trevarthen, C., Atken, K. J. (2001), infant intersubjectivity: Research, theory, and clinical applications, Jownit of Child Psychofogy and Psychiary and Allied Disciplines, $42,3-48$.

van Fooff. J. A. R. A. M. (1962). The facial displays of the catarthine monkeys and apes. In: D. Morris (Ed.), Primare Ethology, (pp. 7-68). Londen: Weidenfield \& Nicholson.

wan Lawick-Goodall, 1 . (1968). The behaviour of free-liwing chimpanzees of the Gombe Stream Nature reserve. diminal Behowior Monographs, 1, 161-331.

Wadia, J. A. (1961). Modification of contically induced responses in brain stem of shift of attention in monkeys. Science $133,40-42$.

Whiten, A. (1997). Evolutionary and developmental origins of the mindreading system. In: $y$. Langer \& M. Killen (Eds.). Piaget, Evolution and Development, London: Lawrence Earlbaum:

Whiten, A., \& Byme, R. W. (1988). The manipulation of attention in primate tactile deception. In R. W. Byme \& A. Whiten (Eds.), Machavelian intelligence: Social expervise and the 
evolution of intellect in monkeys, apes and humans (pp. 211-223) Oxfard, UK. Oxford University Press. 



\section{CHAPTER 1}

\section{LOOKING COMPENSATES FOR THE DISTANCE BETWEEN MOTHER AND INFANT CHIMPANZEE*}

*Submitted for publication:

Okamoto-Barth, S., Kawai, N., Tanaka, M. \& Tomonaga, M. (submitted). 


\section{ABSTRACT}

The development of visual interaction such as eye contact, mutual gaze between mother and infant has long received much attention in developmental psychology, and that not only in humans, but also in non-human primates. Recently, comparative developmental approaches have investigated whether the mechanisms that underlie these issues are common in both species. In the present study, a unique setting in which the mother stayed in one location and the infant moved freely allowed us to analyze the visual interaction between mother and infant chimpanzee during the first year of life. We identified the direction of gazing and recorded the distance between mother and infant at each moment within a small room. Our results show a behavioral sequence of typical "siecure-base" behavior, a behavior characterized by the infant regularly returning to its mother when exploring the environment. Moreover, we showed that the looking between mother and infant with one another increased when body contact became less or when the distance between them increased. Additionally, we found that the mother looked at her infant more than the infant looked at his mother, even when the mother was not interacting with the infant directly. From our findings, we also suggest that some cognitive developments for using a "secure base" are prepared before the development of locomotion. Our present study implies that the basis of mother and infant chimpanzee attachment is also developed and mutually related with other cognitive and physical developments.

Key Words: visual interaction, mutual gaze, attachment, secure base, chimpanzees

\section{INTRODUCTION}

In humans, various kinds of interactions between mother and infant have already been investigated. For example, the development of visual interaction (e.g., eye contact, mutual gaze) has received much attention. Robson (1967) reported the developmental significance of eye contact between mother and infant in the first six months of life. In a variety of ways this interchange facilitates the attachment of mother and infant to one another. Additionally, previous research has also shown that eye contact between mother and infant serves to initiate and structure their interaction, leading to an increase in an infant's smiles and vocalizations (Bruner, 1975; Stern 1974). Mothers use the visual responsiveness of their infants to focus the infant's attention on objects and activities at hand, and through eye contact an infant's mother can engage him or her in structured, concerted activity (Freedle \& Lewis, 1977).

Additionally, once infants start to move their body and travel actively, they show a certain characteristic behavioral pattern of locomotion. When healthy and well-rested infants are in a comfortable setting with their mothers nearby they 
explore the environment by moving away from mother, returning to mother, and moving out to explore again. This behavioral pattern is called "secure base" behavior which is a popular topic in "attachment" theory (Bowlby, 1969, 1973; Ainsworth, 1963, see also review of Cassidy, 1999). Ainsworth (1963) and Bowlby (1969) described infants as being biologically predisposed to use the caregiver, usually the mother, as a "secure base" that gives them a feeling of security while exploring the environment.

In nonhuman primates, the visual interaction between mother and infant was observed in captivity (about primate parenting, see review of Bard, 2002: e.g., chimpanzees; Bard, 1994; squirrel monkeys; Biben, 1994; macaques, Ehardt \& Blount, 1984) and in the wild (e.g., chimpanzees; van Lawick-Goodall, 1968; Plooij, 1979, macaques; Kondo-Ikemura \& Waters, 1995a). Plooij (1979) reported that the developmental pattern of chimpanzees may most closely approach the human pattern of coordinated mother-infant gazing interaction. Additionally, in previous studies (e.g., Kondo-Ikemura \& Waters, 1995b), mother and infant gazing interaction has also been investigated from the aspects of "attachment" theory. In field studies, however, it is hard to accurately describe the changing relational distance between mother and infant which is the most important measure for "secure base" behavior measurements.

Moreover, in humans, mutual gaze, which is defined as eye contact between social partners usually while in a face-to-face position, between mother and infants may be the foundation of attachment, and sets the occasion for communicative exchanges leading to the emotional nature of the mother-infant bond (e.g., Bullowa, 1979, Trevarthen \& Aitken, 2001). Additionally, there is evidence that human infants are sensitive to adults' attentional states from early infancy. From early infancy they can discriminate between a picture that shows an adult face with open eyes and a picture that shows an adult face with closed eyes (Batki, Baron-Cohen, Wheelwright, Connellan, \& Ahluwalia, 2000). They also have a preference for looking at a face that is gazing at them (Farroni, Csibra, Simion, \& Johnson, 2002), and start to follow their mother's gaze in the first year of their lives (e.g., Corkum \& Moore, 1995; Butterworth \& Jarrett, 1991; Moore, 1999).

Chimpanzee infants are also sensitive to a face that is looking at them (Myowa-Yamakoshi, Tomonaga, Tanaka, \& Matsuzawa, 2003; Tomonaga, Okamoto, Myowa-Yamakoshi, \& Yamaguchi, 2002), and start to follow the other's gaze by around one year of age (Okamoto et al., 2002; Okamoto, Tanaka, \& Tomonaga, 2004). Moreover, Bard, et al. (in press) reported that mutual gaze between chimpanzee mother and infant may be a consequence of breaking physical contact, and that early communication can rely on the tactile mode like in human mother and infant (Stack, 2001; Sorenson, 1979). They suggested that a loss of physical contact early in life, when the infant is still very dependent on the mother, creates a need for mutual gaze to re-establish a mother-infant bond. This has also been suggested for macaques (Ehardt \& Blount, 1984). Moreover, chimpanzee and human infants share commonalities in early social communicative exchanges which include gazing interaction (Bard, 2002; 
Matsuzawa, 2001; Plooij, 1979; van Lawick-Goodall, 1968). From findings of previous studies, we assume that mutual gaze plays a role in bridging the distance between mother and infant when physical contact has been lost. By means of mutual gaze, the mother and infant replace physical contact with visual contact (e.g., secure feeling by seeing the states of each other). As mutual gaze is necessary to re-establish a mother-infant bond, we suppose that the looking behavior also plays a role of compensating for the distance between mother and infant. This question may be solved by investigating the relationship between the distances and looking behavior between mother and infant.

To investigate the relation between gazing and the distance between mother and infant chimpanzee from early infancy, we introduced an observational setting which allowed us to identify the direction of looking, and recorded the distance between mother and infant at each moment. This setting makes it possible to record the looking behavior from both subjects and to analyze the distance between them on each orienting event precisely.

\section{METHOD}

\section{SUBJECTS}

One male chimpanzee infant Ayumu ( 15 days after birth to 12 months old), and his mother Ai (about 24 years old) served as the subjects. The infant had been reared with his biological mother since birth at the Primate Research Institute, Kyoto University. Both lived in an enriched outdoor compound in a community of 14 chimpanzees (Ochiai \& Matsuzawa, 1998). There were two more mother and infant pairs in this community. These three infants had participated in a research project on chimpanzee development which started in 2000 and had therefore experienced a variety of tests related to the development of cognitive abilities (e.g., Matsuzawa, 2001, 2003; Tomonaga, Tanaka, \& Matsuzawa, 2003; Tanaka, Tomonaga, \& Matsuzawa, 2002). The mother, Ai was born in the wild, and she also had experience and training on a variety of cognitive and behavioral tasks (e.g., Matsuzawa, 1985; Murofushi, 1997; Kawail \& Matsuzawa, 2000; Tomonaga \& Matsuzawa, 2002). The present observations were possible from the very early infancy of Ayumu, because his mother Ai took up her participation in the daily experimental tasks from when he was 11 days old. Care and use of the chimpanzee adhered to the Guide for the Care and Use of Laboratory Primates (1986) of the Primate Research Institute, Kyoto University. 


\section{SETTING}

The observation was conducted at a chimpanzee experimental booth $(2 \mathrm{~m} \times 2 \mathrm{~m} \times$ $2.4 \mathrm{~m}$ ) which is consist of transparent acrylic board and iron column at the Primate Research Institute, Kyoto University. The behavior of the infant and his mother was continuously recorded by two digital-video cameras (SONY DCR-TRV950), from the beginning of the observation until the end. Camera 1 recorded the whole booth, and Camera 2 was focused on the subjects by observer 1 .

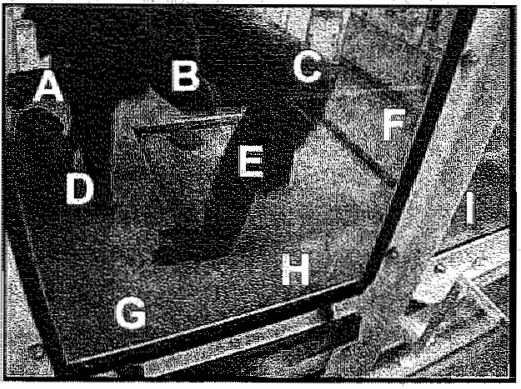

(a)

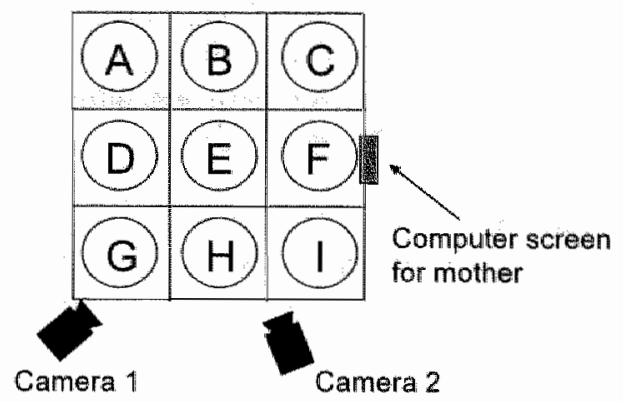

(b)

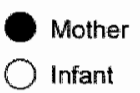

(c)

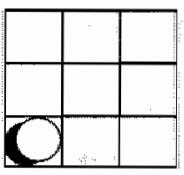

Same

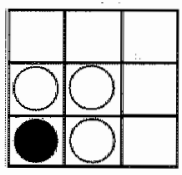

Near

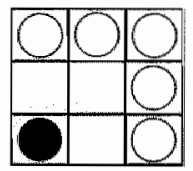

Far

Figure 1 The observational setting of the experimental booth. (a) Mother and infant chimpanze pair is in the experimental booth. The alphabet characters in the picture represent each square of the floor. (b) Pictorial aerial view of the obserwation setting. (c) The pictorial figure represents the posicional relationship between mother and infant. Left figure (Same) mother (filled circle) and infant (opened clipcle) are in the same square, middle figune (wear): the infant is in the square that is next to the square where mother is, right flgure (Far): the infant is not in the same square or mext to the squares where his mother is.

\section{PROCEDURE}

Observations took place when the infant was 15 days to 12 months old. One observational session was conducted each month of age. During the observations, the mother participated in a task on the computer monitor and did not interact with her infant directly.

Prior to the observation, the mother and infant had come into the experimental booth 6 times a week since the infant was 11 days old. Mother and infant were invited to enter the experimental booth from the outdoor enclosure. For this purpose, we simply called them by name until they spontaneously walked into the booth. Both subjects were free to engage in any kind of activity inside the 
booth. After his mother began to work on her task [one of the visual discrimination tasks on computer system (e.g., Kawai \& Matsuzawa, 2000) at one side of the booth], the observation was started. The observation was conducted during about 40 minutes in each session.

\section{DATA ANALYSIS}

We divided the floor of the booth into 9 squares (see Figure 1a, b). That is, the square floor of the booth was analyzed as a $3 \times 3$ matrix (approximately $70 \mathrm{~cm}$ on a side), and each square was named with letters from $A$ to 1 . Furthermore, we defined the distances between individuals were set up the categorized distance (see Figure $1 c$ ) for after analysis:

We used a 5-seconds interval method for analyzing the data. We analyzed 10 minutes (about 5 seconds after the beginning of a session) for acquiring stable data, because the infant sometimes felt asleep in the latter half of a session. We observed their interactions from four points of view (see Table 1). Four variables were coded from the video tapes: First, "Orientation", was defined as the infant looking at; the mother's (1) face, (2) body, (3) arms, (4) the object(s) the mother touches (e.g., PC monitor, food rewards and so on), or (5) all others of the above and the mother looking at (1) infant's face and body or (2) all others of the above. The small size of the infant made it difficult to reliably distinguish between the parts of the infants body the mother was looking at; therefore we decided to collapse the data from the mother's looking behavior as looking to the infant's face and body or all others. However, there were a few clear cases that allowed us to focus on "Mutual gaze". Mutual gaze was defined as the mother clearly looking at her infant's face, and the infant clearly looking at mother's face (Bard, 1994). Second, "Physical contact" or No physical contact between mother and infant was coded. Physical contact was defined to occur if at least some of the mother's body touched some of the infant's body. Third, "Locomotion" of the subjects was defined as the infant or mother moving from one of the squares in the $3 \times 3$ matrix (A to 1) to another. Last, the "Distance" between mother and infant was calculated by using location of the mother and the infant from the data sheet of location coding. 
Table Interactive behaviors between mother and infant.

\begin{tabular}{|c|c|c|}
\hline \multicolumn{2}{|c|}{ Behavioral codes } & \multirow{2}{*}{ Definitans } \\
\hline Orientation & llooks at $M$ & \\
\hline & & $\begin{array}{l}\text { (2) Infant clearly looks at the mother's arms. } \\
\text { (3) Infant clearly looks at the mother's body including } \\
\text { the legs and head. } \\
\text { (4) Infant looks at the object which mother is touching } \\
\text { (e.g. PC monitor, food rewards) }\end{array}$ \\
\hline & others & $\begin{array}{l}\text { (5) Infant clearly does not look at the mother, but } \\
\text { somewhere else: }\end{array}$ \\
\hline & Mlooks at/ & $\begin{array}{l}\text { (1) Mother looks at directly into the infant's face. } \\
\text { (1) Mother clearly looks at the infant's body } \\
\text { including the arms, legs, body and head; but does not } \\
\text { look at the face of the infant. (this definition is for the } \\
\text { after analysis of muttel gaze) }\end{array}$ \\
\hline & others & $\begin{array}{l}\text { (2) Mother clearly does not look at the infant: (looking } \\
\text { somewhere else): }\end{array}$ \\
\hline & Mutual gaze: & $\begin{array}{l}\text { When the infant looks at his mother's face; and the } \\
\text { mother looks at the infant's face (Bard; 2002) }\end{array}$ \\
\hline \multirow[t]{2}{*}{ Physical contact } & Physical contact & $\begin{array}{l}\text { At least some part of mother's body is in touch with } \\
\text { some part of infant's body. }\end{array}$ \\
\hline & No contact & Mother's body is not in touch with infant's body at all. \\
\hline Locomotion & & $\begin{array}{l}\text { Infant's or mother's lacation from one cell to another } \\
\text { cell in the booth. }\end{array}$ \\
\hline Distance & & $\begin{array}{l}\text { Calculated by the geometric distance between } \\
\text { mother's and infant's location. }\end{array}$ \\
\hline
\end{tabular}

The main observer ( $\mathrm{SO}$ ) classified the subject's behaviors according to the data analysis like we mentioned above on the basis of video recordings. To assess inter-observer reliability, two additional coders (YS, HK) watched the $50 \%$ of all video recordings and rated the subject's behavior after training in coding. They coded what the subjects were looking at ("Orientation" coding), whether their bodies made contact with each other ("Physical contact" coding), and which cell they were in ("Location" coding) on the moment of each five seconds interval of all observed periods. All coders used the on screen counter of the video player to time the 5 second intervals. This method prevented look away errors and made it possible to ensure that all coders used the exact same intervals. The inter-observer reliability was calculated by means of Cohen's kappa. The observed agreements and kappa results from each of the three combinations between the observers were averaged. Each observed agreement and kappa coefficient were; "Orientation": observed agreement was $86.3 \%$ and a kappa $=.794$, "Physical contact": observed agreement was $89.9 \%$ and a kappa $=.886$, "Location": observed agreement was $94.4 \%$ and a kappa $=.911$. 


\section{DATA SUMMARY}

1. The number of frames of each location of mother and infant was determined for each session ( 120 frames in one session, that is, every 5 seconds in the 10 minutes observation period). "Locomotion" was defined as the frame in which the infant is not staying in the same cell with his mother. The percentage of "Locomotion" was calculated by dividing this number of frames by all observing frames of 120 .

2. The number of frames of each looking behavior was determined for each session. By dividing this number by all observing frames of 120 , the percentage of each looking behavior was calculated as the "Frequency of looking behavior (mother looking at infant or infant looking at mother)".

3. The "Distance" between mother and infant was calculated by checking the location of the mother and the infant from the data sheet of the location coding. For example, when the infant was in the location " $\mathrm{D}$ " (from the definition of figure 1 ) and the mother was in location " $F$ " at the same moment, the "Distance" was calculated as "Far" (see Figure 1c).

4. The "Looking behavior as a function of the mother-infant distance or physical contact" was calculated from "Frequency of looking behavior" and "Distance".

5. The number of instances of "Mutual gaze" was determined for each session, and this number was divided by all observing frames (120).

Furthermore, we got together all looking behavior and distance for showing the sequential line graph of "secure base" behavior from the aspects of the mother's role as "secure base (c.f. Bowlby, 1969). These data were possible when the mother stayed in one location and did not interact directly with her infant, and only the infant could move freely within the measurable experimental booth during the observation. 


\section{RESULTS}

Figure 2 shows that the percentage of no physical contact and the locomotion of the infant as a function of age by month.
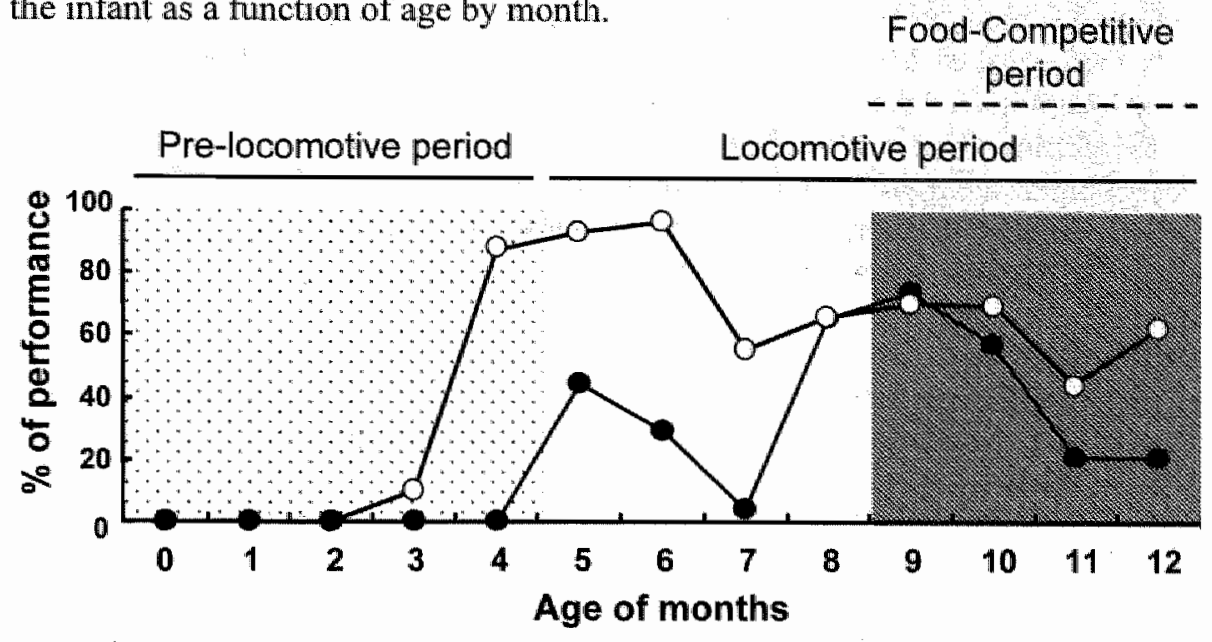

- T- The percentage of no physical contact between mother and infant

- The percentage of locomotion by infant

Figure 2 Percentage of no physical contact and locomotion of infant as a function of the infant"s age of months. Open circle: percentage of no physical contact between mother and infant, filled circle: percentage of locomotion by the infant. Paler shaded anea (from 0 to 4 months old); the Pre-locomotive period, deeper shaded atea (from 9 to 12 months old); the Food-competitive (between mother and infant) period, white colored and deeper shaded area (from 5 to 12 months old); the Locomotive period.

The open circles in Figure 2 clearly show that the mother was holding her infant all the time from 0 month to 2 months old. From 3 months to 4 months of age, the mother started to release her infant but still kept him at her side (defined as the same position in square). The filled circles in Figure 2 show that the infant's locomotion started from 5 months old.

Moreover, we classified this 8 months observation into two periods. The first period, from 0 to 4 months old, is the Pre-Locomotive period. In the first three months of this period, the infant was held by his mother. In the last two months of this period, the infant did not show any locomotion even when his mother did not hold him. In sum, there was a developmental sequence in which the mother let the infant free and put him on her side, and the infant stayed on his mother's side, after a while (in this case, it was two months), the infant started to move around independently. Note that the infant did not try to free himself from his mother during the whole observation. This means that the behavior in which the mother put her infant on her side occurred naturally. 
The second period is the Locomotive period. In this peried, from 5 months, the infant started locomotive behavior. Additionally, the infant began to try getting the food reward from his mother's task from 7 months old. The data of 7 months old show a low percentage of locomotion. The competition for food between mother and infant began to increase from 9 months of age (see also Sousa, Okamoto, \& Matsuzawa, 2003). This competition distracted the infant's natural locomotion, because he wanted to stay or come back quickly to the food tray for getting foods. Therefore, we defined the period after 9 months as a "Food-competitive period", and did not use this period for following analysis.

In the following sections we describe, according to the observational design, the relation between the distance and visual interaction of mother and infant.

Pre-locomotive period (0-4mo):

Figure 3 shows the relation between looking behavior and no physical contact in the Pre-locomotive period.

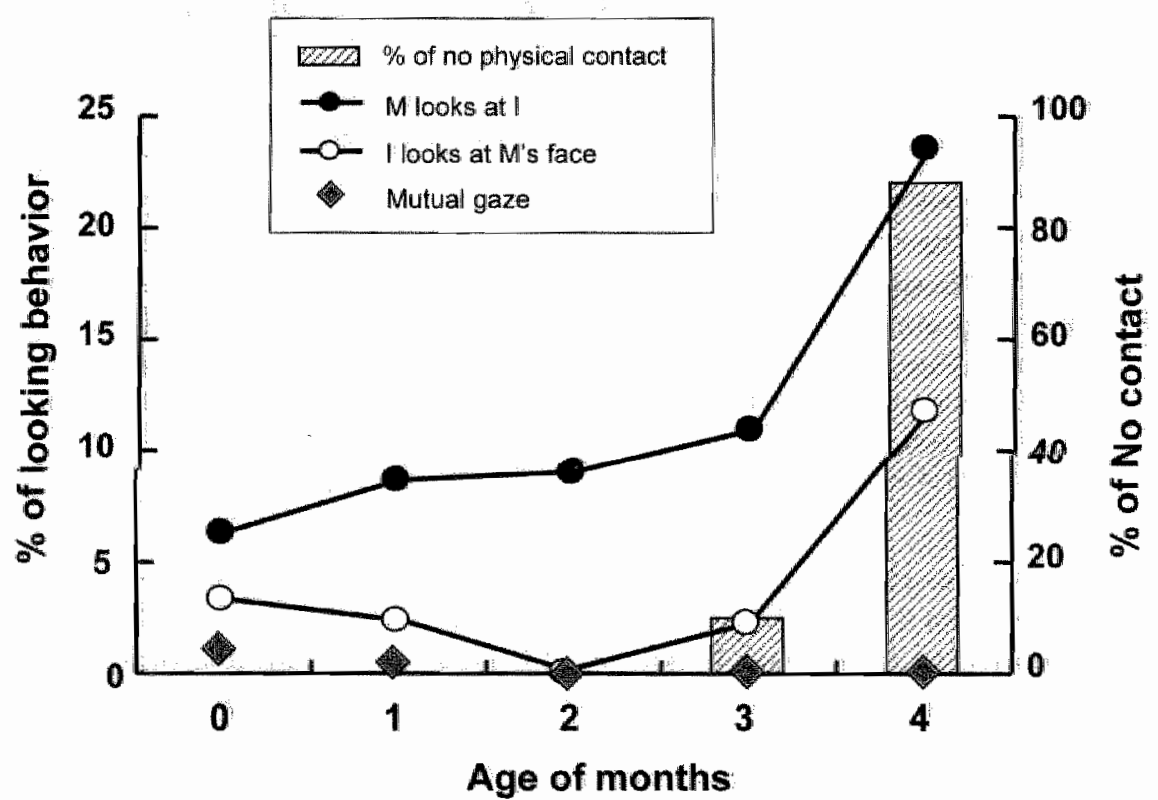

Figure 3 Percentage of looking (left vertical axis and linear line graphs) and percentage of no physical contact (right vertical axis and bar graphs) between mother (M) and infant (I) as a function of the infants age of months $(0-4$ mo.). Colored diamond mark represents mutual gaze interaction between mother and infant. 
A two-way analysis of variance (ANOVA) was conducted with age of months and looking interaction (mother and infant). Independent variable is age of months, dependent variable is looking interaction Results revealed a significant main effect for looking interaction between mother and infant $[F(1,15)$ $=6.086, p<.05]$, but a main effect for age of months was not signifficant $[F(4,15)$ $=0.864$, n.s. $]$. During this period, the mother looked at her infant more often than the infant looked at his mother.

Moreover, Figure 3 shows that looking (among the mother-infant pair) increased when physical contact lost or when physical distance increased. Additionally, there was a low frequency of mutual gaze, but it was observed from 15 days of age. This result shows that the infant started to look at his mother from the early infancy period.

We also analyzed how often the infant looked at the object(s) his mother interacted with (e.g., PC monitor, food rewards) early in his development (0-2 months olds). In two months old, the infant became progressively more interested in the objects his mother interacted with: 0 months: $0.3 \% ; 1$ month: $10.5 \% ; 2$ months: $89.4 \%$. First looking behavior to the PC-monitor at which his mother was doing the task was observed from 0 months old. Moreover, sometimes the infant even twisted himself to look at the PC-monitor when he was 2 months old. 
Locomotive period ( $5-8$ mo.)

Figure 4 shows the relative distance and looking between mother and infant in the Locomotive period. Moreover, we classified the "Same" into two types: Same (physical contact) and Same (no physical contact).

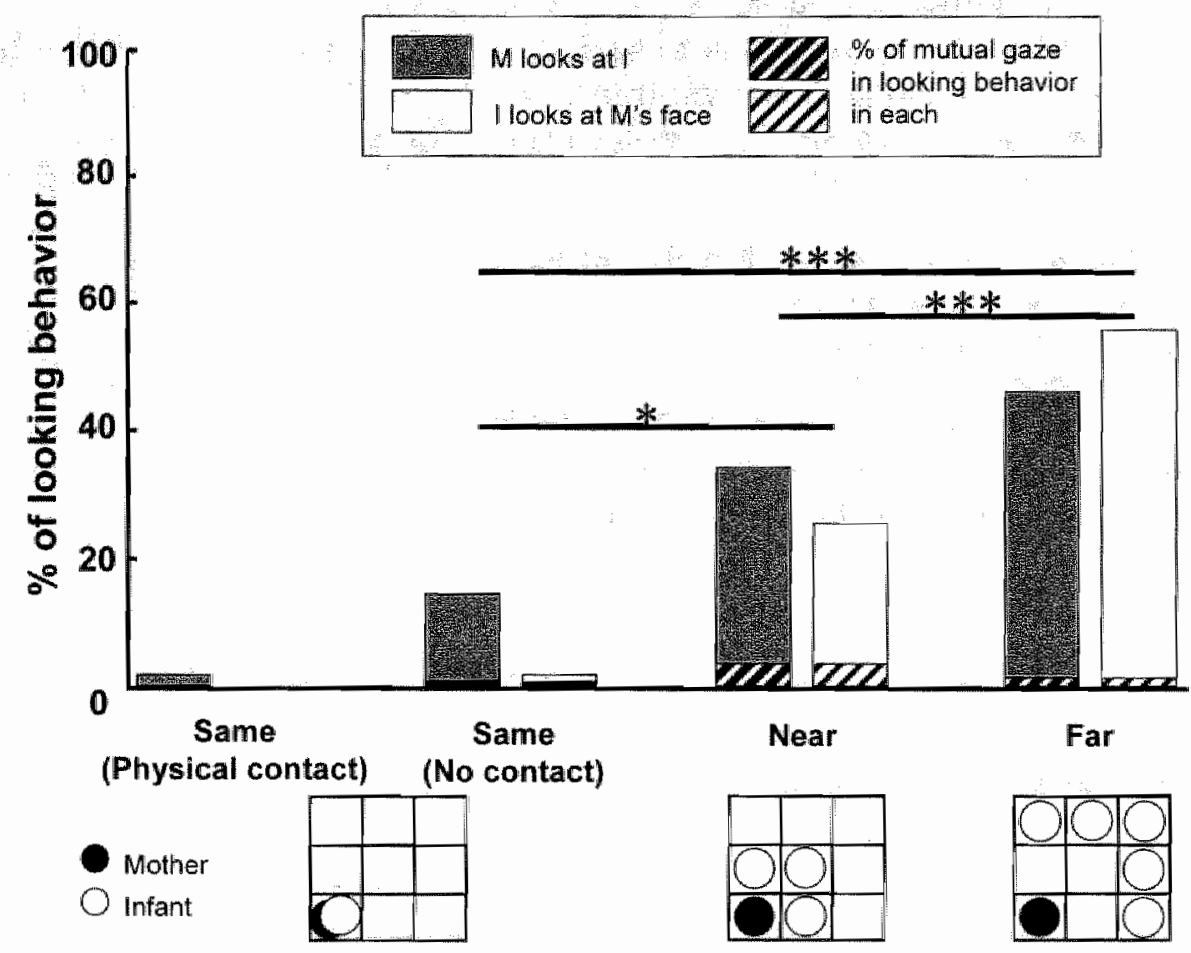

Figure 4 The Locomotive periods (5-8mo, the geometric distance and looking between mother and infint. The pictorial figure under the graph represents the positional relationstwip between moiher and infant (see Figure Ic). Slashed bar in each shaded and opened bar: percentage of mutual gaze in looking for each data.

A two-way ANOVA was conducted with distances (Same with no physical contact, Near, Far position) and looking interaction (mother and infant). Results revealed a significant main effect for distance $[F(2,12)=33.582, p<.001]$, but the main effect for looking interaction was not significant $[F(1,6)=0.073$, n.s.]. The interaction of distances $\mathrm{x}$ looking interaction was also not significant $[F(2,12)$ $=2.781, \mathrm{n.s.}$. . The frequency of looking behavior to mother/infant increased with increasing distance. A least significant difference test (Ryan's procedure test) revealed that in the "Near position", mother and infant looked at each other more often than in the "Same (no physical contact) position" $(p<.05)$. Similarly, this looking behavior was also observed in the "Near position" than in the "Far 
position" $(p<.001)$. Additionally, mother had the tendency to look at her infant many times even in the same position when she made physical contact with her infant. The frequency of mutual gaze was low (average $1.6 \%$ ).

Moreover, Figure 5 shows the distance as a function of time. This sequential line graph indicates the transition of the relative distance between mother and infant.

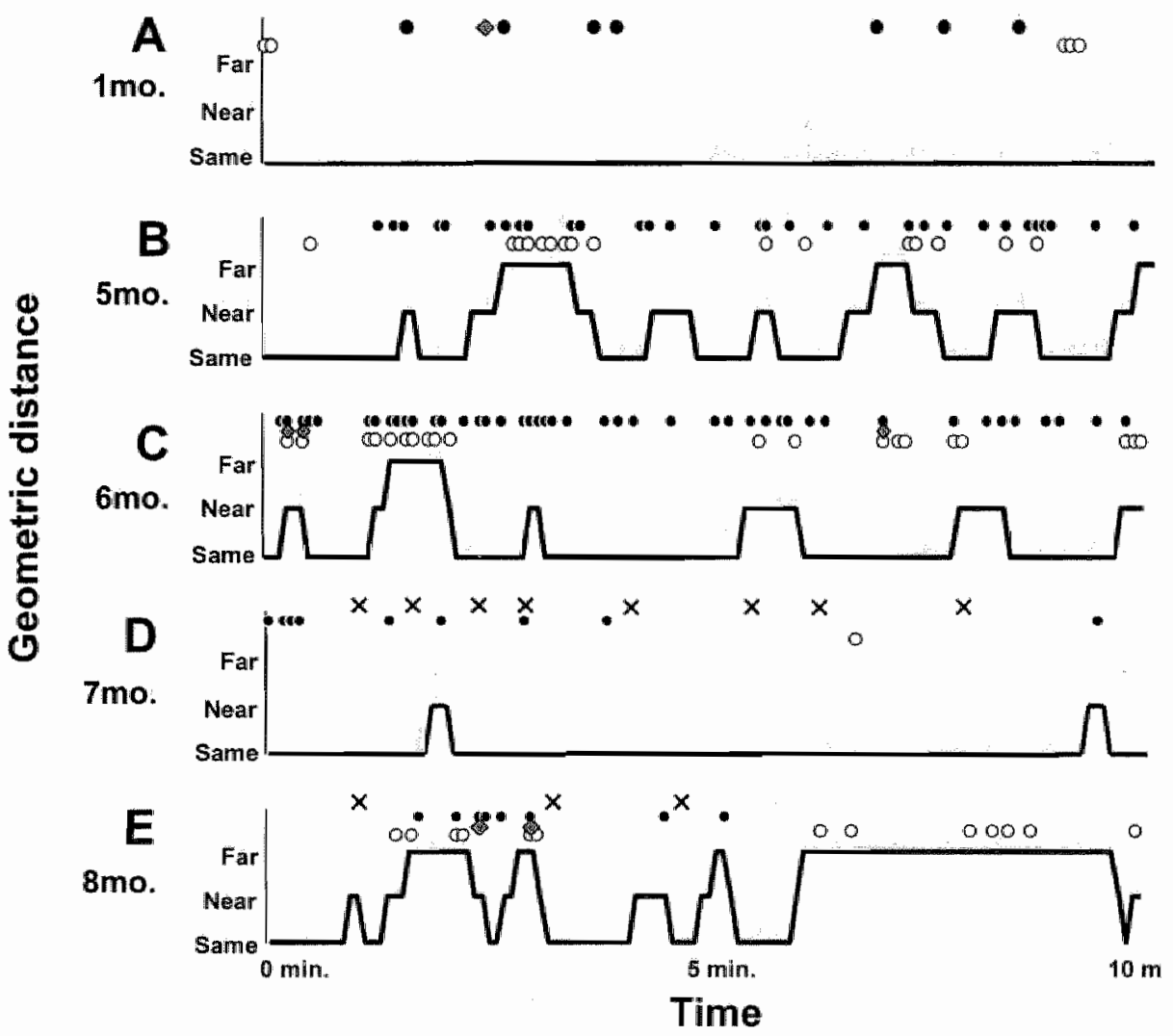

Figure 5 Geometric distances and looking between mother and infant as a function of the time during the observation. Each figure shows the data of each month of age: (A) 1 month of age as a sample of Pre-Locomotive period, (B) 5 months of age, (C) 6 months of age, (D) 7 months of age, (E) 8 months of age. Linear graph: the geometric distance between $M$ (mother) and I (infant), colored diamond mark: mutual gaze interaction between mother and infant filled circle: each event that the mother is looking at her infant, opened circle: each event that the infant is looking at his mother, $X$ mark: each event in which the infant gets the food reward from his mother's task.

These line chart data came only from the infant's locomotion, because his mother was doing her monitor task and did not move around. Therefore, Hinde's index of who is responsible for leaving and approaching the other depends only on the infant's data (Hinde \& Atkinson, 1970; Brown, 2001). During the whole 
Pre-Locomotive period (Figure $5 \mathrm{~A}$ ), the line charts show only linearly shapes. As an example we show the graph at 1 month old as a sample of this period. On the other hand, in the Locomotive period (Figure 5B-E), the four line charts are difterent from the first period. The infant repeatedly moved away from his mother and returned to her again. Thus, "secure-base" behavior (e.g., Bowlby, 1969) was clearly present from 5 months of age.

Furthermore, Figure $5 \mathrm{~B}, \mathrm{C}$, and $\mathrm{E}$ indicate that looking behavior occurred mostly when the mother and infant were separated, and the moment after separation. This figure also clearly shows that the mother looked at the infant more often than the infant looked at his mother; especially when the infant was young $(5,6$ months olds). Figure $5 \mathrm{D}$ ( 7 months old) indicates that the infant took away the food reward from his mother. The infant did not move around but stay close to the food trey which is in the same cell with his mother. Moreover, mother's looking behaviors were observed at returns of the infant to the mother (16 events out of all 19 returns; $84.2 \%$ ). Mother's looking behaviors were also observed after relatively immediately the infant's leaves from the mother (17 events out of all 21 leaves; $81.5 \%$ ). Although there are many incidents of looking at the other, mutual gaze (diamonds mark) occurred only a few times.

\section{DISCUSSION}

The results of this observation study demonstrate that the looking behavior between mother and infant increased when physical contact between them became less or the distance between them increased. Moreover, the mother looked at her infant more than the infant looked at his mother, even when the mother was not interactive to infant directly. Furthermore, mother's looks were linked in time with the infant's returns and leaves. We suggest that the looking behavior between each other compensates for the distance between mother and infant.

These results have a similar tendency as the previous finding by Bard, et al. (in press) that mutual gaze in chimpanzee mother and infant may be a consequence of breaks in physical contact. In our study, mutual gaze was observed 15 days after birth. This result confirms the previous finding that chimpanzee mothers and infants, as early as 2 weeks of age, spend some time in mutual gaze (Bard, 1994). In our study, however, the distance between mother and infant was not always accompanied by mutual gaze. It has previously been reported that mutual gaze between mother and infant chimpanzee occurs with a high frequency in first three months of their life (Bard et. al., in press). Contrary to this result, in our study we did not observe this behavior frequently. We suggest the factor that is responsible for the differences is in the observational setting. First of all, in most of the cases of our study, the mother had participated in her own task with a computer screen which was attached one side of the experimental booth. On the other hand, in Bard et al's study, there was no task in which the mother participated. Therefore, it is clear that mutual gaze will be less when there 
are events in the environment to which the mother must attend.

After the infant started to move around independently (from 5 months old), we observed that the infant who took the distance from mother was glancing to his mother even when she was not looking at him. And then, he restarted to do the locomotive behavior. This behavioral sequence was observed frequently. From attachment behavior Q-set for infant macaques, infants showed similar behavior (Kondo, 1995b). Macaque infants follow their mother visually, when she moves or changes activities. This result allows us to conclude that the chimpanzee mother plays a role of "secure-base" for their infant:

Ainsworth described the attachment and exploratory systems of an infant's use of an attachment figure as a "secure base from which to explore" (1963). Additionally, according to Bowlby (1969), the exploratory behavior is defined as a developed and evolved sequential behavioral system from which the infants can get information about their environment. In our study, the infant always began to explore his environment starting from his mother, thus using his mother as an attachment figure and "secure base" from which to explore. Moreover, in a field study, Doran (1992) reported that an $0-3$ months old chimpanzee infant stayed on or near mother at all times. At $4-6$ months old, independent locomotion occurred near by the mother, and the infant moved short distances on the ground by aided bipedal. In our study, the infant chimpanzee started to move around independently from 5 months old. Our results clearly confirm this previous field report.

Furthermore, for human infants, "secure-base behavior" is usually seen around the age of 9-12 months (e.g., Ainsworth, 1963; Bowlby, 1969). The differences in the "secure-base behavior" of human and chimpanzee infants may have to do with differences in the both rate of development and the characteristics of the physical environment of humans and chimpanzees. Chimpanzee infants start locomotion by aided bipedal at 4-6 months of age, while human infants start locomotion by crawling at 6-9 months of age (Bremner, 1994). Moreover, our observational setting was a smaller empty experimental booth which has a flat surface that was totally different from a natural human infant's environment (e.g., room with furniture, doors, and other people). Additionally, the booth in our observational setting was already familiar enough to the chimpanzee infant. Given the smaller size of the booth in our study the infant could not travel far away from mother and there was no distraction between mother and infant. Bowlby (1973) described as important not only the physical presence of an attachment figure, but also the infant's belief that the attachment figure will be available if needed. We also suggest that because there were no worries about the safety in this observation booth, the chimpanzee infant started to explore his environment as soon as he is physically able to do so. Future studies may wish to introduce a stressor such as a remote controlled toy in the testing situation. This stressor may alter the infant's natural exploratory tendencies.

In a study with humans, Kondo (2001) suggested that the cognitive development that underlies "secure base" behavior is already prepared even when infants do not show locomotion yet, because the "secure base" behavior is 
observed immediately after infants become able to do locomotion. In our present study we found that the chimpanzee infant started to look at the object which his mother was touching from a very early age and the frequency of looking at the objects increased gradually with age. Some objects that the mother was touching like the computer screen or foods got the infant's interest. However, we suggest that these looking behaviors show that the motivation which let the infant to explore his environment had already existed even when the infant could not move yet. In chimpanzees also, it is possible that some cognitive developments like exploratory motivation that are necessary for the use of a "secure base" are already prepared before the development of locomotion as Kondo (2001) suggested in human study.

In summary, from our findings we suggest that the looking behavior to the mother and the exploratory behavior already start in infant chimpanzees before they show locomotion. These behaviors are likely to play an important role to the constitution of "attachment" which is necessary to "secure-base behavior" and the "exploratory motivation" which is necessary to locomotion. Furthermore, our present study implies that the basis of mother and infant chimpanzee's relationship like "attachment" is also developed and mutually related with other cognitive and physical developments. Unfortunately, we only observed a single pair of mother and infant chimpanzee in this study. Thus, tests with more subjects are needed to verify the generality of the present results. Nevertheless, the present results have many implications for comparative research on visual communication in mother and infant chimpanzee.

\section{ACKNOWLEDGEMENTS}

This research was financially supported by the Cooperative Research Program of the Primate Research Institute, Kyoto University to S. Okamoto, Grants-in-Aid for Scientific Research from the Ministry of Education, Culture, Sports, Science and Technology, Japan to T. Matsuzawa (\#12002009), and M. Tomonaga ( 13610086 ), and the Grant-in-Aid for the 21st Century COE Program (A2 to Kyoto University). We would like to express our thanks to the members of the PRI for their support for this research. Special thanks are due to K. A. Bard and T. Matsuzawa for their valuable suggestions and critical comments on early version of this manuscript. We also wish to express our thanks for the critical reading of the manuscript to J. Barth.

\section{REFERENCES}

Ainsworth, M. D. S. (1963). The development of infantmother interaction among the Ganda. In B. M. Foss (Ed.), Determinants of infant behavior (Vol. 2, pp. 67-112). New York: Wiley.

Bard, K. A. (1994), Evolutionary roots of intuitive parenting: Maternal competence in chimpanzees. Early Developinent and Parenting, 3, 19-28.

Bard, K. A. (2002). Primate parenting. Bornstein, Marc H. (Ed). Handbook of parenting: Wol. 2:

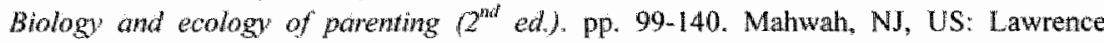


Erlbaum Associates.

Bard, K. A., Myowa-Yamakoshi, M., Tomonaga, M., Tanaka, M. Quinn, J, Costall, A, Matsuzawa, T. (in press). Group differences in the mutual gaze of chimpanzees (Pan troglodyles). Developmental Psychology.

Batki, A., Baron-Cohen, S., Wheetwright, S., Connellan, J., \& Ahluwalia, J. (2000). is there an innate gaze module? Evidence from human neontes. Infant Behowor \& Development, 23, 223 229.

Biben, M. (1994). Eye contact and vocal responsiveness in squirrel monkey infants and their caregivers. Early Development and Parenting, 3, 29-36.

Bowlby, 1. (1969). Attachment and Loss: Vol 1. Atrachment. New York: Basio Books.

Bowlby, J. (1973). Atachment and Loss: Vol. 2. Separation. New York: Basic Books.

Bremner, J. G. (1994). Infoncy (2 ${ }^{\text {nd }}$ edition). Oxford: Basil Blackwell.

Brown, G. R. (2001). Using proximity measures to describe mother-infant relationships. Folia Primatologica, 72, 80-84.

Bruner, J. S. (1975). The ontogenesis of speech acts. Joumal of Child Language, 2, 1-19.

Bullowa, M. (1979). Introduction: Prelinguistic communication: a field for scientific research. In Bullowa, M. (Ed.), Before speech: The beginning of interpersonal communication. (pp. 1-62). New York: Cambridge University Press.

Butterworth, GE., \& Jarrett, N. L. M. (1991). What minds have in common is space: Spatial mechanism serving joint visual attention in infancy. British Journal of Developmentol Psychology, 9, 55-72.

Cassidy, J. (1999). The nature of the child's ties. In Cassidy , J. \& Shaver, P., $\mathbb{R}$. (Eds.), Handbook of attachment: Theory, research, and clinical applications. (pp. 3-20). New York: The Guilford press.

Corkum, V., \& Moore, C. (1995). Development of joint visual attention in infants. In C. Moore \& P. J. Dunham (Eds.), Joint attention: its origins and role in development (pp. 61-83). Hillsdale, NJ: Erlbaum.

Doran, D. M. (1992). The ontogeny of chimpanzee and pygmy chimpanzee locomotor behavior: a case sudy of paedomorphism and its behavioral correlates. Journal of human evolution, 23 , $139-157$.

Ehardt, C. L., \& Blount, B. G. (1984). Mother-infant visual interaction in Japanese macaques. Dewelopmental Psychobiolog: 17, 391-405.

Farroni, T. Csibra, G. Simion, F, \& Johnson, M. H. (2002). Eye contact detection in hunans from birth Procedings of the National Academy of Sciences of the Unired States of America, 99 , $9602-9605$.

Frtedle, R. \& Lewis, M. (1977). Prelinguistic conversations, In M. Lewis and L. Rpsenblum (Eds.), Interaction. Conversation, and the Developwent of Language. (pp. 157-185). New York: Willey.

Hinde, R. A., \& Atkinson, $\$$. (1970). Assessing the roles of social partners in maintaining mutual proximity, as exemplified by mother-infant relations in thesus monkeys. Animat Behaviour, 18, 169-176.

Kawai, N., \& Matsuzawa, T. (2000) Numerical memory span in a chimpanzee. Nature, 403, 39-40.

Kondo-lkemura, K., \& Waters, E. (1995a). Maternal behavior and infant security in old world monkeys. In E. Waters, B. E. Vaughn, G. Posada, \& K. Kondo-lkemura (Eds.), Caregiving, cultural, and cognitive perspectives on secure-base behavior and working model Monograpls of the Sociey for Research in Child Development, 244, 97-110.

Kondo-lkemura, K., \& Waters, E. (1995b). Background and sorting instructions for the attacthment Q-set for infant macaques and the maternal Q-set for macaques. In E. Waters, B. E. Vaughn, G. Posada \& K. Kondo-lkemura (Eds.), Caregiving, cultural, and cognitive perspectives on secure-base behavior and working model. Monographs of the Soctery for Research in Child 
Dewelopment, $244,255-279$.

Kondo, K. (2001). Emergence and development of attachment. In Okano, T. (Ed.), pp. 161-172. Dexelopmental Psychology of Social Skills. Tokyo: Art and Brain (Japanese text).

Matsuzawa, T. (1985). Use of numbers by a chimpanzee. Norture $315,57-59$.

Matsuzawa, T. (2001) Primate origins of human cognition and behovior. Tokyo: Springer-Verlag.

Matsuzawa, T. (2003). The Ai project: historical and ecological contexts. Animal Cognixion, 6, $199-211$.

Moore, C. (1999). Gaze following and the control of attention. In P. Rochat (Ed), Earby social cognition (pp. 241-256). Mahwah, $\mathrm{NJ}_{*}$ Lawrence Erlbaun Associates, Inc.

Murofushi, K. (1997). Numerical matching behavior by a chimpanzee (Pan troglodytes): Subitizing and analogue magnitude estimation. Japonese Psychologicol Research, 39, 140-153.

Myowa-Yanakoshi, M., Tomonaga, M., Tanaka, M., Matsuzawa, T. (2003). Preference for human direct gaze in infant chimpanzees (Pan troglodytes). Cognition, 89, 53-64.

Ochiai, T. \& Matsuzawa, T. (1998). Planting trees in an outdoor compound of chimpanzees for an enriched environments In: Proceedings of the Third International Conference on Environmental Enrichment. Hare, V. J., Worley, E. (eds), 355-364. The Shape of Enrichment, San Diego, CA.

Okamoto, S., Tomonaga, M., Ishii K., Kawai N., Tanaka, M., \& Matsuzawa, T. (2002). An infant chimpanzee (Pan troglodyres) follows human gaze. Animal Cognition, 5, 107-114.

Okamoto, S." Tanaka, M., \& Tomonaga, M. (2004). Looking back: the "representational mechanism" of jount attention in an infant chimpanzee. Japanese Psychological Research, 46, 236-245.

Primate Research Institute, Kyoto University (1986). Guide for the care and use of laborafory primates, Kyoto University, Kyoto, Japan.

Plooij, F. (1979). How wild chimpanzee babies trigger the onset of mother-infant play - and what the mother makes of it. In Bullowa, M. (Ed.), Before speech: The beginning of interpersonal cammunication. (pp. 223-244). New York: Cambridge University Press.

Robson, K. S. (1967). The role of eye-to-eye contact in maternal-infant attachment. Journal of Child Psychology \& Psychiany \& Allied Disciplines. 8, 13-25.

Sorenson, E. R. (1979). Early tactile communication and the patterning of human organization: a New Guinea care study. In Bullowa, $M$. (Ed.), Before speech: The beginning of

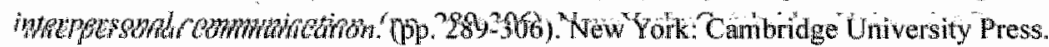

Stack, D. M. (2001). The salience of touch and physical contact during infancy: Unraveling some of the mysteries of the somesthetic sense. Bremner, G. (Ed.); Fogel, A. (Ed.). Blachwell hondbook of infant development. Handbooks of developmental psychology. (pp. 351-378). Malden, MA, US: Blackwell Publishers.

Stern, D. N. (1974). Mother and infant at play: The dtadic interaction involving facial, vocal, and gaze behaviors. In M. Lewis and L. Rosenblim (Eds.), The Effect of the infont on its Caregiver. (pp. 187-213). New York: Wiley.

Tanaka, M., Tomonaga, M., \& Matsuzawa, T. (2002). A developmental research project with three mother-infant chimpanzee pairs: A new approach to comparative developmental science. Japanese Psychological Review, 45, 296-308. (Japanese text)

Tomonaga, M. \& Matsuzawa, T. (2002). Enumeration of briefly presented items by the chimpanzee (Pam troglodytes) and humans (Homo sapiens). Animal Learning \& Behovior, 30, 143-157.

Tomonaga, M., Okantoto S., Myowa-Yamakoshi, M., \& Yamaguchi, M. (2002). Recognition of face and gaze in infant chimpanzees (Pan troglodytes). Paper presented at the Second international symposium on comparative cognitive science, "Social transmission of knowledge", Inyuma, Japan. 
Tomonaga, M., Tanaka, M., \& Matsuzawa, T. (Eds.) (2003) Cogitive and behoworal dewelopwent in chimpanzees: A comparative approach Kyoto, Japan: Kyoto University Press (Japanese text).

Tomonaga, M., Tanaka, M, Matsuzawi, T., Myowa-Yamakoshi, M, Kosugi, Dis, Mizuno, Y., Okamoto, S., Yamaguchi, M. K., \& Bard, K. A. (2004). Development of social cognition in infant chimpanzees (Pan troglodytes): Face recognition, smiling, nutual gaze, gaze following, and the lack of triadic interactions. Japanese Psychologicol Research, 46, 227-235.

Trevarthen, C. \& Aitken, K. J. (2001). Infant intersubjectivity: Research, theory, and clinical applications. Joumal of Child Psychology and Psychiary and Alhed Disciplines, $42,348$.

van Lawick-Goodall, J. (1968). The behaviour of free-living chimpanzees of the Gombe Stream Nature reserwe. Animal Behonior Monographs, 1, 161-331. 



\section{CHAPTER 2}

\section{AN INFANT CHIMPANZEE (PAN TROGLODYTES) FOLLOWS HUMAN GAZE*}

\section{*Published as:}

Okamoto, S., Tomonaga, M., Ishii, K., Kawai, N., Tanaka, M. \& Matsuzawa, T. (2002) Animal Cognition, 5, 107-114. 


\section{ABSTRACT}

The ability of nonhuman primates to follow the gaze of other individuals has recently received much attention in comparative cognition. The aim of the present study was to investigate the emergence of this ability in a chimpanzee infant. The infant was trained to look at one of two objects, which an experimenter indicated by one of four different cue conditions: a) tapping on the target object with a finger; b) pointing to the target object with a finger; c) gazing at the target object with head orientation; d) glancing at the target object without head orientation. The subject was given food rewards independently of its responses under the first three conditions, so that its responses to the objects were not influenced by the rewards. The glancing condition was tested occasionally, without any reinforcement. By the age of 13 months, the subject showed reliable following responses to the object that was indicated by the various cues, including glancing alone. Furthermore, additional tests clearly showed that the subject's performance was controlled by the "social" properties of the experimenter-given cues but not by the nonsocial, local-enhancing peripheral properties.

Key Words: chimpanzee, infant, gaze-following, joint attention, social cues

\section{INTRODUCTION}

The ability to follow another individual's gaze has been demonstrated in young human infants. This ability is a required prerequisite for "joint visual attention". Scaife and Bruner (1975) demonstrated that human infants as young as 2 months adjust their gaze contingent on a change in the focus of attention of an adult, suggesting that already 2 month-old infants are sensitive to the gaze of others.

Butterworth and his colleagues (Butterworth \& Cochran, 1980; Butterworth \& Jarrett, 1991) conducted a series of experiments that replicated and extended these findings. They obtained evidence for three successive mechanisms of joint visual attention in infants ranging in age from 6 to 18 months. At 6 months, infants progress graduaily from responding to the head. movements of others to orienting in the same general direction within their visual field. By 12 months, infants are able to localize the particular object at which the other is looking. By 18 months, infants can follow someone else's gaze into space that is outside their own visual field (see Butterworth and Jarrett,
1991).

This ability to follow the gaze of others is found not only in humans but also in some nonhuman primates. A variety of primate species visually track the gaze direction of conspecifics to external objects (chimpanzees, mangabeys, and macaques; Emery et al. 1997; Tomasello et al. 1998; Tomonaga, 1999). Following the gaze direction of conspecifics is an important ability for social 
primates because it allows individuals to take advantage of the visual experience of group mates that spot interesting or important objects and events, such as food, predators, or significant social interactions. Furthermore, chimpanzees also visually follow the gaze direction of humans. They do this on the basis of eye direction alone, independent of head direction (Itakura \& Tanaka, 1998; Povinelli et al., 1996), even when the target is located above and/or behind them (Itakura, 1996; Povinelli et al., 1997; Call et al., 1998).

Various related experiments have been conducted in other nonhuman primates. Peignot and Anderson (1999) tested captive lowland gorillas (Gorilla gorilla) on object-choice tasks in which the correct object was indicated by the human experimenter. They reported that the gorillas did not use the experimenter's gaze without head orientation. Anderson and Mitchell (1999) compared the propensity of lemurs (Eulemur macaco) and macaques (Macaca arctoides) to engage in visual co-orientation, defined as turning to look in the same direction as the human experimenter whose focus of attention changes. They reported that the macaques consistently showed visual co-orientation whereas the lemurs showed no such response. Itakura and Anderson (1996) demonstrated that a male capuchin monkey could learn to follow the experimenter's gaze in object-choice tasks after intensive training. He learned to use the following experimenter-given cues: tapping, pointing, and gazing plus head orienting, but he failed to use eye gaze cues alone to solve the task. However, Vick and Anderson (2000) found that the capuchin monkeys were able to learn to use the experimenter's glancing at the correct object as a cue.

Human infants progressively develop the ability for gaze following between 6 and 18 months of age, as described above. Contrary to the huge amount of human infant literature, there are very few studies on joint visual attention / gaze following by young nonhuman animals. Myowa-Yamakoshi and Tomonaga (2001) found that between 1 and 6 weeks of age an infant gibbon (Hylobates agilis) preferred to look at a schematic direct-gaze face rather than an averted-gaze face, suggesting the possibility that nonhuman primates can discriminate gaze directions in very early infancy. Tomonaga, Myowa-Yamakoshi, and Terazawa (2000) preliminarily reported that human-raised Japanese macaque infants (4-6 months of age) followed pointing and head orienting cues made by the caregiver. Ferrari, Lohler and Gallase (2000) assessed in juvenile and adult pig-tailed macaques (Macaca nemestrina) the ability to follow the eye gaze of an experimenter. The juvenile monkeys were not able to orient their attention on the basis of eye cues alone. Tomasello, Hare and Fogleman (2001) studied the ontogeny of gaze following in two species: Rhesus macaques and chimpanzees. The rhesus infants first began reliably to follow the direction of gaze at the end of the early infancy period, at about 5.5 months of age. Chimpanzees did not reliably follow human gaze until 3-4 years; this age corresponds to the latter part of the late infancy period for this species.

The present longitudinal study was conducted to clarify the ability in chimpanzees to follow experimenter-given cues, including tapping, pointing, 
gazing with head orientation, and glancing (eye movement alone) in early infancy. Our study started at the neonatal stage (6 months of age) and ended in early infancy ( 17 months of age).

\section{EXPERIMENT 1}

We first presented a gaze-following task to a chimpanzee infant, and observed longitudinally the developmental changes in response to the social cues including gaze.

\section{METHODS}

\section{SUBJECT}

One male chimpanzee infant, Ayumu, served as the subject from 6 months to 13 months of age (see Figure 1). Ayumu had been reared with his mother since birth at the Primate Research Institute, Kyoto University. Both lived in a community of 14 chimpanzees. Ayumu was born after artificial insemination of its mother. He is one of the three subjects for the research project on chimpanzee development. $\mathrm{He}$ has experience with a variety of tests for the development of cognitive abilities (Holden, 2001; Matsuzawa, 2001a; Matsuzawa, 2001b). He maintained his free-feeding body weight throughout the present study, that is, no food deprivation was used. Care and use of the chimpanzee adhered to the Guide for the Care and Use of Laboratory Primates (1986) of the Primate Research Institute.

\section{APPARATUS AND STIMULI}

The experiment was conducted in the chimpanzee experimental booth at the institute (Figure 2a). The experimental apparatus consisted of a food tray (Figure $2 \mathrm{~b})$, and objects that served as targets. The food tray $(12 \times 15 \times 40 \mathrm{~cm})$ was made of transparent acrylic board and was placed at the bottom of a wall in the experimental booth. Three small holes $(4 \mathrm{~cm})$ through which food rewards were given were on the top of the tray ( $14 \mathrm{~cm}$ apart center to center). At each trial, two identical toys (mean size $2 \mathrm{~cm}$ ) were presented, each attached to one end of an acrylic bar (length: $28 \mathrm{~cm}$ ). Forly-five different objects (such as golden balls, little teddy bears, little colored bells, and so on) were presented across the trials to keep Ayumu interested. The behavior of the chimpanzee was video recorded.

Prior to the experiment, Ayumu had been taken into this experimental booth with his mother five times per week since he was 11 days old. Thus, at the beginning of the experiment he was already very familiar with both the experimental booth and the experimenters. 


\section{PROCEDURE}

Ayumu came to the experimental booth with his mother. After his mother began working on another task [one of the visual discrimination tasks facing to a computer system (Kawai \& Matsuzawa, 2000; see Figure 1a) at one side of the booth], the experiment for the chimpanzee infant began. At the onset of each trial, the experimenter laid on the floor of the outside the booth, $20 \mathrm{~cm}$ behind the objects (see Figure 2a). She called the subject by name or made a play face in order to attract his attention. After Ayumu approached the food tray, the experimenter looked at the center of the food tray with her hands placed in front of her body.

(a)

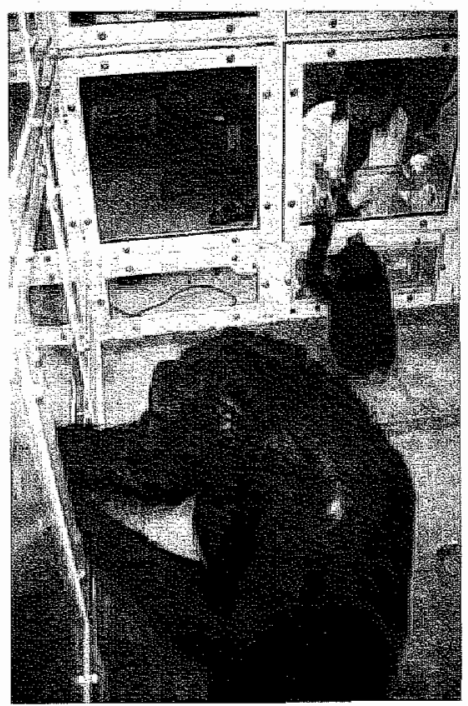

(b)

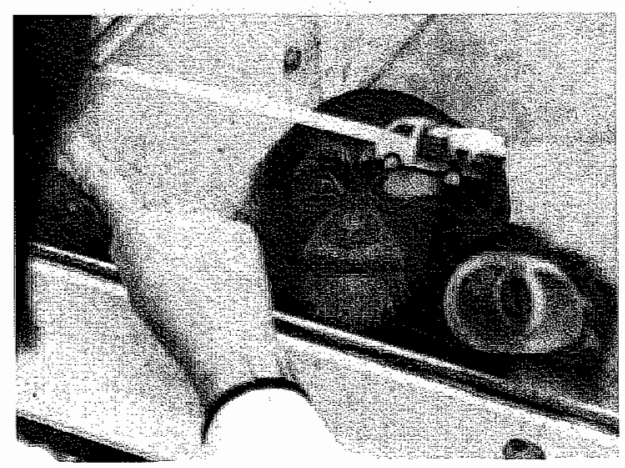

Figure 1 (a) The subject Ayumu, performing the experimental task. His mother worked at her own tasks in the same experimental booth, (b) Ayumu looked at the target object which the experinenter pointed at (with permission from "]lhe Mainichi Newspaper, Japan). 
Preliminary training When Ayumu was 5 months of age (155 days) preliminary training was conducted to achieve familiarization with the experimental setting: When Ayumu looked at the experimenter's face, the target object and social cue were presented. Three seconds after the cue, the experimenter presented food rewards independently of his behavior (a variation of the fixed-time schedule of reinforcement). There were 7 such sessions, each consisting of 5 trials.

Experimental setting At 7 months (211 days of age), the experimental training started. When the subject looked at the experimenter's face, the experimenter presented a cue to the target object for $3 \mathrm{sec}$, followed by the presentation of the food reward (a piece of fruit) through a hole in the tray nearest to the target object, independently of the subject's response (Figure $2 b$ ).

(a)

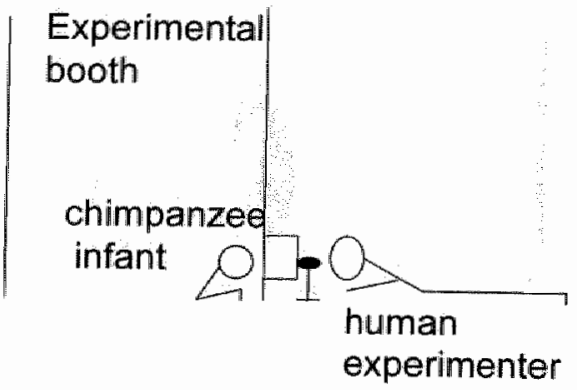

(b)

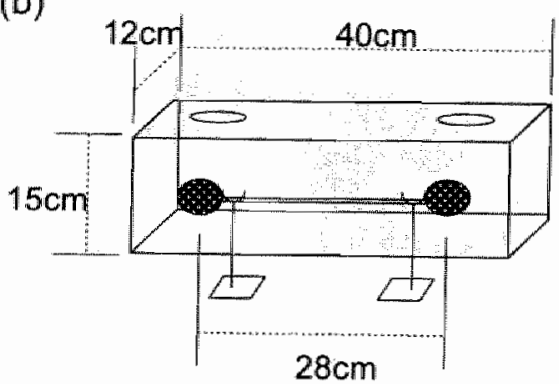

Figure 2 (a) Experimental setting, (b) schematic representation of the food-tray and a pair of objects.

We used four types of social cues as follows (Figure 3).

Tap: The experimenter gazed at and tapped the target object with an index finger. Point: The experimenter gazed at and pointed to the target object with an index finger. The distance between the finger and a target object was approximately 5 $\mathrm{cm}$.

Head aurn: The experimenter turned her head and gazed toward the target object. The distance from the experimenter's head to the object was approximately 20
$\mathrm{~cm}$.

Glance: The experimenter only glanced at a target object without any head turn. At the start of this condition, the experimenter gazed at the center of the food-tray. Then she glanced at one of the objects back and forth, three times within $3 \mathrm{sec}$. The distance from the experimenter's head to the object was approximately $20 \mathrm{~cm}$. Furthermore, irrespective of the subject's response no food reward was presented: this condition was considered as the test for understanding of the social cues. 

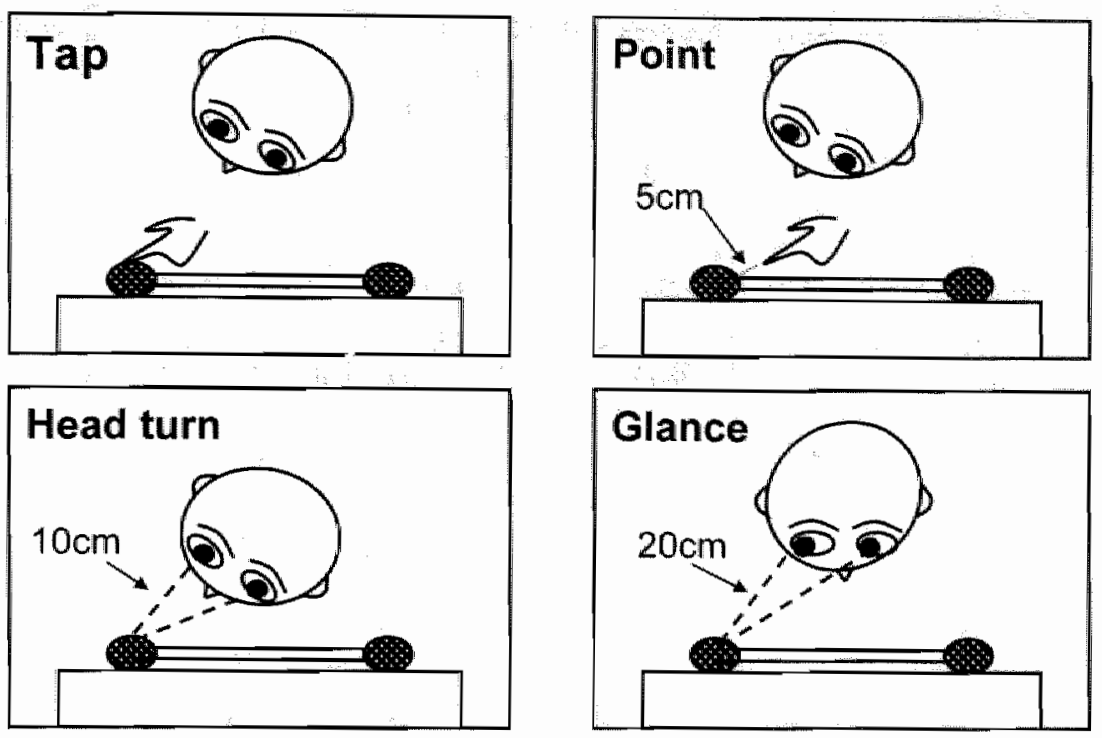

Figure 3 The four types of cue conditions in Experiment 1 .

The subject also received three kinds of control (non-cued) trials, corresponding to each of the four types of social cues described above:

Control-1: The experimenter formed the hands a fist at the midline between the 2 objects ( 4 trials). This was the control condition for the tapping and pointing conditions.

Control-2: The experimenter jiggled the head from side to side at the midline between the objects ( 4 trials). This was the control condition for gazing with head orientation.

Control-3: The experimenter looked at the center point and blinked repeatedly ( 4 trials). This was the control condition for glancing.

For these 12 control trials per session, food reward was presented as in the Tap, Point, and Head turn conditions. Food reward was given through either the left or right hole according to a predetermined order irrespective of the subject's response. 
Table 1 shows the design for Experiment 1 . The experimental training consisted of 2 phases.

Table I Number of trials for each cue condition per session and for each phase in Experiment 1

\begin{tabular}{|c|c|c|c|c|}
\hline \multirow[t]{2}{*}{ Cue } & \multicolumn{3}{|l|}{$\begin{array}{l}\text { Phase } 1 \\
\text { Age }\end{array}$} & \multirow{2}{*}{295 days- } \\
\hline & 211 days- & 238 days- & 281 days- & \\
\hline Tap & 20 & 20 & 20 & 10 \\
\hline Point & & 20 & 20 & 10 \\
\hline Head turn & & & 20 & 20 \\
\hline Giance & & & & $11(5-23)^{a}$ \\
\hline Control & & & & 12 \\
\hline
\end{tabular}

In the first phase (age $6.5-9.5$ months), the subject was initially trained with the Tap cue, followed by the successive introduction of the Point and Head turn cues. The Point cue was introduced in the 5th session, and the Head turn cue was introduced in the 10 th session. The number of trials per session during Phase 1 is shown in Table 1. In the second phase (age 3.5-13.2 months), the Glance cue and control trials were introduced. In phase 2 , each session was comprised of approximately 60 trials including baseline (Tap, Point, and Head turn cues) trials. The Glance cues were presented on an average of 11 trials in a session (range 5 23 trials), depending on the subject's motivation. One session was conducted each week. In all conditions, the position of the target object (left or right) and the order of the conditions were randomized using Gellermann's random sequences (Gellermann, 1933). The target appeared equally often at the left and right sides. The acquisition criterion for each cued condition was $80 \%$ or more "follow"-responses (see Data analysis) for two consecutive sessions.

\section{DATA ANALYSIS}

The subject's responses were categorized into five types: (1) subject looks at the target object during cue presentation, (2) subject looks at the target object but only after the arrival of a reward, (3) subject looks at the experimenter's face, (4) subject does not look anywhere relevant, and (5) subject looks at the object at the opposite side to the target object during cue presentation. The first type of response was defined as "follow", and the latter four as "not follow". The experimenter categorized the subject's responses into these five types on the basis of video recordings. Two additional observers also judged for a sample of 4 
sessions, the subject's response on the basis of video recordings to assess inter-observer reliability. Observers were not informed which cues were presented. They judged whether the subject looked left or right instead of at the target or distracter for categories (1), (2), and (5). Inter-observer reliability was computed by means of a Cohen's kappa: kappa $=0.89$.

All the present data stem from a single subject. In a strictly theoretical sense, it is inappropriate to use parametric and nonparametric tests for these non-independent data. However, the subject's responses in the Glance conditions were not differentially reinforced, so that one can assume that none of the trials was severely influenced by the previous trials' outcomes within a session. Thus, we used Fisher's exact probability tests and binomial tests for these data to determine whether gaze following occurred reliably using the number of "follow" and "not follow" responses in the trials for each session. The theoretical chance level for the binomial tests was set at $50 \%$ because we categorized the subject"s responses into the two categories ("follow" and "not follow"). Furthermore, the performance for the Glance condition was compared with that for the control condition (indicating "actual" chance performances) by using Fisher's exact probability tests. 


\section{RESULTS}

Figure 4 shows the percentages of trials in which the subject made "follow"-responses in each condition as a function of sessions and the subject's age.

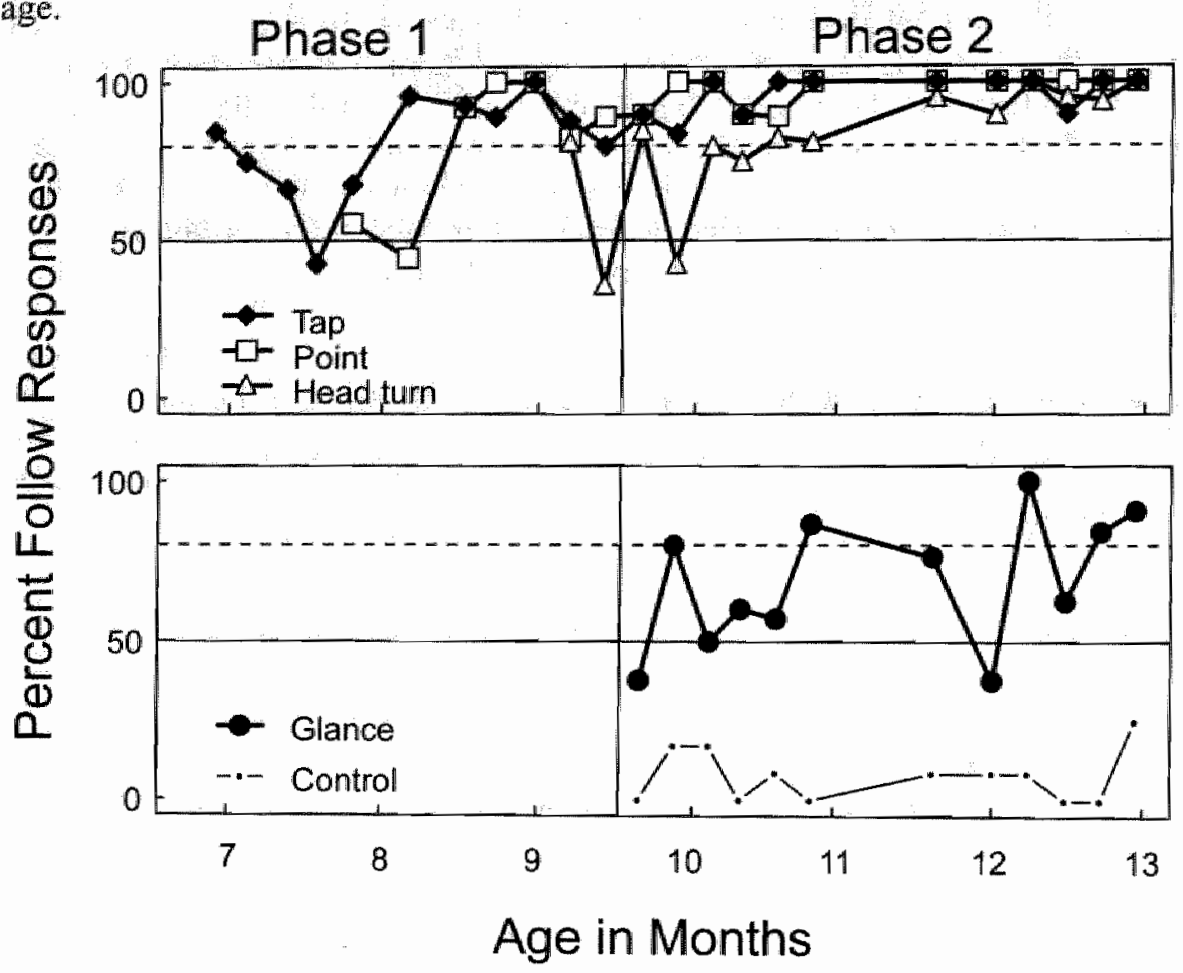

Figure 4 Percentage of gaze following as a function of the subject's age in months.

In the Tap condition, the subject scored $85 \%$ in the first session, and performance reached the criterion in the 7 th session. In the Point condition, performance was initially $55.5 \%$, and reached criterion in four sessions. When the Head turn condition was introduced, the subject's performance fluctuated during early sessions, and become stable at approximately $80 \%$. It took 8 sessions to reach the criterion.

In Phase 2, the subject's responses to these social cues were consistently accurate. Mean percentages of follow responses for the last 6 sessions were $98.3 \%$ for the Tap, $100 \%$ for the Point, and $95.6 \%$ for the Head turn, respectively.

In control trials, the subject showed considerably fewer orienting responses. On average, he responded to the target object on $7.6 \%$ of trials, and to the opposite side to the predetermined location on $2.8 \%$ of trials. The results of each of control condition are shown in Table 2. 
Table 2 The results of control trials in Experiment 1.

\begin{tabular}{llll}
\hline & $\begin{array}{l}\text { Look at the } \\
\text { target }(\%)\end{array}$ & $\begin{array}{l}\text { Look at the } \\
\text { opposite object } \\
(\%)\end{array}$ & Other (\%) \\
\hline Control 1 & 8.3 & 2.1 & 89.6 \\
Control 2 & 10.4 & 2.1 & 87.5 \\
Control 3 & 4.2 & 4.2 & 91.7 \\
\hline Average & 7.6 & 2.8 & 89.6 \\
\hline
\end{tabular}

In the Glance condition, in which the non-reinforcement test was applied, the subject showed "chance" performance during the early sessions (57\% averaged for the first 5 sessions). From the 6th session (before 11 months of age), the subject's performance was gradually improved. Spearman's rank correlation between the sessions and performances $(\mathrm{N}=12)$ was $\mathrm{r}_{\mathrm{s}}=.558$, and this value was significantly different from noncorrelation, $\mathrm{r}_{\mathrm{s}}=0[p=.0313$, using a randomization test (Edgington, 1987) on the basis of 100000 random permutations].

Binomial tests revealed significant following to the Glance cue $(p \mathrm{~s}<.05)$ in the 6th, 7th, 9th, 11th, and 12th sessions (from under 11 months to 13 months of age). When comparing performance in control trials (the number of follow responses) using Fisher's exact probability tests, the subject showed significantly more "follow"-responses in the glance condition than in the control conditions in 10 out of 12 sessions ( $p s<.05$ ) except the 3 rd and 8 th sessions. His performance reached criterion in the 12th session (13 months of age).

Note that in some sessions, the subject's performance was less accurate than in other sessions. For example, the subject was only slightly motivated by food in the 4th session in the Tap condition at the age of 231 days and showed a drop in performance. In contrast, in the 8th session in the Glance condition at the age of 365 days, the subject was very active and walked around insicle the booth. But, the decrease of accuracy was limited to the Glance condition in this session: he showed accurate performance when the well-trained cue was presented.

\section{DISCUSSION}

Experiment 1 clearly demonstrated that a chimpanzee infant less than 1 year old can reliably follow gaze cues by the human experimenter to shift his attention to a target object even when only the eye movements were given to the subject as social cues.

One of the procedural problems in such a type of gaze-following tasks, 
however, is the difficulty in dissociating social cues and local-enhancement cues (Itakura, Agnetta, Hare, Tomasello, 1999). Local enhancement is defined as the shift of attention to the objects (or locations) that the other individual manipulated (Heyes, 1993). Furthermore, nonsocial peripheral cues presented near the objects also capture the attention of both human infants and adults (Itakura, 2001; Posner, 1980; Matsuzawa \& Shimojo, 1997). It might be possible to interpret the present results on the basis of local enhancement or nonsocial peripheral cues account. That is, the subject shifted his attention simply because the peripheral cues near the target captured his attention not by following the "social" cues made by the human experimenter. This may be true especially for the Tap, Point, and Head turn conditions. Both in the Point and Head turn conditions, the distances between cues and target objects were shorter than in the Glance condition: the approximately $5 \mathrm{~cm}$ in the Point and Head turn conditions (see Figures 2 and 3 ).

To rule out the local enhancement or nonsocial peripheral cues accounts, we conducted a further experiment.

\section{EXPERIMENT 2}

\section{METHODS}

\section{SUBJECT}

Infant chimpanzee Ayumu served again as subject in Experiment 2. Ayumu was 17 months of age at the beginning of Experiment 2.

\section{APPARATUS AND STIMULI}

The apparatus and the stimuli were the same as in Experiment 1 .

\section{PROCEDURE}

After Experiment 1, follow-up training was continued from 14 months to 17 months of age. Each week one session was conducted. The subject's responses to the previous social cues were consistently accurate. The mean percentages for the "follow"-responses were $100 \%$ for the Tap, $99.2 \%$ for the Point, $96.1 \%$ for the Head turn, and $81.6 \%$ for the Glance (non-reinforced) conditions, respectively.

After follow-up training, Experiment 2 was initiated. The experimental procedure was the same as in Experiment 1. But we did not present the Tap and Glance cues in Experiment 2. In addition to the Point and Head turn cues, we used two new types of cues as follows (Figure 5).

Incongrnent point: The experimenter gazed at and pointed to the target object with an index finger from the side of the other object (distractor). The distance between the knuckle and the distractor object was approximately $1 \mathrm{~cm}$, and that between the finger and the target object was approximately $20 \mathrm{~cm}$. 
Incongruent head tum: The experimenter oriented head and eyes toward the target object from the side of the distractor object. The distances between the head and the target and distractor object were approximately $20 \mathrm{~cm}$ and $3 \mathrm{~cm}$, respectively.

These incongruent cues indicated the different objects regarding to the social and local-enhancement properties. If the subject mainly used the local-enhancement property, he would select the distractor object. In contrast, if he attended to the social property of these cues, he would orient to the target object.
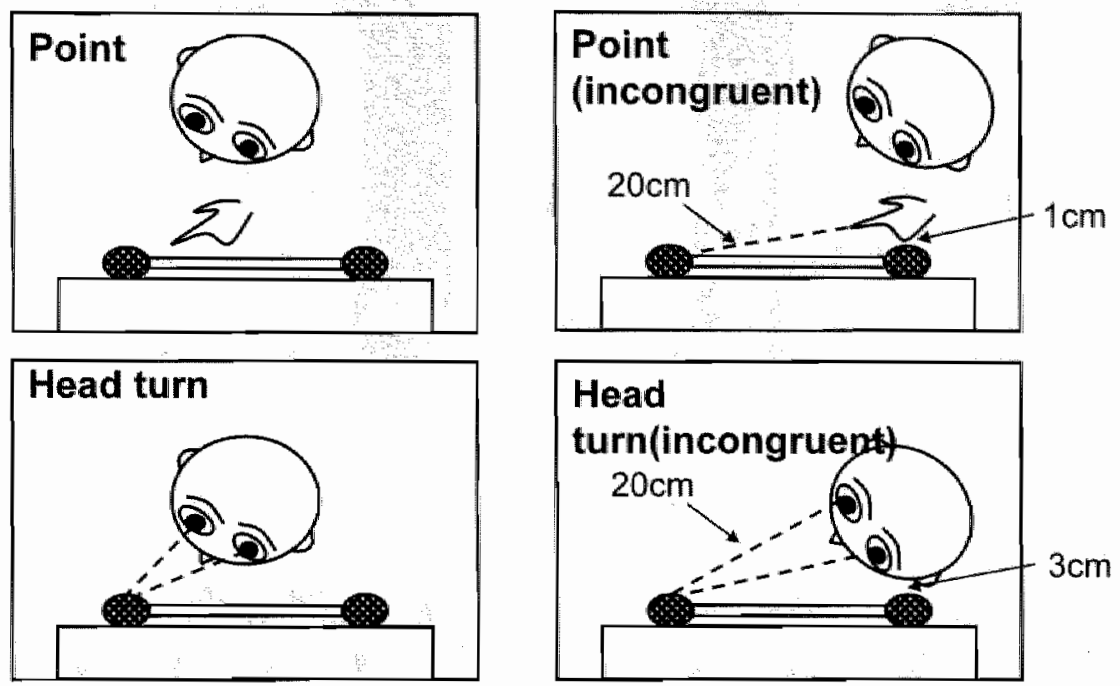

Figure 5 The four types of cue conditions in Experiment 2.

In both incongruent cueing conditions, no food reward was presented irrespective of the subject's response, so that these conditions were considered as a test for the understanding of the social cues.

Each session consisted of 40 trials including 14 Point, 14 Head turn trials, and 6 Incongruent Point and 6 Incongruent head turn trials. One session was conducted each week and two sessions were given to the subject.

\section{DATA ANALYSIS}

Data analysis was conducted in the same manner as in Experiment 1. Two additional observers (not informed about the cues) also judged the subject's response on the basis of the video recordings to assess inter-observer reliability, calculated for a sample of 1 session. Inter-observer reliability was 0.90 (Cohen's kappa). 


\section{RESULTS AND DISCUSSION}

Figure 6 shows the percentages follow responses for each condition averaged across two test sessions.

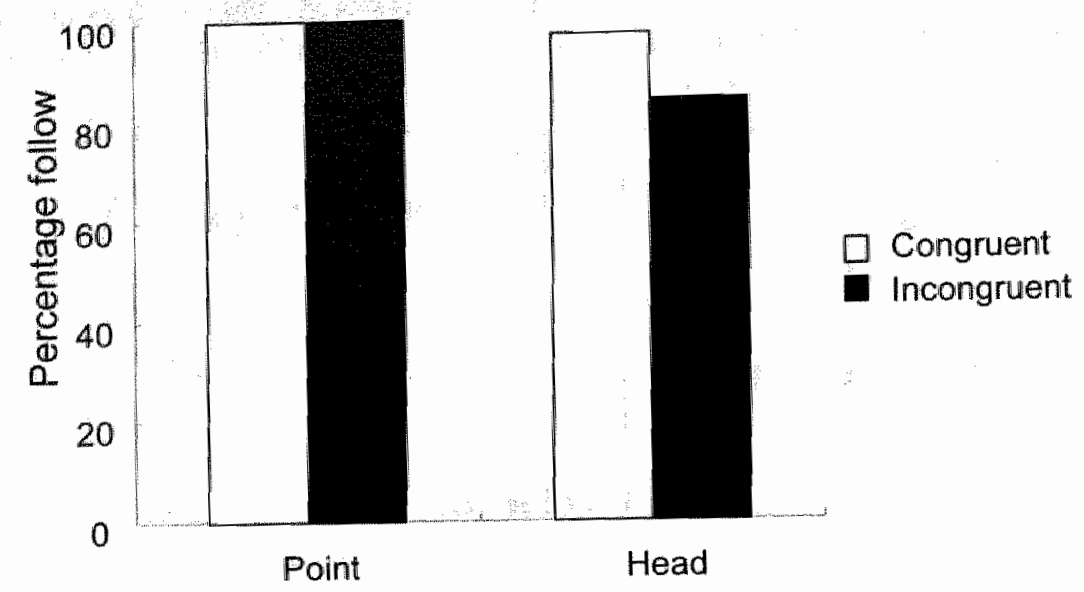

Figure 6 Percentage of "follow"-responses for each condition averaged across sessions in Experiment 2.

In both the normal Point and Head turn conditions, the subject showed highly accurate performances, $100 \%$ for the Point, and $96.9 \%$ for the Head turn respectively. Furthermore, Ayumu looked significantly more often at the socially-cued object (target) in both the incongruent conditions: $100 \%$ for the Incongruent point condition ( 12 (follow) $/ 12$ (total), $p<.01$, binomial test) and $83.3 \%$ for the Incongruent head turn condition $(10 / 12, p<.05)$.

These results clearly show that the subject's performance was controlled by the "social" properties (orientation of the finger tip or head) of the experimenter-given cues but not by the nonsocial, local-enhancing peripheral properties.

\section{GENERAL DISCUSSION}

The results of the two experiments clearly demonstrate that a chimpanzee infant less than 1 year old can reliably follow the gaze cues by a human experimenter to shift his attention to a target object. This behavior was not controlled by the nonsocial peripheral property (or local enhancement) of the experimenter-given cues. Unfortunately, we only tested a single chimpanzee infant in this study. Thus, tests with more subjects are needed to verify the generality of the present results. Nevertheless, the present results have many implications for comparative research of gaze following. 
It has previously been reported that infant chimpanzees less than $3-4$ years old do not use Head turn cues (Tomasello et al., 2001). Contrary to this result, our subject reliably used 'head turn' as a cue at 11 months and 'glance' at 13 months of age. One possibie reason for this inconsistency might be differences in the experimental settings. In Tomasello et al.'s study, the experimenter looked up to the sky or the ceiling, while in the present study, the experimenter looked at the toy as a target object in the subject's visual field. A more important point is that these procedures focus on different aspects of joint visual attention. As mentioned in the introduction, Butterworth and Jarrett (1991) reported three successively emerging mechanisms of joint visual attention in human infants from 6 to 18 months. In the present study, we used a specific object within the subject's visual freld as a target. This procedure may investigate the "ecological" or "geometric mechanism" of joint visuall attention of their terminology. Tomasello et al.'s study, on the other hand, used no specific objects, but subjects were required to move their heads or bodies. This procedure may require the "representational mechanism". Tomasello, Hare, and Agnetta (1999) reported that chimpanzees follow the gaze direction of other individuals to specific locations geometrically, in much the same way as human infants do. Our experiment used only the two specific locations in the subject's visual field. This procedure might be insufficient for distinguishing between the ecological and geometric mechanisms (see Butterworth and Jarrett, 1991). To address problems concerning the underlying mechanisms of gaze following in chimpanzee infants, we need further experimental manipulations, for example, a greater number of specific locations for the target.

In the present experiment, the infant followed the glance cues without explicit differential reinforcement training by 13 months of age. Povinelli and Eddy (1996) reported that 5-6 year old chimpanzees responded appropriately both to head turns and eye movement alone. Itakura and Tanaka (1998) also reported that adult chimpanzees can use eye movement as a cue in object-choice tasks. However, with the exception of the present study, there has been no evidence that infant chimpanzees can use eye movements alone as a cue. Human infants at 9 months of age are unable to shift attention by glance cues without head turning. At 12 and 14 months of age, half of the subjects can shift their attentions using glance cues (Butterworth \& Jarret, 1991; Lempers, 1979; but see also Corkum \& Moore, 1995). These chronological ages apparently correspond to the chimpanzee infant in the present study. However, it is well known that the speed of body growth and perceptual development in chimpanzees is approximately twice as faster than that of humans. We need further studies both in humans and chimpanzees to draw clear conclusions conceming the onset of gaze-following abilities.

It is necessary to verify both geometric and representational mechanisms in young chimpanzees. From which age on can young chimpanzees look back to the target? It is necessary to conduct a more detailed examination of the concept of gaze following and joint visual attention. Such studies will provide a clearer idea of visual communication including joint visual attention and the 
understanding of social-cognitive abilities in nonhuman primates.

\section{ACKNOWLEDGEMENTS}

This research was financially supported by the Cooperative Research Program of the Primate Research Institute, Kyoto University to Sanae Okamoto and a Grant-in-Aid for Scientific Research from the Ministry of Education, Culture, Sports, Science and Technology, Japan (\$12002009) to Tetsuro Matsuzawa.

We thank Drs. K. Mochizuki and T. Mori for their advice on data analyses. We wish to express our thanks for the critical reading of the manuscript to Dr. J. Anderson and Dr. M. A. Huffman. Thanks are also due to the members of the PRI for their support for this research.

\section{REFERENCES}

Anderson JR, Sallaberry P, Barbier $H$ (1995) Use of experimenter-given cues during object-choice tasks by capuchin monkeys. Anim Behan 49:201-208

Anderson JR, Mitchell RW (1999) Macaques but not lemurs co-orient visually with humans. Folia Primatol 70:17-22

Butterworth $G$, Cochran $\mathbb{E}(1980)$ Towards a mechanism of joint vistal attention in human infancy. Int J Behav Dev 3:253-272

Butterworth G, Jarrett NLM (1991) What minds have in common is space: Spatial mechanism serving joint visual attention in infancy. Brit J Dev Psychol 9:55-72

Call J, Hare BA, Tomasello M (1998) Chimpanzee gaze following in an object-choice task. Anim Cogn I:89-99

Corkum V, Moore C (1995) Development of Joint Visual Attention in Infants. In C. Moore \& P.J. Dunham (eds.), Joint attention: Its origins and role in development (pp.61-83). Hillsdale, NJ: Erlbaum.

Edgington, ES (1987) Randomization lest Qnd. Ed.). NY: Dekker.

Emery NJ, Lorincz EN, Perrett DI, Oram MW, Baker Cl (1997) Gaze following and joint attention in thesus monkeys (Macaca mulatia). I Comp Psychol I/1:286-293

Fenari PF, Kohter E. Gallese V (2000) The ability to follow eye gaze and its emergence during developnent in mactque monkeys. PNAS 97:13997-14002

Gellermann LW (1933) Chance orders of alternating stimuli in visual discrimination experiments. $y$ Gener Psychol 22:207-208

Heyes CM (1993) Imitation, culture and cognition. Anim Behaw 46:999-1010

Holden C (2001) Like nother, like son. Science 292:205

ltakum $S$ (1996) An exploratory study of gaze-monitoring in nonhuman primates. Jph Psychol Res $38: 174-180$

Itakura S, Agnetta B, Hare B, Tomasello M (1999) Chimpanzee use of human and conspecific social cues to locate hidden food. Dev Sci $2: 448-456$.

Itakura S, Anderson JR (1996) Learning to use experimenter-given cues during an object-choice task by a capuchin monkey. Curx Psychol Cogn 15:103-112

Itakura S, Tanaka M (1998) Use of experimenter-given cues during abject-choice tasks by chimpanzees (Pan rroglodyles), an orangutan (Pongo pygmaeus) and human infants (Homo sapiens). J Comp Psychol 112:119-126 
Kawai N, Matsuzawa T (2000) Numerical memory span in a chimpanzee. Narure 403:39-40

Lempers JD (1979) Young children's production and comprehension of nonverbal deictic behatiors. $J$ Genet Psychol 135:93-102

Matsuzawa M, Shimojo $\$(1997)$ Infants fast saccades in the gap paradigm and development of visual attention. Infant Behov Dev 20:449-455.

Matsuzawa T (2001a) The Baby and Ai. Kodansha, Tokyo Japan (Iapanese text)

Matsuzawa T (2001b) Primate origins of human cognition and behovior. Springer, Tokyo

Myowa-Yamakoshi M, Tomonaga M (2001) Perceiving eye gaze in an infant gibbon (Hylobates agilis). Psychologia 44:24-30

Peignot P, Anderson JR (1.999) Use of experimenter-given manual and facial cues by gorillas (Gorillat gorilla) in an object-choice task. J Comp Psychol 113:253-260

Posner M I (1980) Orienting of attention. Q J Exp Psychol 32:3-25.

Povinelli DJ, Eddy TJ (1996) Chimpanzees: Joint visual attention. PSychol Sci 7:129-135

Povinelli DJ, Eddy TJ (1997) Specificity of gaze-following in young chimpanzees. Brit I Dev Psychol 15:213-222

Primate Research Institute, Kyoto University (1986) Guide for the care and use of laboratory animals. Kyoto, Japan

Scaife M, Bruner JS (1975) The capacity for joint visual attention in the infant. Narure 253:265-266

Tomasello M, Call J, Hare B (1998) Five primate species follow the visual gaze of conspecifics. Anim Behaw 55:1063-1069

Tomasello M, Hare B, Fogleman TT (2001) The ontogeny of gaze following in chimpanzees, Pan troglodytes, and rhesus macaques, Macaca mulatta. Anim Behaw 61:335-3443

Tomasello M, Hare B, Agnetta B (1999) Chimpanzees, Pan troglodyres, follow gaze direction geometrically. Anim Behav 58:569-777

Tomonaga M (1999) Attending to the others' attention in macaques: Joint attention or not? Prim Ress 15:425 (Japanese text)

Tomonaga M, Myowa-Yamakoshi M, Terazawa N (2000) Gaze recognition in nonhuman primates. In the Anmual Research Report of the Grant-n-Aid from the Ministry of Education. Culture, Sports and Science "Development of Mind", pp.28-33. Tokyo, Japan (Japanese text)

Vick SJ, Anderson JR (2000) Learning and limits of use of eye gaze by capuchin monkeys (Cebus apella) in an object-choice task. $J_{\text {Comp }} P_{\text {sychol }} 114: 200-207$ 


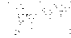

$\because$ 


\title{
CHAPTER 3
}

\author{
LOOKING BACK: \\ THE "REPRESENTATIONAL \\ MECHANISM" \\ OF JOINT ATTENTION \\ IN AN INFANT CHIMPANZEE \\ (PAN TROGLODYTES)*
}

*Published as:

Okamoto, S., Tanaka, M., \& Tomonaga, M. (2004)

Japanese Psychological Research, 46, 236-245. 


\section{ABSTRACT}

An infant chimpanzee"s joint visual attention to objects behind him was investigated. A recent study has shown that a 13-months-old infant chimpanzee can follow human social cues including glancing (Okamoto et al., 2002). In humans, 12-month-olds do not follow gaze to objects behind them but 18-month-olds do (Butterworth \& Jarrett, 1991). In the present study, from 13 months old, the infant chimpanzee had been tested to look at one of two identical objects, which an experimenter indicated by pointing or head turning. The objects were set in front of or behind the subject. In our series of experiments, we used moving or stationary objects as targets. Moreover, the experimenter manipulated a computer at the onset of each block of trials. The results show that by the age of 20 months, the infant reliably followed the experimenter's cues and looked back to the target behind him. Moving targets elicited more responses than stationary targets, and the subject showed more follow responses after having seen the experimenter manipulating the computer.

Key words: joint attention, "representational mechanism", looking back, social cues, chimpanzee infant

\section{INTRODUCTION}

By the end of their first year, human infants are sensitive to information specifying where others are looking. Scaife and Bruner (1975) demonstrated that infants as young as 2 months old tend to follow an adult's gaze. The ability to follow the gaze of other individuals is a critical component of joint visual attention, defined as looking toward the object of others' attention. Joint attention is considered as an early social cognitive ability leading to the later development of the ability to infer others" mental states (cf. Baron-Cohen, 1995; Tomasello, 1995).

Butterworth and his colleagues (Butterworth and Cochran, 1980; Butterworth and Jarrett, 1991; Butterworth, 1991) propose a naturalistic approach of joint visual attention with three successive mechanisms that develop in human infants between the ages of 6 to 18 months. At 6 months, infants progress gradually from responding to the head movements of others to orienting in the same general direction within their visual field (ecological mechanism). At this age, however, infants terminate their search at the first salient object in their scan path. By 12 months, infants are able to localize the particular object at which the other is looking (geometric mechamism). They also found that infants establish joint attention to objects within their visual field before they do so for objects outside their visual field. That is, infants younger than 18 months cannot yet represent their whole environment, some region of which might be visible to another person. By 18 months, infants can follow someone else"s gaze into space 
that is outside their own initial visual field (representational mechanism). On the other hand, Corkum and Moore, who advocate an empirical and parsimonious approach, assumed that when infants follow the adults' gaze, they often see interesting objects and events, and hence learn to use the gaze direction of others as a cue to where such events might be located (Corkum \& Moore, 1995, 1998; Moore, 1999). That is, social learning drives joint attention, though learning is constrained by certain causal and social sensitivities.

This ability is found not only in humans but also in some non-human animals, especially in primates. Following the gaze direction of conspecifics is an important ability for social primates because it allows individuals to take advantage of the visual experience of group mates that spot interesting or important objects and events, such as food, predators, or significant social interactions. A variety of primate species visually track the gaze direction of conspecifics to external objects (chimpanzees, mangabeys, and macaques; Emery, Lorincz, Perrett, Oram, \& Baker, 1997; Tomasello, Call, \& Hare, 1998; Tomonaga, 1999). Moreover, chimpanzees also follow the gaze direction of humans. They can do this on the basis of eye direction alone, independent of head direction (Iltakura \& Tanaka, 1998; Povinelli, \& Eddy, 1996), even when the target is located above and/or behind them (Call, Hare, \& Tomasello, 1998; Itakura, 1996; Povinelli, \& Eddy, 1997). In a previous study with an infant chimpanzee, Okamoto et al. (2002a) found that the subject showed reliable following responses to the object that was indicated by various cues, including glancing alone by the age of 13 months. In this previous study, however, since the target objects were within the subject's visual field, the ability to follow cues to a target outside the subject's view was not tested. Tomasello, Hare, \& Fogleman (2001a) reported that chimpanzees less than 3-4 years old do not look outside their own visual field when using the experimenter's head turn cue. In their study, however, the target objects were not presented outside the subject's visual field.

Since joint attention has an important role for social animals" development, it is also important to understand how the actions of others elicit infants' joint attention. Along the lines of Corkum and Moore's empirical and parsimonious account, in another study with human subjects, pointing cues elicited more episodes of joint attention than looking alone, and distinctive and complex targets elicited more episodes of joint attention than identical targets (Deák, Flom, \& Pick, 2000). The authors also found that infants looked more at front than at back targets, but there was also an effect of magnitude of head turn. They also suggested that human infants' joint attention to targets behind them is affected by the distinctiveness and complexity (i.e., interesting) of the targets. Thus, environmental factors also affect the infant's joint attention.

The present longitudinal study was conducted to clarify the ability of an infant chimpanzee to follow the experimenter-given cues to targets outside his visual field, the representational mechanism in Butterworth's terminology. Moreover, we manipulated two factors to investigate what affects the chimpanzee"s joint attention to objects outside his visual field: distinctiveness and memory of targets. 


\section{METHODS}

\section{SUBJECT}

One male chimpanzee infant, Ayumu, served as the subject from 13 months of age (Figure 1). He had been reared with his mother since birth at the Primate Research Institute, Kyoto University. Both live in a community of 14 chimpanzees in an enriched outdoor compound (Ochiai \& Matsuzawa, 1998). He participated in a variety of tests investigating the development of cognitive abilities (Matsuzawa, 2001 a, b; Tomonaga, Tanaka, \& Matsuzawa, 2003; Hirata \& Celli, 2003; Sousa, Okamoto, \& Matsuzawa, 2003). He maintained his free-feeding body weight throughout the present study. Care and use of the chimpanzee adhered to the Guide for the care and use of laboratory primates of the Primate Research Institute (1986).
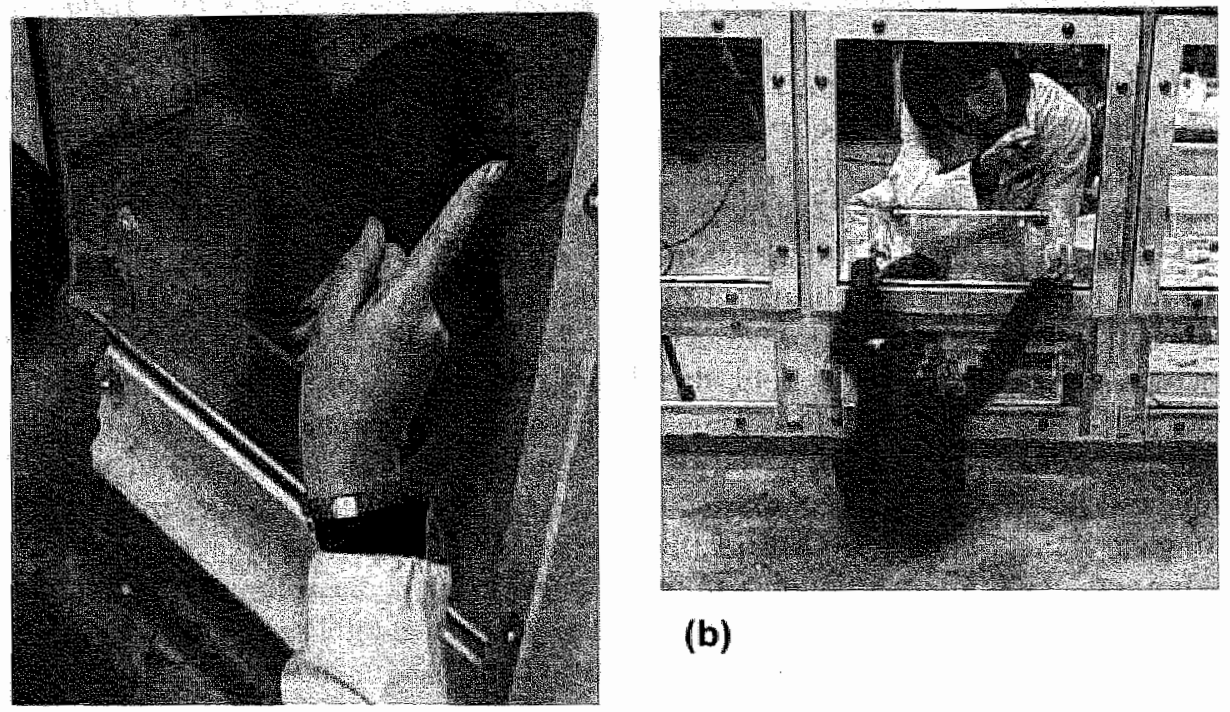

(b)

(a)

Figure 1 (a) The sibject Ayumu, performing the experimental task. He looks at the target object which the experimenter points to (firom camera 1). (b) The experimental situation from camera 2.

\section{APPARATUS}

The experiment was conducted in the chimpanzee experimental booth $(2 \mathrm{~m} \times 2 \mathrm{mx}$ $2.4 \mathrm{~m})$ at the Primate Research Institute. The experimental apparatus consisted of a feeder and two types of objects that served as targets (Figure 2). The feed cylinder was made of one transparent acrylic board and two cylinders (length; $10 \mathrm{~cm}$ ). It was placed at the middle of a panel in the experimental booth. Two cylindrical holes $(4 \mathrm{~cm})$ through which food rewards were given were $50 \mathrm{~cm}$ above the floor. 
In the experiment, we used two types of objects as targets (Figure la, b).

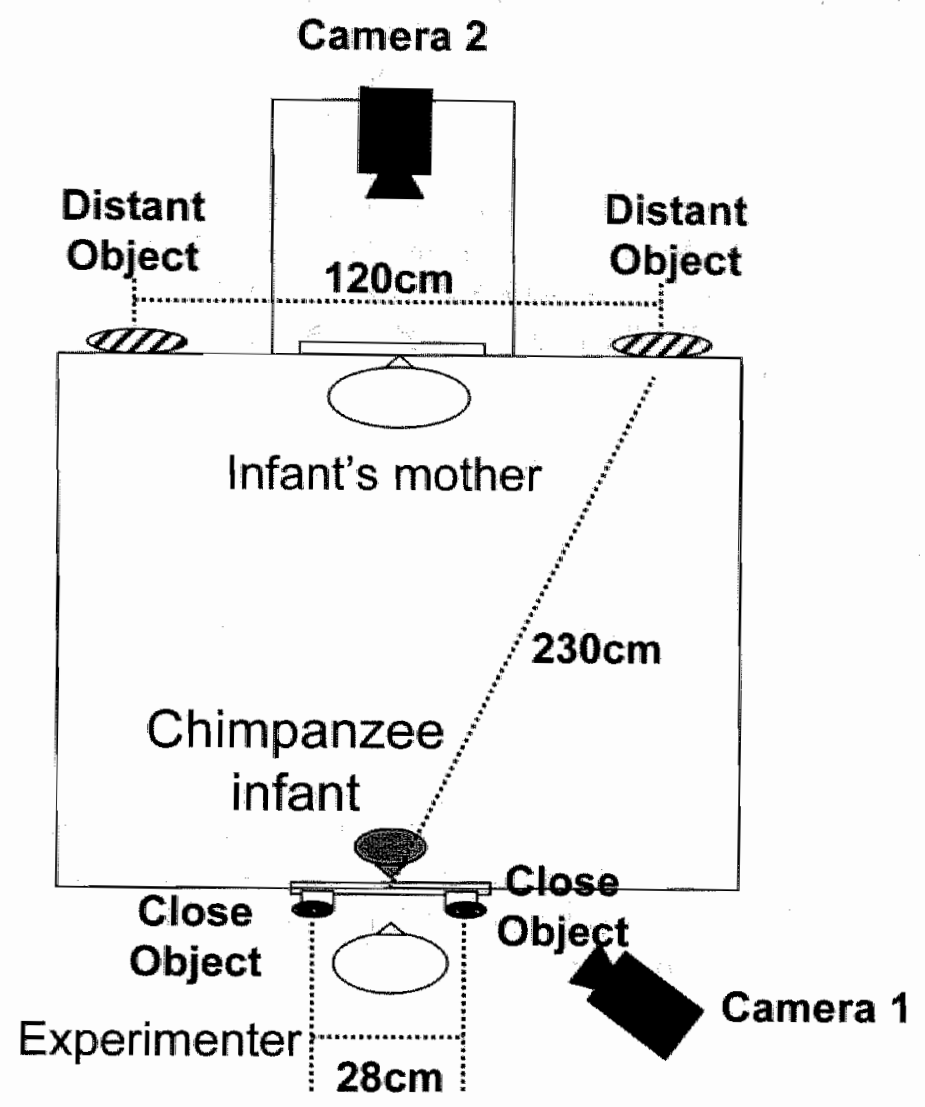

Figure 2 Experimental setting (aerial view).

Close Object: Two identical stationary toys (mean size $2 \mathrm{~cm}$ ) were presented between the subject and the experimenter. Each of them was attached to one end of an acrylic bar (length: $28 \mathrm{~cm}$ ). Forty different toys (such as little bears, little colored ball, etc.) were presented across the trials to keep Ayumu interested.

Distant Object: Two identical stationary and large toys (mean size $25 \mathrm{~cm} \times 25 \mathrm{~cm}$ : such as balloon toys, cartoon mask, etc.) or two identical screens $(16 \mathrm{~cm} \times 21 \mathrm{~cm})$ of mobile computers were presented behind the subject. In the beginning of the experiment, we presented a stationary blue screen, and then, we presented one of 32 moving color images (geometric objects, animals, animated cartoons, etc.), in the moving targets condition or just continued to show the stationary blue screen in the stationary targets condition.

Prior to the experiment, the subject had been taken into the experimental booth with his mother since he was 11 days old (e.g., Okamoto et al., 
2002a). Thus, at the beginning of the experiment he was already very familiar with both the experimental booth and the experimenter. The behavior of the subject was video-taped (Figure 2a, b).

\section{PROCEDURE}

Gaze following fask The general procedure was almost the same as in the previous study (see Okamoto et al., 2002a). At first, the subject came to the experimental booth with his mother. After his mother began working on another task [one of the visual discrimination tasks that had her facing a computer system (Kawai and Matsuzawa, 2000) at another side of the booth], the experiment for the subject began. At the onset of each trial, the experimenter sat on the floor outside the booth, $20 \mathrm{~cm}$ behind the objects in the "Close Object" condition (see Figure 1). After the subject approached the front of the experimenter, the experimenter looked at the center of the acrylic board with two food cylinders with her hands resting on her knees. As soon as the subject looked at the experimenter's face, the experimenter presented a cue to the target object for three seconds, followed by the presentation of the food reward (a piece of fruit) through a cylinder nearest to the target object, independently of the subject's response. One session was conducted once a week.

Preliminary test Before shifting to the main experiment, the preliminary test was conducted when the subject was between 13 and 20 months old. This period was a part of another experiment (follow-up training in Okamoto et al., 2002a). This test had started to maintain the subject's motivation in the experimental setting and test his behavior to the experimenter-given cues. In this phase, we mainly used "Close Object" as target conditions like in the previous study (see the phase 2 of experiment 1 in Okamoto et al., 2002a). We used the same kinds of experimenter-given cues (see Okamoto et al., 2002a), including tapping on the object ( 10 trials), pointing to the object ( 10 trials, see Main test), head turning to the object ( 20 trials, see Main test), glaneing toward the object without head movement ( 8 trials), and no social cue (12 trials). In this phase, each session comprised approximately 60 trials. Moreover, during each month we used the "Distant Object" set-up to test the emergence of looking back behavior presenting the Distant Point cue (see below) as in Phase 1 of the Main test period. The subject received 16 "Distant Point" trials in total.

Main test At 21 months old, the main test was introduced. The subject was tested to look at one of two identical objects behind him (Figure 1), which the experimenter indicated by giving social cues. In this period, four types of experimenter-given cues were used (Figure 3). The first two cues were baseline cues: Close Point, where the experimenter gazed at and pointed to the Close Object target with her tip of the index finger, and Close Head turn, where the experimenter turned her head and gazed towards the Close Object target. The other two cues were experimental cues: Distant Point, where the experimenter gazed at and pointed to the Distant Object target with the tip of her index finger, and Distant Head tum, where the experimenter turned her head and gazed 
towards the Distant Object target. These cues were presented only one time during each trial with the action performed at normal speed as in daily human interaction. (It should be mentioned that it is likely that the subject had previously seen human pointing or head turning during his daily interaction with humans). The distance between the finger or the experimenter's head and the target object was approximately $230 \mathrm{~cm}$ for Distant Point and $245 \mathrm{~cm}$ for Distant Head turn respectively. Irrespective of the subject's response to experimental cues, no food reward was presented. The subject also received the control (non-cued) trials in Phase 3 (see below). In this condition, the experimenter looked down and put down her hand after attracting the subject's attention. The food reward was given through either the left or right cylinder according to a predetermined order irrespective of the subject's response.

\section{Baseline cues}

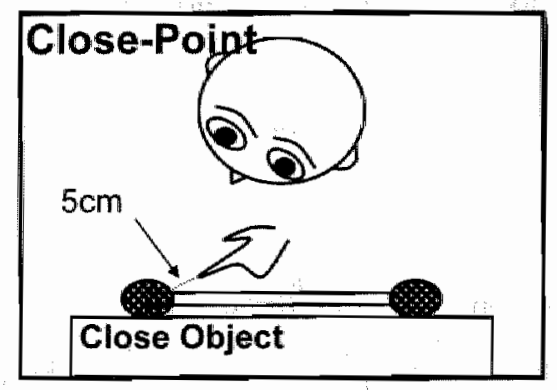

\section{Close-Head turn}

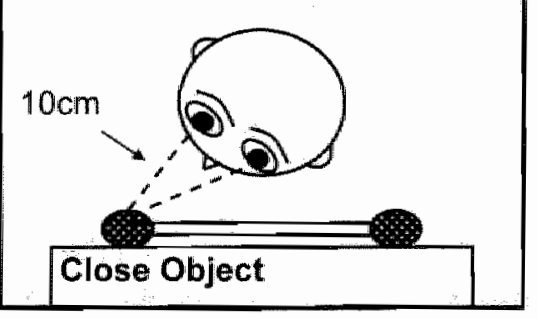

Figure 3 The conditions in the Main test.

\section{Experimental cues}

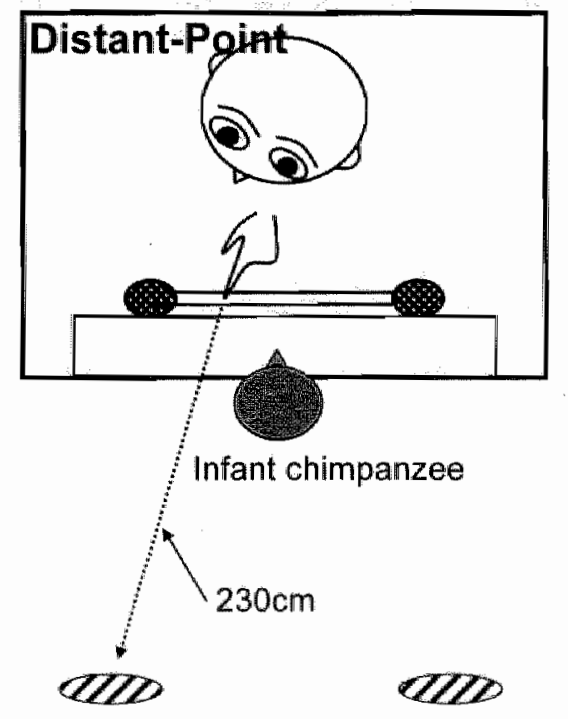

Distant Object

\section{EXPERIMENTAL DESIGN}

In the main test, two factors were manipulated: incentive and memory of targets. The main test consisted of four phases. Phase 1: Two stationary and largely identical toys (mean size $25 \mathrm{~cm}$ ) were presented as Distant Objects. Phase $2 a$ : Two identical computer screens showing moving screen savers served as Distant Objects. The screen savers were activated according to a predetermined time setting $(1,2,3,4,5$ or 6 minutes) at the same time. The order of the time settings was randomized. Approximately 20 seconds after activating the screen savers, the 
experimenter indicated one of the Distant Objects by giving one of the experimental cues. Phase $2 b$ : The computers with stationary screen savers served as targets. The computers were not activated. The experimenter indicated one of the Distant Objects by using one of the experimental cues according to the predetermined time setting like in Phase $2 \mathrm{a}$. Sessions of Phases $2 \mathrm{a}$ and $2 \mathrm{~b}$ were randomly alternated. Phase 3: Instead of the experimental cues, a control condition was used with a moving screen saver according to the predetermined time setting as in Phase 2. Phase 4: This phase is the same as phase $2 \mathrm{a}$. It was considered as the recovery condition for investigating the effect of the cues. In the latter three phases, the experimenter manipulated the computer in front of the subject at the onset of each block of trials.

Each session comprised approximately 4 blocks of trials. One block consisted of about 20 trials ( 18 baseline cues: 9 trials each, experimental cues: 2 trials each). During almost every month (at $22,23,24,25,27,28$, and 29 months of age), we administered only one probe trial to test the subject's follow responses by using the Distant Head turn cue. In all phases, the position of the target object (left or right) and the order of the conditions were randomized using Gellermann's (1933) random sequences. The target appeared equally often on the left and right sides.

\section{DATA ANALYSIS}

The subject's responses during cue presentation and after three seconds were categorized into two types for each target object. In Baseline cues using Close Object, the subject's responses were categorized into "Follow" (the subject looked at the target object) and "no Follow" (all other behaviors including looking at the target object only after receiving a reward, looking at the experimenter's face, not looking anywhere relevant, and looking at the object on the side opposite to the target object during cue presentation). In Experimental cues using Distant Object, responses were categorized into "Looking back" (the subject looked back to the Distant Object irrespective of left or right) and "no Looking back" (all other behaviors).

The main experimenter ( $\mathrm{SO}$ ) categorized the subject's responses into these two types on the basis of video recordings. Especially, "Looking back" behavior was scored only when the subject's face was visible to the observer on the video picture (from camera 2, see Figure 1). To assess inter-observer reliability, two additional observers watched the video recordings and judged the subject's response for a sample of four sessions. Observers were not informed which cues were presented. They judged whether the subject looked at the target to his left or right, or behind him. Inter-observer reliability was computed by means of a Cohen's kappa: mean kappa was 0.90 . 


\section{RESULTS}

Table 1 shows the percentage of trials in which the subject made "Follow" responses in each condition in Preliminary and Main tests. The subject's responses to the baseline social cues were consistently accurate during the present study.

Table 1 Mean percentage of "follow" responses in the Close Object (Baseline cue) trials in Preliminary and Main tests.

\begin{tabular}{llllll}
\hline & Tap & Point & Head tum & Glance & $\begin{array}{l}\text { No social } \\
\text { cue }\end{array}$ \\
\hline $\begin{array}{l}\text { Preliminary } \\
\text { test }\end{array}$ & 100 & 99.4 & 95.2 & 83.3 & 10.8 \\
Main test & - & 98.7 & 92.6 & & \\
\hline
\end{tabular}

Figure 4 shows the percentage of "looking back" responses in the Distant Point trials as a function of sessions and the subject's age. The subject did not make any "looking back" responses to the Distant Point cue during the preliminary test. By the age of 21 months (Phase 1 in Main test), however, the subject began to make "Looking back" response although his performance fluctuated. The mean percentage of Phase 1 was $42.2 \%$, significantly higher than preliminary test (Fisher's exact probability test, $p=.0009$ ).

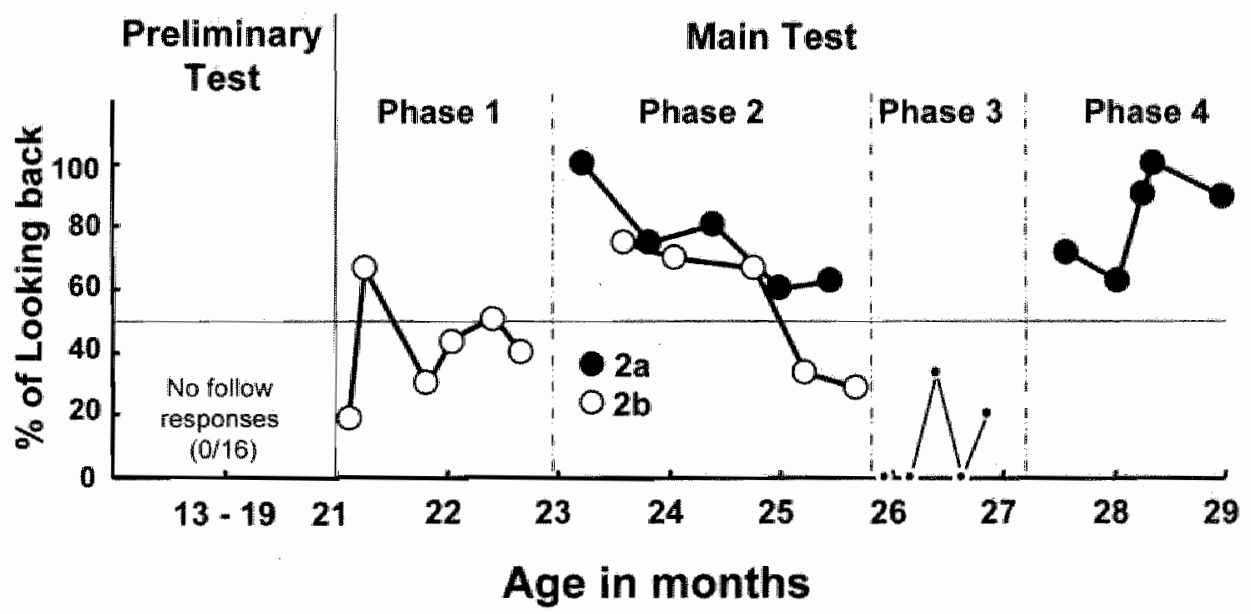

Figure 4 The percentage of "Looking back" responses in the Distant-Point condition as a function of session and the subject"s age. 
In Phase 2, the subject's looking back response to the Distant Point cue increased. These responses decreased gradually from the beginning to the ending of this phase, however, presumably because the subject's habituated to the targets gradually. In phase $2 b$ (stationary target conditions), the average response rate was as low as in Phase 1 (stationary target condition) (Phase 1; 42.2\%, Phase 2a; $73.1 \%$, Phase $2 \mathrm{~b} ; 54.5 \%$ ). There was a significant difference in the number of looking back responses when comparing the last 4 sessions of Phase 1 and the first 4 sessions of Phases 2 (Fisher's exact probability test, $p=.008$ ). More interestingly, the subject showed more looking back responses in Phase 2a (moving targets) than in Phase $2 \mathrm{~b}$ (stationary targets: Wilcoxon's signed rank test, $\mathrm{N}=5, \mathrm{Z}=2.023, p<.05$ ).

In Phase 3 (control condition), the subject showed considerably fewer looking back responses. On average, he responded to the object behind him on $11.5 \%$ of the trials. In Phase 4 (recovery condition) the subject's looking back responses increased quickly. The mean percentage of phase 4 was $83.7 \%$.

We compared the performances between each experimentall condition (Phases 1, 2a, 2b, and 4) and control condition (Phase 3) using Fisher's exact probability tests with correction for multiple comparisons using the Bonferroni method. These analyses revealed significantly more follow responses to the Distant Point cue in each of the experimental phases than in the control phase (all ps<.05).

We also gave 7 probe trials with the Distant Head turn cue (1 trial in Phase 1, 3 in Phase 2, and 3 in Phase 4), and the subject showed looking back responses in all trials (binomial test using 0.5 as chance probability, $p=.008$ ).

Although he often turned his head or body to the left side $(71.7 \%$ of total looking back responses), the side he turned his head to and the side the experimenter pointed to matched in $80.4 \%$ of total looking back responses (Fisher"s exact probability test, $p=.0001$ ). One more important result to be noted is, however, that the subject did not look at the experimenter again once he looked back behind him.

\section{DISCUSSION}

In the present study, by the age of 21 months, the infant chimpanzee reliably followed the experimenter's cues and looked back to the target behind him. Unfortunately, we only tested a single chimpanzee infant in this study. Thus, tests with more subjects are needed to verify the generality of the present results. Nevertheless, the present results have many implications for comparative research on joint attention.

Our previous study (Okamoto et al., 2002a) and the present study clearly indicate that mechanisms of joint attention also emerge successively in an infant chimpanzee as in human infants (cf. Butterworth et al., 1980; Butterworth et al., 1991). Moreover, factors like the distinctiveness of targets also influenced the 
chimpanzee's joint attention as in human infants (Deák et al, 2000). The comparison of results between Phase 1 and Phase 2 suggest that the subjects looking back behavior was facilitated by seeing the experimenter manipulating the computer. Some episodic memory of targets being manipulated may influence joint attention in the sense of increased expectancy of a subsequent event. Furthermore the attractiveness of subsequent events also affected the subject's response (moving vs. stationary targets both of which were manipulated by the experimenter; Phases $2 \mathrm{a}$ vs. 2b). In Phase 2, we introduced $2 \mathrm{a}$ (moving target) first, and then, the $2 \mathrm{a}$ and $2 \mathrm{~b}$ (stationary target) conditions aiternately. It is possible that the mean responses of $2 a$ are higher than that of $2 b$, because the more interesting condition was presented first and the conditions were not presented in a random order. However, as can been seen in Figure 4, the main tendency that the looking back response is higher in condition $2 a$ than in the adjacent condition $2 b$ is preserved. This tendency indicates that distinctive (e.g., attractive, interesting) targets elicited more looking back responses than identical ones. Moreover, we stress that the looking back behavior only occurred when the experimenter indicated the targets, even though the response rate decreased gradually. In other words, only the experimenter's gesture was used as a trigger to look back to the target behind the chimpanzee infant. Additionally, since the side that the subject looked back to often matched the side the experimenter pointed to, we can suggest that the subject's responses might represent a "representational mechanism".

Looking back responses according to the other's gaze cue is apparently evidence for a "representational mechanism" in chimpanzee infants. As noted in the Results section, however, the subject showed a lack of subsequent behavioral sequences after looking back which is observed very common in human infants. That is, the subject did not look at the experimenter again after looking back at the target. This result implies that there must be some substantial difference in "joint attention" between these two species. So that the question arises: are the present results really evidence for "Joint attention" in chimpanzee infants? Chimpanzee infants follow the other's gaze, but do not interact with him/her. Carpenter, Nagell, \& Tomasello (1998) and Tomasello (1999) described the three main types of joint attentional interaction as; check attention (9-12 months), follow attention (11-14 months), direct attention (13-15 months). According to their distinction, the chimpanzee infant followed the other's attention but did not direct the other's attention to the external object. Similarly, Emery (2000) noted that joint attention is different from shared attention. "Joint attention" is the same as "gaze following" except that there is a focus of attention (such as an object). "Shared attention", on the other hand, is a combination of mutual attention and joint attention, where the focus of individuals A's and B's attention is on the object of joint focus and each other. That is to say, "Triad relationship-based" joint attention is an important component of social cognitive skills in human infants older than one year. On the basis of Emery's definition, the present results suggest that the chimpanzee infant and human experimenter jointly attended to the object behind the infant, but did not share their attention with each other. More strictly speaking, 
the experimenter's behavior was a mere trigger for the subject to initiate appropriate reactions like searching behind him. As in previous studies, it remains unresolved whether chimpanzees attribute referential intent and visual experience to the signaler or merely follow gaze direction geometrically to specific locations (e.g., Povinelli \& Eddy, 1996; Tomasello, Hare \& Agnetta, 1999).

Is it impossible for the chimpanzee to engage in real joint (shared) attention, that is, "triad relationship-based joint attention"? In a dyad interaction, infant chimpanzees do show "mutual gaze" when interacting with their mother from early infancy (cf. Bard, Myowa-Yamakoshi, Quinn, Tomonaga, \& Matsuzawa, 2002; Okamoto et al., 2002b). Furthermore, the present results show that some factors influence joint attention to objects outside the visual field in a chimpanzee infant as in human infants (Deak et al., 2000). In the future, we should conduct more detailed comparative examinations concerning the developmental changes from dyad- to triad-based interactions involving gazing behaviors and factors affecting these interactions. Such studies will provide a clearer idea of visual communication including joint attention and the understanding of social-cognitive abilities in non-human primates.

\section{ACKNOWLEDGEMENTS}

This research was financially supported by the Cooperative Research Program of the Primate Research Institute, Kyoto University to S. Okamoto, Grants-in-Aid for Scientific Research from the Ministry of Education, Culture, Sports, Science and Technology, Japan to O. Takenaka (\#10CE2005), T. Matsuzawa (\#12002009), and M. Tomonaga (+13610086), and the Grant-in-Aid for the 21st Century COE Program (A2 to Kyoto University). We thank $O$. Takenaka for his generous support of this study, and T. Matsuzawa, K. Bard, and J. Call for their valuable comments on this study. We wish to express our thanks for the critical reading of the manuscript to J. Barth. Thanks are also due to the members of the Language and Intelligence Section for their support of the research project.

\section{REFERENCES}

Bard, K., Myowa-Yamakoshi, M., Quinn, J., Tomonaga, M., \& Matsuzawa, T. (2002). "Cultural differences in mutual gaze between mother and infant chimpanzees." Paper presented at the 19 th Congress of the International Primatological Society, Beijing, China. August 2002.

Baron-Cohen, S. (1995). The eye direction detector (EDD) and the shared attention mechanism (SAM): Two cases for evolutionary psychology. In C. Moore \& P. J., Dunluam (Eds.), Joint attention: Its origins and role in development (pp.41-59). Hillsdale, NJ: Erlbaum.

Butterworth, $G$. E. C Cochran, E. (1980). Towards a mechanism of joint visual attention in humam infancy. International Joumal of Behavioral Development, 3, 253-272.

Butterworth, G E. (1991). The ontogeny and phylogeny of joint visual attention. In A. Whiten (Ed.), Natural theories of mind (pp. 223-232). Oxford, England: Basil Blackwell.

Butterworth, G.E, \& Jarrett, N. L. M. (1991). What minds have in common is space: Spatial mechanism serving joint visual attention in infancy. British Jatomal of Developmental 
Psychology, 9, 55-72.

Call, J., Hare, B., \& Tomasello, M. (1998). Chimpanzee gaze following in an object-choico task. Animal Cognition, 1, 89-99.

Carpenter, Nagell, \& Tomasello (1998). Social cognition, joint attention, and communicative competence fram 9 to 15 months of age. Monographs of the Sociey for Research in Child Developwent 63 .

Corkum, V.\& Moore, C. (1995). Development of joint visual attention in intants. In C. Moore \& P. J. Dunham (Eds.), Join atrention: its origins and role in development (pp. 61-83). Hillsdale, NJ: Erlbaum.

Corkum, V: \& Moore, C. (1998). The origins of joint visual attention in infants. Developmentelt Psycholagy, 34. 28-38.

Deăk, G. O., Flom, R. A. \& Pick, A. D. (2000). Effects of gesture and target on 12- and 18-month-olds" joint visual attention to objects in front of or behind then. Dewelopmental Psychologi, 36, 511-523.

Emery N. J, Lorincz, E. N., Perrett, D. I., Oram, M. W. \& Baker, C. I. (1997). Gaze following and joint attention in thesus monkeys (Macaca mulatta). Journal of Comparative Psychology, 111 . 286-293.

Emery, N. J., (2000). The eyes have it: the neuroethology, function and evolution of social gaze. Neuroscience and Biobehavioral Reviews, 24, 581-604.

Gellermann, L. W. (1933). Chance orders of atternating stimuli in visual discrimination experiments. Jounal of Genetical Psychology, 42, 207-208.

Hirata, S., Celli, M. L. (2003). Role of mothers in the acquisition of tool use behavior of captive infant chimpanzees. Animal Cognition, 6, 235-244.

Itakura, S. (1996). An exploratory study of gaze-monitoring in nonhuman primates. Japanese Psychological Research, 38, 174-180.

Itakura, S., \& Tanaka, M. (1998). Use of experimenter-given cues during object-choice tasks by chimpanzees (Pan troglodyres), an orangutan (Pongo pygmaeus) and human infants (Homo sapiens). Joumal of Comparative Psychology, 112, 119-126.

Kawai N., \& Matsuzawa, T. (2000). Numerical memory span in a chimpanzee. Narure, 403, 39-40.

Matsuzawa, T. (2001 a). The Baby and Ai. Kodansha, Tokyo Japan (Japanese text).

Matsuzawa, "T. (Ed.) (2001 b). Primate origins of human cogninion and behavior. Springer: Tokyo.

Moore, C. (1999). Gaze following and the control of attention. In P. Rochat (Ed.), Early sockal cognition (pp. 241-256). Mahwah, NJ: Lawrence Erlbaum Associates, Inc.

Ochaia, T, \& Matsuzawa, T. (1998). Planting trees in an outdoor compound of chimpanzees for an enriched environment. In: Proceedings of the Third International Conference on Environmental Enrichment. Hare, V. J., Worlley, E. (eds), 355-364. The Shape of Enrichment, San Diego, CA..

Okamoto, S. Tomonaga, M., Ishii K., Kawai N., Tanaka, M. \& Matsuzawa, T. (2002a). An infant chimpanzee (Pan troglodyres) follows thuman gaze. Animal Cognition, 5, 107-114.

Okamoto, S., Kawai, N., Sousa, C., Tanaka, T., Tomonaga, M., Ishii, K., \& Matsuzawa, T. (2002b). Interaction between of mother and infant chimpanzees in the experimental setting. Primate Research, 18, 394. (Japanese abstract only)

Povinelli, D. J., \& Eddy, T. J. (1996). Chimpanzees: Joint visual attention. Psychological Science, 7. $129-135$.

Povinelli, D. J., \& Eddy, T. J. (1997). Specificity of gaze-following in young chimpanzees. British Journal of Developmental Psychologgy, 15, 213-222.

Primate Research Institute, Kyoto University (1986). Gude for the care and use of laboratory primates. Kyoto University, Kyoto, Japan.

Scaife, M. \& Bruner, J. S. (1975). The capacity for joint visual attention in the infant. Nature, 253, 
$265-266$.

Sousa, C., Okamoto, S, \&atsuzawa, T. (2003): Befiavioural development in a natching-to-sample task and token use by an infant chimpanzee reared by his mother Amimal Cogmition, 6 , 259.267 .

Tomasello, M. (1995). Joint attention as social cognition [n C Moore \& P J Dunham (Eds.), Joimt atterition: Its origins and role in development (pp. 103-130). Hillsdale, NJ: Erlbaum.

Tomasello, $\mathrm{M}_{2}, \mathrm{Cal}, \mathrm{J}$, \& Hare, B. (1998). Five primate species follow the visual gaze of conspeeifics. Aniwat Behavior, 55, 1063-1069.

Tomaselvo, M. (1999). The cultural origins of human cognition. Harvard University Press: London.

Tonissello, M." Hare, B., \& Agnetta, B. (1999). Chimpanzes (Pan troglodytes) follow gaze direction geometrically. Amimal Behavior, 58, 769-777.

Tomasello, M., Hare, B., \& Fogleman, T. (2001a). The ontogeny of gaze following in chimpanzees, $P a n$ iroglodytes, and rhesus macaques, Macaca mulatta. Animal Beharvior, 61, 335-343.

Tomasello, M. (200lb). Two hypotheses about primate cognition. In C. Heyes \& L. Huber (Eds.), The evolution of cognition (pp.165-184). The MIT Press: Massachusetts.

Tomonaga, M. (1999). Attending to the others' attention in macaques: Joint attention or not? Primate Ressearch, 15, 425. (Japanese text)

Tomonaga, M., Tanaka, M. \& Matsuzawa, T. (Eds.) (2003). Cognitive and behavioral development in chimpanzees: A comparative approach. Kyoto University Press: Kyoto. (Japanese text) 


\section{CHAPTER 4}

\section{THE ROLE OF ATTENTION IN THE FACILITATION EFFECT \\ AND \\ ANOTHER “INHIBITION OF RETURN"*}

* Submitted for publication:

Okamoto-Barth, $S, \&$ Kawai, N. (in review). 


\section{ABSTRACT}

The present study investigated how anticipation of a target's appearance affects human attention to gaze cues provided by a schematic face. Subjects in a "catch" group received a high number of 'catch' trials, where no target stimulus appeared; subjects in the control group did not receive any catch trials. As in previous studies, both groups evidenced a facilitation effect to the cued location during shorter stimulus onset asynchrony (SOA). In both groups, an analysis of tracked eye movements confirmed that subjects' eyes remained on the fixation point which ruled out the possibility that the effect was due to shifting eye movements (saccades) as opposed to a shift in covert attention. However, at longer SOAs there were significant differences between groups. The mean response time (RT) of the control group decreased as SOA increased, whereas the mean RT of the catch group displayed a $U$-shaped pattern. These results suggest that subjects in the catch group disengaged their attention during long SOAs because they expected the trial to be a catch trial. A decrease in the vigilance of subjects in the catch group might result in, a delay before attention could be re-focused ("IOR (Inhibition of Return)"-like-phenomenon). In the catch group, moreover, the delay in RT was significant in the valid condition, where the target always appeared in the cued location, rather than the invalid condition, where the target always appeared in the opposite of the cued location, at the longest SOA (1005 $\mathrm{ms}$ ). These results suggest that attention is disengaged by the subjects' strong anticipation, which inhibits a return to the previous location.

Keywords: Gaze direction; Eye movements; Facilitation effect; Inhibition of return

\section{INTRODUCTION}

Humans are particularly attuned to the focus of others' attention, perhaps because of the adaptive significance of monitoring others' attentional signals. For instance, gaze-following can help other individuals to perceive the location of important objects or events (e.g., Langton \& Bruce, 1999; Moore, 1999; Tomasello, 1999). This ability should serve the same adaptive function in other species, particularly those who form complex social groups. Not surprisingly then, the ability to follow the gaze of others is not unique to humans. For instance, chimpanzees also follow the gaze of conspecifics and humans, even when the target is located above and/or behind them (e.g., Povinelli and Eddy, 1996; 1997; Call, Hare, \& Tomasello, 1998, Okamoto, Tanaka, \& Tomonaga, 2004). Additionally, they start to follow human's eye-gaze as early as 13 months of age (Okamoto et al., 2002). The fact that this phenomenon is wide-spread in the aninal kingdom verifies its adaptive significance.

Gaze direction produces shifts in others' focus of attention, a 
phenomenon that has been investigated mainly in human adults by using the cueing paradigm (e.g., Posner, 1980). In previous studies (e.g., Driver et al., 1999; Friesen \& Kingstone, 1998; Langton \& Bruce, 1999), researchers found that subjects responded more quickly to targets appearing at a location gazed at by a centrally presented face image (i.e. valid cues) than to targets appearing at a location that are not gazed at (i.e. invalid cues). This facilitation effect occurs even though gaze direction does not predict the location in which the target stimulus will appear or when the subjects are instructed not to move their eyes during trials.

The facilitative effect of eye-gaze seems to be largely reflexive. This conclusion is supported by data demonstrating that the effect occurs in response to spatially non-predictive gaze cues at a short stimulus onset asynchrony (SOA), such as $100 \mathrm{~ms}$ (Langton \& Bruce, 1999). Other studies (e.g., Friesen \& Kingston, 1998; 2003) have reported that the facilitative effect also occurs at longer SOAs $(300,555$, and $600 \mathrm{~ms})$. The facilitation for a gazed-at target location at these intermediate and longer SOAs might result from subjects voluntarily shifting covert attention to that spatial location or moving their eyes to the gazed-at location. It is important to clarify whether the effect is due to a shift in covert attention as opposed to shifting eye movements (saccades).

These saccades could bring the subjects closer to the congruent location of the cued targets. Only a few studies have monitored subjects' eye movements by means of an eye tracking device. However, Mansfield, Farroni, \& Johnson (2003) did use an eye-tracking device and ruled out cue-driven saccades as a significant contributor to the facilitation effect. Their procedure, however, differs from previous studies (e.g., Friesen \& Kingstone, 1998) that used a standard detection task, in which the subjects were required to keep looking at the center of the screen and to press a corresponding key when they detected the target. Instead, Mansfield et al. measured eye movements as a response to a peripheral target. To our knowledge, no other study monitored subjects' eye movements during a task in which subjects were required to maintain gaze at a central fixation point until the detection of a target.

In the present study, we investigated whether subjects' gaze was consistently directed at the fixation point during a trial by means of an eye-tracking device. Moreover, of special interest was whether the subjects ' anticipation of the appearance of a target stimulus affects attention to the gaze direction cue. In a pilot study, subjects "response times (RTs) increased at longer SOAs in sessions with many catch trials (i.e. a trial without a target stimulus). This increase in RT might result from subjects disengaging attention to the target stimulus. To test this hypothesis, we introduced two groups. In a standard target detection task, one group (catch group) received a high number of catch trials (i.e., absence of a target stimulus), while the other group (control group) did not receive any catch trials. This procedure has been widely used (e.g., Friesen \& Kingstone, 1998). We assessed how a high number of catch trials affected performance. 


\section{METHOD}

\section{APPARATUS}

The experiment was controlled and responses were recorded using SuperLab software (Cedrus, Inc.). Stimuli were presented on a 17 -inch monitor. Reaction time and accuracy measures were based on a key press (Cedrus RB-420). Subjects were seated $60 \mathrm{~cm}$ from the monitor in a dimly lit room. They were asked to place their chin and nose on an apparatus (QuickClamp Hardware, Arrington Research, Inc.) that stabilized the head in order to record eye movements. Their fixation point and eye movements were recorded with a ViewPoint EyeTracker software that is accurate to approximately $0.25^{\circ}$ following 16-point calibration. The frequency of measurements was $60 \mathrm{~Hz}$. Measures were collected from a small infrared camera attached to the QuickClamp. The infrared camera was located at a distance of $6 \mathrm{~cm}$ diagonal from the face centered below the left eye (without blocking the subject's view). Subjects were asked not to move their heads because their pupil and corneal reflection had to remain within the camera image throughout the entire experiment once calibration was completed.

\section{PROCEDURE}

Twenty eight subjects ( 7 females and 7 males in the catch group; 9 females and 5 males in the control group) between the ages of 23 and 30 participated in this experiment. They all had normal or corrected (i.e., wearing contact lenses) vision.

Figure 1 shows the sequence of events on a trial. Each trial began with the presentation of a face with blank eyes. After $680 \mathrm{~ms}$, pupils appeared within the eyes, looking left or right. Following this cue, a target letter appeared to the left or the right of the face except during catch trials. The face, pupils, and target remained on the screen until a response was made or $2,700 \mathrm{~ms}$ had elapsed, whichever came first. The experiment consisted of valld and invalid conditions, including catch trials (only in the catch group). In the valid condition, a target appeared in the location to which the eyes were directed. In the invalid condition, a target appeared in the location to which the eyes were not directed. On catch trials, no target was presented for a remaining $2,700 \mathrm{~ms}$. The inter-trial interval was $680 \mathrm{~ms}$. Cue-target SOA duration, measured from the appearance of the pupils to the appearance of the target, was randomly selected from durations of 105,300 , 600 , and 1,005 ms. Stimuli were all colored black and presented on a white background (mostly based on Friesen \& Kingstone, 1998). The target letter F subtended $0.8^{\circ}$ wide and $1.3^{\circ}$ high, face $6.8^{\circ}$, mouth $2.2^{\circ}$, nose $0.2^{\circ}$, eye outlines $1.0^{\circ}$, pupils $0.5^{\circ}$. The eyes were located $1.0^{\circ}$ from the central vertical axis and $0.8^{\circ}$ above the central horizontal axis. The target letters were presented $5.0^{\circ}$ to the left or right of the eyes, as measured from the center of the nearest eye to the center of the target letter. 


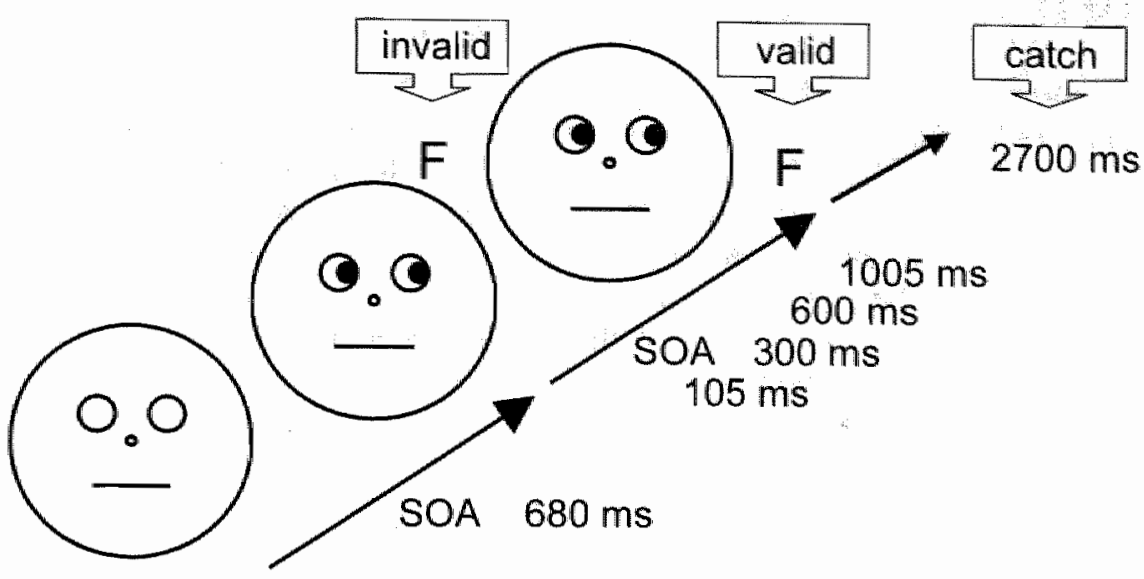

Figure 1 The sequence of events on a trial.

In the catch group, each subject received 12 practice trials followed by 10 blocks of 24 test trials, for a total of 240 test trials ( 80 trials of each condition; valid, invalid and catch). In the control group, each subject received 12 practice trials followed by 10 blocks of 16 test trials, for a total of 160 test trials ( 80 valid and 80 invalid trials). All conditions were counterbalanced within blocks of trials. As illustrated in Figure 1, a trial started by the presentation of a face with blank eyes. After $680 \mathrm{~ms}$, pupils appeared within the eyes, looking left or right. Following this cue, a target letter appeared to the left or the right of the face, except during catch trials. The face, pupils, and target remained on the screen until a response was made or $2,700 \mathrm{~ms}$ had elapsed, whichever came first. Subjects were instructed to indicate that they had detected the appearance of a target on the screen by pressing one of two buttons (left / right), which corresponded to the spatial location of the target. If the target did not appear (i.e., catch trials), subjects were instructed not to respond. Subjects were informed that the direction of gaze depicted by the schematic face predicted neither the direction nor the occurrence of the target, and they were instructed to respond to the target as quickly and as accurately as possible. Following the practice trials, we calibrated the measurement of the subject's left eye with the eye-tracking system. During trials, subjects were required to fixate on a point in the center of the monitor (nose of the schematic face). 


\section{RESULTS}

Eyes did not move to the gazed-at location.

In each trial we measured consecutive eye movements in order to answer whether the subjects' eyes made any reflexive saccades when the pupil stimuli appeared. We analyzed the subjects' eye movements for $300 \mathrm{~ms}$ after presenting the pupill stimuli, because the latency of saccades occurring after presented stimuli is approximately $200-250 \mathrm{~ms}$ (e.g., Bartz, 1962). Figure 2 represents the overal: mean consecutive eye movements of the catch group during this period. The overall pattern of the data did not differ between the two groups. The vertical lines in Figure 2 correspond to the angle of the eye on a horizontal plane against the monitor. These results indicate that subjects' eyes did not move towards the direction of the pupil stimuli. This result demonstrates that the subjects kept their eyes fixated to the fixation point (nose of schematic face).

\section{Left Gaze}

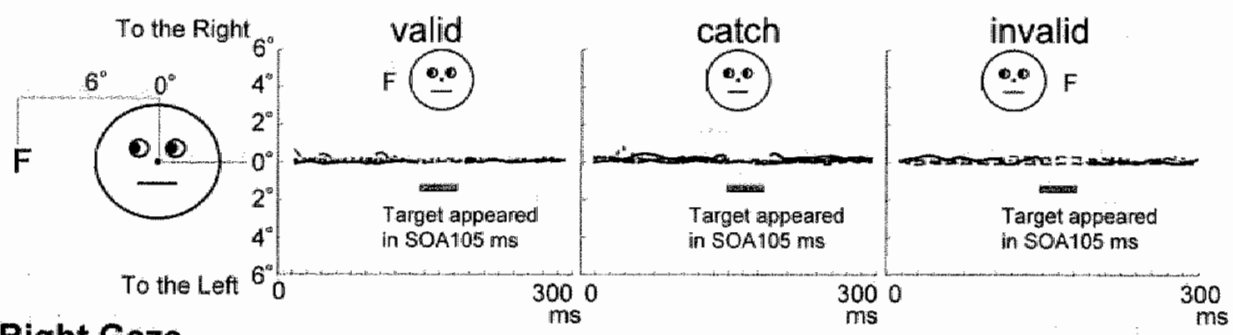

Right Gaze

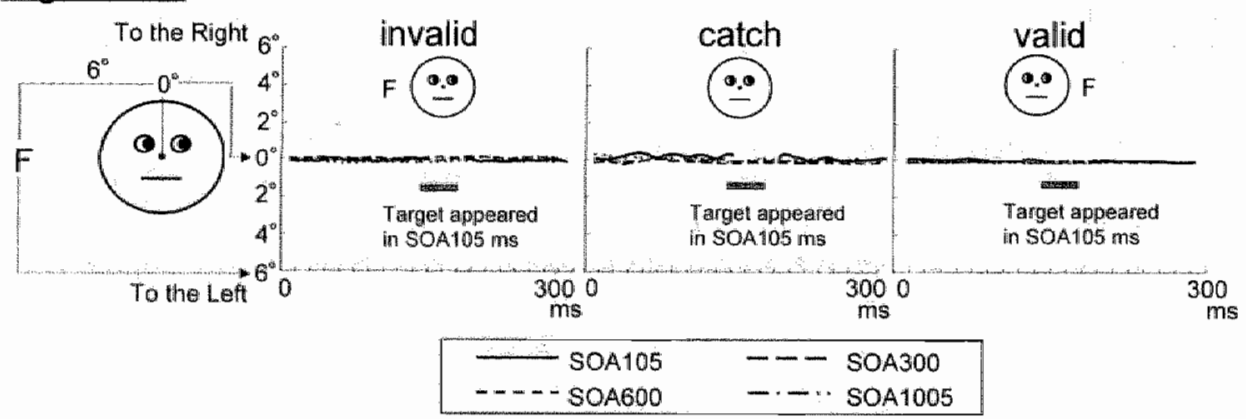

Figure 2 'The subjects' eye movements for $300 \mathrm{~ms}$ after the pictorial pupils' appearance (catch group). The vertical lines correspond to the horizontal eye angle on the monitor.

Attention dynamics were influenced by the gaze cue.

Incorrect responses and timed-out trials were classified as errors, and were excluded from the analysis. Mean error rate was $0.43 \%$ and the highest error rate among all groups was $1.1 \%$. Mean RTs for each condition of the two groups are presented in Figure 3 (Note that there is no RT data for the catch condition). 


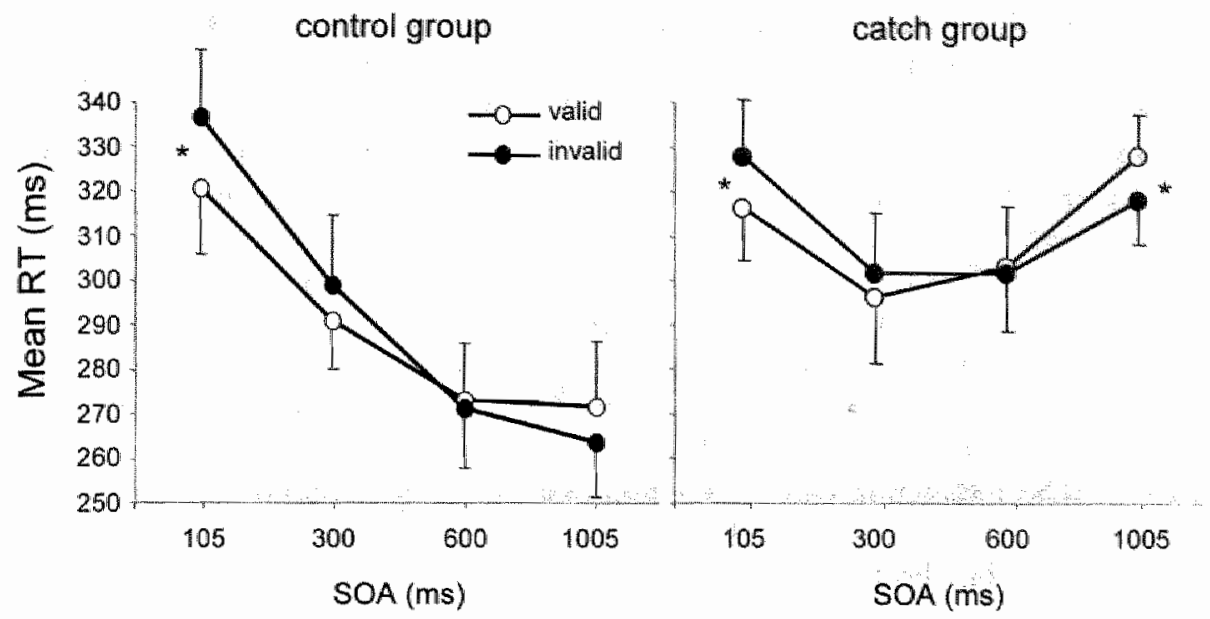

Figure 3 Mean response time (RT) as a function of cue-target stimulus onset asynchrony ( $\mathrm{SOA}$ ).

The pattern of the RTs was quite different between the two groups. The RTs of the control group demonstrates a well-documented pattern: the mean RTs decreased as a function of SOA and the facilitation effect from the valid cue was obtained at short SOAs $(100 \mathrm{~ms})$. These results are consistent with previous findings (Friesen \& Kingstone, 1998; Langton \& Bruce, 1999).

In contrast, in the catch group, the mean RTs produced a U-shape pattern in relation to the increase in SOAs. Further, in the catch group, the mean RT of the valid condition was faster than that of the invalid condition at the shortest SOA (105 ms) as in the control group; the opposite was true at the longest SOA (1005 ms). Moreover, the mean RTs at the longest SOA did not differ from the RTs at the shortest SOA (105 ms).

Statistic analyses confirmed this pattern. A three-way ANOVA was conducted with SOA $(105,300,600$, and $1005 \mathrm{~ms}$ ), cue validity (valid and invalid) as within-subjects factors, and group (catch and control) as a between-subject factor. Results revealed a significant main effect for SOA [F $(3,78)=45.53, p<.001]$. LSD post-hoc tests revealed that the mean RTs at the shortest SOA (105 ms) were significantly longer than those at the other SOA conditions $(300,600,1005 \mathrm{~ms}$ ) (all $p \mathrm{~s}<.001$ ). The mean RT at two of those SOAs (i.e., $300,1005 \mathrm{~ms}$ ) was also longer than that at an $\$ O A$ of $600 \mathrm{~ms}$ (both $p \mathrm{~s}$ $<.05)$. However, this effect was only found in the catch group, as will be described later. There was neither a main effect for cue validity $[F(1,26)=1.13$, n.s. $]$ nor group $[F(1,26)=1.36$, n.s. $]$.

The interaction of group $\times$ SOA was significant $[F(3,78)=31.67, p$ $<.001]$. This interaction derives from the different pattern of RT data in response to the SOA manipulation between the two groups. Post-hoc LSD tests for the control group revealed that the mean RT at the shortest SOA was significantly 
longer than those of the other three SOA conditions, and the mean RT at SOA 300 $\mathrm{ms}$ was also longer than those of the longer SOA conditions (600, $1005 \mathrm{~ms})$. Nevertheless, the LSD tests for the catch group revealed that the mean RTs at the shortest SOA (105 ms) were significantly longer than those at the intermediate SOAs $(300,600 \mathrm{~ms})$, and the mean RT at the longest SOA $(1005 \mathrm{~ms})$ was also longer than that at SOA of $300 \mathrm{~ms}$. Additional LSD tests between groups revealed that the mean RTs of the catch groups and the control group differed at the longer SOAs $(600,1005 \mathrm{~ms})(p \mathrm{~s}<.001)$ but not at the shorter SOAs $(105,300 \mathrm{~ms})$. In sum, the mean RTs in the control group decrease as a monotonic function of SOA, whereas those in the catch group constitute a U-shape pattern. Thus, the mean RTs in the catch group were delayed at the longer SOAs ("IOR (Inhibition of Return)"-like-phenomenon) regardless of cue validity.

The interaction of cue validity $\mathrm{x}$ SOA was also significant $[F(3,78)=$ $7.68, p<.001]$. A post-hoc LSD test demonstrated that there was a facilitation effect only at the shortest SOA $(105 \mathrm{~ms})(p<.001)$, although there was also a marginally significant facilitation effect at SOA $300 \mathrm{~ms}(p<.062)$. These results are consistent with previous findings (Friesen \& Kingstone, 1998; Langton \& Bruce, 1999). Interestingly, in the catch group, there was a "reversed" cueing effect at the longest SOA $(1005 \mathrm{~ms})(p<.002)$, whereas the mean RTs at intermediate SOAs did not differ between the two validity conditions. In order to understand this reverse cueing effect, we compared RTs for the two validity conditions at only the longest SOA (1005) in each group. This analysis showed that the RTs for the valid condition at the longest SOA were significantly longer than that of the invalid condition in the catch group $(p<.05)$ but not in the control group. Therefore, this significant reversed cueing effect at the longest SOA is mainly due to the valid condition in the catch group.

\section{DISCUSSION}

The present study could be summarized as follows. First, the facilitation effect by a gaze direction cue occurs without subjects" making eye movements to the gazed-at location. Second, this facilitation effect was observed at only the shorter SOAs (105, and $300 \mathrm{~ms})$. Although, previous research obtained the gaze direction effect at the intermediate SOA ( $300 \mathrm{~ms}$ ) with a higher number of trials ( 500 trials) (Friesen \& Kingstone, 1998), the present study did not find the effect at the intermediate SOAs. These differences may be due to the number of trials in a session. The number of trials (160 trials in total) of the present study may be insufficient to obtain a significant facilitation effect at the intermediate SOA (300 $\mathrm{ms}$ ). In fact, another experiment by the second author of the present study demonstrated the same facilitation effect by the gaze direction cue at the intermediate SOA ( 300 but not $600 \mathrm{~ms}$ ) with a relatively high number of trials (320 trials) (Kawai, in preparation) (see also, Langton and Bruce, 1999).

Third, a delay in RT was observed at longer SOAs $(600,1005 \mathrm{~ms})$ in 
the catch group as compared to the control group. Therefore, this effect can be attributed to the presence of a high number of catch trials in the session. In the catch group of the present study, catch trials occurred on one third of the total trials. Thus, subjects in the catch group might disengage their attention because, as time passed and no target appeared, they were likely to think that the present trial was a catch trial. Subjects in the control group would have no such expectation. Such a decrease in vigilance might increase RT at the longer SOAs, because it would take time to re-focus attention. Such an increase in RT at the longer SOAs produced a U-shaped RT pattern in the catch group, whereas the RTs of the control group produced a monotonic function to SOAs. In Friesen and Kingstone (1998), only half of the subjects received catch trials and the other half did not receive any catch trials. The catch trials for the subjects who received them comprised only $6 \%$ of their total number of trials ( 30 trials of 510 trials in total). Therefore, subjects in the present study (control group) and in the previous study (Friesen and Kingstone, 1998) would strongly await the appearance of the target without disengaging their attention. As a result, their RTs got shorter as the SOA got longer. Taken together, these delays suggest that the subjects' expectation that long SOAs indexed catch trials, resulted in a disengagement of attention that, in turn, inhibited a return to the previous location. This account seems to be consistent with the finding that the delay had a stronger effect (i.e., "reversed" cueing effect) in the valid condition than the invalid condition at the longest SOA (1005 ms), because in the valid condition, subjects should have anticipated more strongly the appearance of the target at the gazed-at location.

These delays seem to be analogous to the well-known phenomenon of inhibition of return (IOR). This phenomenon predicts that, after attention is withdrawn from one spatial location, it is inhibited, momentarily, from returning there (Posner \& Cohen, 1984). According to Posner and Cohen (1984), however, IOR usually occurs at approximately 300 to $600 \mathrm{~ms}$ after an onset of a novel stimulus. Therefore, if IOR plays a role in the delay in the catch group, it should be most significant at the intermediate SOAs (300 and $600 \mathrm{~ms})$. In the present study, however, an "IOR"-like-phenomenon was observed at the longer SOAs (600 and $1005 \mathrm{~ms}$ ). Previous studies (e.g., Friesen \& Kingstone, 1998; Langton \& Bruce, 1999) reported that IOR does not usually occur in a gaze (and face) orienting task. For instance, by introducing the onset of an abrupt peripheral cue, Friesen \& Kingstone (2003) demonstrated that the facilitation effect by a central gaze cue occurred independently of the conventional IOR effect. However, in our study, the emergence of the facilitation effect and the "IOR"-like phenomenon overlapped with a time course. The fact that both effects (the facilitation effect by the gaze cue and "IOR"-like phenomenon by disengaging attention from a target stimulus) were not independent suggests that this delay in RT ("IOR"-like phenomenon) has different properties from the conventional IOR.

The occurrence of an "IOR"-like phenomenon may be explained as follows: A cognitive load like "avoidance of a false alarm" may contribute to the gaze cueing task by influencing the extent to which attention to the target is disengaged. This phenomenon did not appear in a control group in which a target 
appeared on every trial. Therefore, this phenomenon seems to be related to the subjects' readiness potential. At longer SOAs there is an increase in the readiness potential, because subjects have had a longer period of time in which to anticipate the target, relative to the shorter SOAs. This account explains the shorter RT at the longer SOAs in the control group, in comparison to the eatch group, because in the absence of catch trials, control subjects remain highly vigilant. On the contrary, in the cateh group, the high probability of a catch trial $(33 \%)$ would encourage the disengagement of attention to a target stimulus. This high probability, however, would lead to longer RTs at longer SOAs. Regardless of underlying processes, this finding suggests an interesting additional characteristic of attention in the cued target paradigm.

Our findings demonstrate an "TOR"-like phenomenon which seems to have occurred via a process of disengaging attention to the target. However, this phenomenon needs further investigation. Future experiments should make use of other kinds of arbitrary and nonarbitrary cues to clarify the generalizability of the findings. In addition, manipulating the proportion of catch trials would elucidate the degree to which the effect depends on catch trial frequency. A better understanding of the facilitation effect will provide important insights into human visual communication.

\section{ACKNOWLEDGEMENTS}

This research was financially supported by the Ministry of Education, Science, and Culture of Japan (Grants- in-Aid for Scientific Research 14710042 to Nobuyuki Kawai. We would like to express our thanks to Joel Fagot, Jochen Barth, Francys Subiaul, and Jennifer Vonk for their useful suggestions.

\section{REFERENCES}

Bartz, A. E (1962), Eye movement latency; duration and response time as a function of angular displacement. Joumal of Experimental Psychology: Human Percepion and Performanoe, 64. $318-324$

Call, J., Hare, B., \& Tomasello, M. (1998). Chimpanzee gaze following in an object-choice task. Animal Coginition, 1, 89-99.

Driver, J., Davis, G., Ricciardelli, P., Kidd, P., Maxwell, E., \& Baron-Cohen, S. (1999). Gaze perception triggers reflexive visuospatial orienting. Visual Cogmition, 6, 509-540.

Friesen, C. K. Kingstone, A. (1998). The eyes have it!: Reflexive orienting is triggered by nonpredictive gaze. Psychonomic Bulletin and Review, 5, 490-495.

Friesen, C. K., \& Kingstone, A. (2003). Abrupt onsets and gaze direction cues trigger undependent reflexive attentional efiects. Cognition, $87,1-10$.

Langton, S. R. H., \& Bruce, V. (1999). Reflexive visual orienting in response to the social attention of others. Visual Cognition, $6,541-567$.

Mansfield, E. M., Farroni, T., do Jolnson, M. H. (2003). Does gaze perception facilitate overt orienting? Fiswal Cognition, 10,7-14.

Moore, C. (1999). Gaze following and the control of attention. In P. Rochat (Ed), Early social 
cognition (pp. 241-256). Mahwalh, Nil: Lawrence Erlbaum Associates, lno.

Okamoto, S. Tomonaga, M., Ishii K., Kawai N., Tanaka, M., \& Matsuzawa, I. (2002). An infant chimpanzee (Pan troglodytes) follows human gaze. Animal Cogmition, $5,107-114$.

Okamoto, S. Tanaka, M., \& Tomonaga, M. (2004). Looking back: The "representational mechanism" of joint attention in an infant chimpanzee (Ban troglodytes). Japanese Psychologich Research, 46, 236-245.

Posner, M. I. (1980). Orienting of attention. Ouarterly Journal of Experimental Psychologn, 32, 3225.

Posner, M. I. \& Cohen, Y (1984). Components of wisual orieiting. In H. Bouma \& D. G. Bowhuis (Eds), Attention and Performance X (pp. 531 -556). Hove, UK: Lawence Erlbaum Associates Ltd.

Povinelli, D. J., \& Eddy, T. J. (1996). Chimpanzees: Joint visual attention. Psychological Science, 7, $129-135$.

Povinelli, D. J., \& Eddy, T. J. (1997). Specificity of gaze-following in young chimpanzees. British Journat of Developmental Psychology, 15, 213-222.

Rafal, R. D., Calabresi, P. A., Brennan, C. W., \& Sciolto, T. K. (1989). Saccade preparation inhibits reorienting to recently attended locations. Journal of Experimental Psychology: Humow Perception and Performance, $15,673-685$.

Tomasello, M. (1999). The cultural origins of human cognition. Cambridge: Harvard University Press. 
GENERAL DISCUSSION 
Recent interest in the study of gaze and social attention has been stimulated by a number of studies from a developmental, evolutionary, cognitive science, and neurocognitive perspective. Though the results of these studies have inspired various ideas, and models of social cognition, they all emphasize pivotal role of gaze detection and gaze direction.

The present studies investigated the visual interaction between an infant chimpanzee and his mother (Chapter 1), and the infant chimpanzee's ability of following gaze over the course of his development (Chapter 2 and 3). In another study, human adults' eye movements when exposed to eye-like stimuli were measured in the traditional cueing paradigm (Chapter 4).

Chapter 1 investigated the development of visual interaction (e.g., eye contact, mutual gaze) between a mother chimpanzee and her infant over time. The results show a behavioral sequence of typical "secure-base" behavior. Moreover, looking at mother/infant increased when physical contact became less or when the distance between them increased. Results also suggest that other necessary developments (e.g., motivation for exploration) of a "secure base" precede the physical development for independent locomotion. The development of the mother-infant bond, in turn, affects cognitive and physical developments.

Chapter 2 investigated the emergence of the ability to follow the gaze of other individuals in an infant chimpanzee. By 13 months of age, the infant reliably showed following responses to objects that were indicated by various cues, including glancing alone. Additional tests showed that the infant's performance was controlled by the "social" properties of the experimenter-given cues but not by nonsocial, local-enhancing or peripheral properties.

Chapter 3 investigated the development of gaze following in an infant chimpanzee. Mainly, it focused on the emergence of the ability to follow an experimenter's gaze to an object located behind the infant. The results show that by 21 months of age, the infant reliably followed the experimenter's cues and looked back to a target behind him. Moving targets elicited more responses than stationary targets, and the subject showed more gaze following responses after seeing the experimenter manipulate the computer that controlled the targets.

Chapter 4 tested human adults to investigate whether human adults' expectation of a target affects attention to the gaze direction cue of a line drawing face. Specifically, does a longer SOA result in decreased expectation of the appearance of a target? The results suggest that subjects disengage attention when no target appears because they expect the trial to be a trial without a target (catch trial). In the catch group, the delay in response time was significant in the valid condition as compared to the invalid condition at the longest SOA (1005 ms). This result suggests that attention is disengaged by the subjects' strong anticipation, which inhibits a return to the previous location. 


\section{SIMILARITIES AND DIFFERENCES OF GAZE PROCESSING IN CHIMPANZEES AND HUMANS}

The present studies found similarities in certain levels of gaze processing between human and chimpanzee infants. For example, the visual interaction experiment (Chapter I) found that looking at mother/infant increased when body contact became less or when the distance between them increased. The results suggest that the looking behavior between the mother-infant pair compensates for the distance between them. Moreover, the results show a behavioral sequence of typical "secure-base" behavior, characterized by the infant regularly returning to its mother when exploring the environment. A similar phenomenon has been well-documented in human infants.

Two consecutive gaze following experiments (Chapter 2 and 3) clearly showed that an infant chimpanzee did follow social cues (e.g., tapping, pointing, head turning), including eye gaze from around 9 months of age. The infant began to reliably follow gaze at 13 months. Although, for the gaze cues, a non-differential reinforcement design was introduced to avoid any type of shaping, it is still possible that the infant may have learned to follow human gaze by "generalizing" from the other cues. Starting at 21 months of age, the infant looked back to targets located behind him, even when there was a distracter in front of him. In this study, infant chimpanzees exhibited the looking back response, which Butterworth and Jarrett (1991) have interpreted as evidence of a "representational mechanism" in 18 month old human infants. Although there are some developmental differences about the onset of each "level" of gaze following, on the surface, the development of gaze following in human and chimpanzee infants appears to be highly similar.

However, unlike human infants, the chimpanzee infant in our study failed to look back at the experimenter after following her gaze to an object located behind him. This triadic interaction between mother, child, and object of interest has been widely reported in the human developmental literature. The absence of this behavior in the infant chimpanzee we observed suggests a fundamental difference in the gaze following behavior of humans and chimpanzees.

In humans, a number of qualitative changes in social communication occur at around 9 months of age (Carpenter, Nagell, \& Tomasello, 1998). Human infants, at 6 months, interact "dyadically" with objects or with a person in a turn-taking (or reciprocally exchanging) sequence. However, they do not interact with the person who is manipulating objects (Tomasello, 1999). From 9 months on, they start to engage in "triadic" exchanges witl others. Their interactions involve both objects and persons, resulting in the formation of a referential triangle of infant, adult, and object to which they share attention (Rochat, 2001; Tomasello, 1999). That is to say, "Triad relationship-based" joint attention ("shared attention" in Emery [2000]"s definition) is an important component of social cognitive skills in human infants 12 months of age and older. According to these theories, the present results suggest that the chimpanzee infant and human experimenter jointly attended to the object behind 
the infant, but did not engage in "Triad relationship-based" joint attention (or did not share their attention with each other via the target). These results imply that there must be substantial differences in "gaze following" between these two species.

\section{OTHER METHODOLOGY TO INVESTIGATE JOINT ATTENTION AND GAZE FOLLOWING}

One common method used to investigate non-human primates' ability to use social cues such as gaze, is the "object-choice task." In this task, subjects must choose one of two containers, only one of which is baited. Anderson and his colleagues used this task for measuring the sensitivity to social cues in primates. In a series of studies, they investigated the ability of capuchin monkeys. (Anderson, Sallaberry, \& Barbier, 1995) and rhesus macaques (Anderson, Montant, \& Schmitt, 1996) to utilize hurnan attention cues to gain food rewards in a Wisconsin General Testing Apparatus (WGTA). A human experimenter presented the subjects with different cues: "pointing only", "gaze only (head orientation and eyes cues)" and "gaze and pointing" to the subjects. None of the capuchin monkeys or macaques could be trained to use the "gaze only" cues to guide their responses. Two subjects of each species could be trained to use either "pointing only" or "gaze and pointing". However, it is likely that "local enhancement" may explain the subjects' success in the "gaze and pointing" situation (e.g., they might learn to use the proximity of the hand to the correct container).

Using a similar paradigm, Itakura \& Tanaka (1998) found that chimpanzees, an enculturated orangutan and human infants $(18-27$ months old) used all gaze cues, including pointing and glancing (without head turning), to chose the baited container. The responses of all subjects appeared to be spontaneous, not requiring learning. Povinelli and colleagues (1999), however, found that their chimpanzees failed to use the eyes only (glancing) cue when responding in a similar task. Although, these differences may be due to the age, experimental experience, testing design, and enculturation (e.g., developmental history) of the different groups of chimpanzees, it is clear that non-ape primates (monkeys) were not good at using gaze cues in the object-choice task (see also Itakura \& Anderson, 1996).

Povinelli and Eddy (1996a, b) have offered an explanation for the differences between monkeys and apes in this task. They argued that following another individual's gaze might be an automatic response and form part of a primitive orienting reflex (POR) triggered by the food reward. This reflex does not require the attribution of other's mental states. The use of an operant task to test gaze following would fail to test for the presence of a POR as compared to a more complex social cognition mechanism (e.g., a theory of mind). Monkeys may follow gaze (especially that of conspecifics), but do not learn how to use gaze as a cue in operant tasks.

This interpretational confound introduced by the use of an operant task 
such as the object-choice task to investigate gaze following is not only a problem when studying monkeys, but also when studying infant chimpanzees. Okamoto, Tomonaga, Ishii, \& Matsuzawa (2002) investigated the ability of infant chimpanzees to use social cues in an object-choice task (one of the three was the subject in the present study). They started using social cues after 12 months of age (e.g., tapping cue: after 11 months; pointing cues: after 20 months on average). One of the three infants began using a gaze cue (head direction with eyes) when he was 2 years old. However, this data still implies the "difficulty" of object-choice tasks.

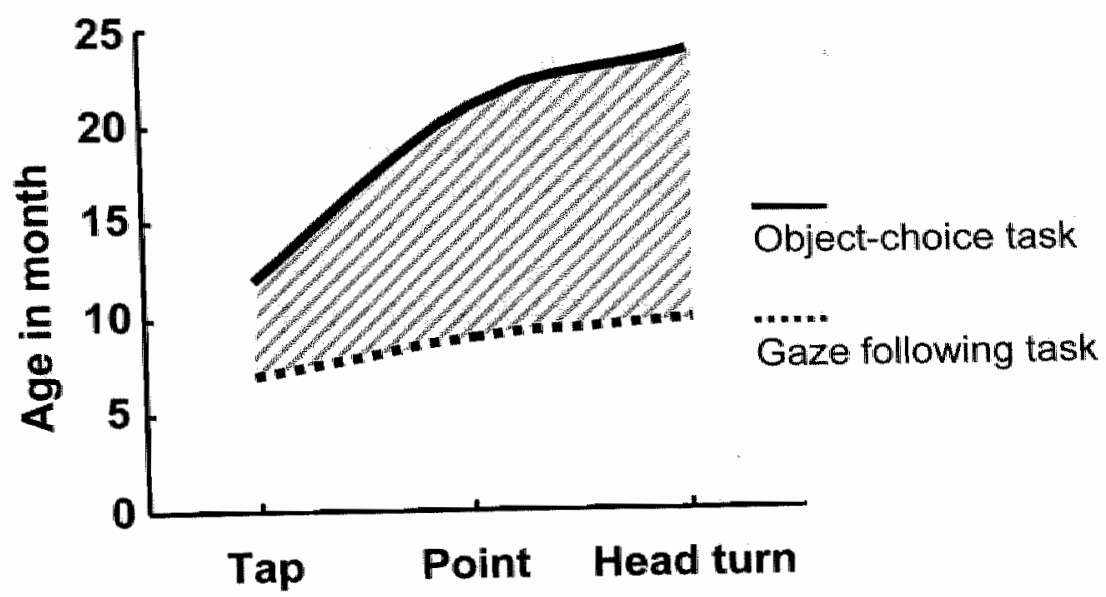

Figure The comparison between the performance in the gaze following task and the object-choice task. Both linear curves (straight and broken) represent the age which the infant subject acquired each social cues for following (in gaze following task) or using (in object-choice task). Shaded area represents the age difference between the data from both tasks.

The infant chimpanzee subject showed a delayed time course compared to the gaze following data (see the Figure). There are several possible reasons for this delay. First, subjects must learn that they only have one opportunity to respond per trial and only one container holds a food reward. This differs from the gaze following task which relies on the subject's natural response to an experimenter's behavior. Second, knuckle-walking is not fully-developed. Poor coordination may interfere with performance. Third, subjects have not reached critical cognitive milestones such as object permanence and avoiding search errors. Piaget (1954) was the first to describe in young children the systematic search for an object that has been displaced behind an opaque occluder. This behavior has often been interpreted to support the idea that subjects mentally reconstruct the path followed by an object. Object permanence is roughly defined as the ability to locate objects that have been hidden from view. Without the ability to track hidden objects, subjects will be unable to solve the object-choice task. In the present study, subjects began to show evidence of 
tracking the hidden food reward (i.e., object permanence) after 11 months of age. For example, they started to grasp the cup carefully, and also changed their behavior after choosing (and grasping) the cup. They inspected the inside of cups when they could not find a piece of food under them. Finally, infant's performance may have been adversely affected by the experimental setting which was not designed from an infant's perspective, but rather, an adult's perspective. A related problem has been identified by Barth, Reaux, and Povinelli (2005). In an object-choice task with chimpanzees, these investigators reported that when subjects walked towards the experimental setting they were $100 \%$ accurate in using the experimenter's gaze cue. However, when subjects should respond when they sat in front of the apparatus, subjects' accuracy did not significantly differ from chance. Once these results have been put in context, it is clear that the object-choice task requires more than just gaze following skills. Therefore, it is not an ideal task for measuring gaze following. Unlike just following gaze, the ability of solving this task requires other abilities which may be acquired a posteriorit.

\section{GAZE FOR INFERRING ANOTHER'S MENTAL STATES}

A number of recent studies have proposed that domestication may affect the use of social cues by dogs (e.g., Miklosi, Polgardi, Topal, \& Csanyi, 1998). Others have argued that being reared by humans (enculturation) may have a similar effect on gaze following among primates (e.g., an orangutan from Itakura \& Tanaka, 1998). As mentioned above, however, there are still some essential differences in gaze following between humans and non-human animals. Triadic relationship based exchanges have not been shown in this study's subject. Which factors might explain this difference?

Non-human primates may not be able to infer another's intentions from the presence or direction of their eyes. The eyes may only be used to communicate another's emotional state (e.g., such as anger displayed as a threat), or to communicate the presence of objects within the immediate environment.

There are many instances in the primate literature which suggest that some primates may use gaze to convey information about their intentions, not just of emotions or referring to objects, but also events or individuals in the environment. Some individuals, during complex behavioral interactions, may utilize the knowledge that other monkeys and apes automatically follow gaze. For instance, Whiten and Byrne (1988) describe a young baboon who manipulates another's use of attention cues, as a form of deception.

Distinguishing another individual's visual perspective from one's own is thought to be an important step in interpreting their intentions and thoughts about the world. Kummer, Anzenberger, Hemelrijk (1996) trained macaques to take a reward, only if a human experimenter was not in a position to observe them taking the reward. The human experimenter threatened the monkeys if they took the reward while in the experimenter's view. However, the subjects never learned to discriminate between an experimenter who could see them and 
one who could not. Kummer and colleagues interpreted this as a lack of perspective taking or a lack of 'experiencing' another's visual perception. Povinelli and colleagues also tested whether chimpanzees can choose between an experimenter who can see and an experimenter who cannot see them (1996c). For example, when subjects had to choose between two experimenters, one whose head was covered by a bucket and another experimenter with a bucket next to his head (but not covering it), subjects correctly gestured to the experimenter with the bucket next to their head. However, in instances where one experimenter's eyes were covered and the other experimenter's eyes were not, subjects begged indiscriminately, failing to differentiate between the experimenter that could see them and the one that could not. The chimpanzee subjects could not make the inference that seeing (when using only eyes as a cue for inferring what the other is seeing) leads to knowing about an event, but could when using the head as a cue. That is, though chimpanzees respond correctly when the head is visible, their performance degrades when only eyes are invisible. This suggests that chimpanzees fail to appreciate that eyes correlate with the experience of "seeing'. Povinelli and Eddy have suggested that chimpanzees may use a sophisticated level of gaze following, but their use of gaze is not within a mentalistic framework (i.e. they do not have a concept of another individual's mind from gaze).

The observational episodes of baboons in their natural habitat, and experimental studies of apes in the laboratory, suggest that non-human primates may understand the social significance of gaze and social attention cues. However, Emery (2000) suggested that some apes (and possibly some monkeys) may process another's gaze within a "behaviorist" framework, but not within a framework which requires a more cognitively based system of mental state attribution. A behaviorist interpretation would state that non-human primates respond to attentional cues in terms of associated rewards, and learn only stimulus-response relationships (Whiten, 1996). According to the argument by Emery (2000), there are two possible interpretations of an animal's behavior. For example, chimpanzee $A$ is watching an orange, because $A$ wants to eat it. Chimpanzee $B$ infers that chimpanzee $A$ wants to eat an orange from the behavior in which chimpanzee $A$ is watching the orange. Difficulties in interpretation arise, not just when interpreting meaning in animals" behavior, but also when suggesting that individuals can interpret and understand another"s intention from the other individual's behavior patterns.

\section{ACTIVE JOINT ATTENTION AND GAZE FOLLOWING}

In previous studies with primates, the topic of gaze following (and joint attention) was mainly about the subjects' responses to another individual's gaze and social attention cues. However, the ability of sending the social attention cues to another individual has not been investigated. There is also no clear evidence that primates show their gaze intentionally to other individual to let them follow it. Some studies, however, have reported that apes can use their eye contact or pointing to direct a person's attention to their requests (e.g., Gomez, 
1990). But, Emery (2000) argued that these studies can be interpreted in ways that do not rely on mental state attribution. Although these apes' behavior may have a communicative meaning (e.g., begging for food), it can be considered as "imperative" directing behavior. Because of this, it might be more appropriate to investigate chimpanzee's ability to send "declarative" (rather than imperative) social cues.

In this dissertation, the ability to send social cues (declaratively) is defined as "active" joint attention. There is no direct evidence of active joint attention in non-human primates (in a declarative fashion as opposed to an imperative fashion in which food is requested). Tomasello (2000) argued that non-human primates do not point or gesture to outside objects for others and do not show objects to others. Povinelli, Bering, and Gimabrone (2003) have argued that several chimpanzee gestures resemble pointing (e.g., in object exploration or when requesting food) yet upon closer evaluation do not represent behaviors that are analogues to human pointing (see below about details of human pointing). Consequently, active joint attention is considered to be an important difference between humans and non-human primates. Supporting this hypothesis is a study by Tomonaga et al. (in press) who reported that chimpanzee infants never showed an object or gave an object to a caregiver. Such actions are taken to be indicative of referential communication in triadic relationships in humans. One exceptional case of these actions was reported for an 18-month-old nursery-raised chimpanzee by Russell, Bard, and Adamson (1997). There is also no clear evidence of "active teaching" in non-human primates (e.g., Tomasello, 2000; Sousa, Okamoto, \& Matsuzawa, 2003). Only two instances of active teaching between chimpanzee mothers and infants have been reported (Boesch, 1991). It must be noted, however, that these episodes were the only two ever recorded over many years of observation at the site.

What is "active" joint attention based on? Why can we intentionally gesture to one another in order to communicate basic desires? For instance, we infer that when an individual looks at an object, he wants that object. Moreover, we know that others can track our gaze to objects and locations. In the typical sequence of joint attention episodes, we "catch" the attention of others individual and "take" it to a particular object. In our daily communication, we expect and predict that other individuals will notice (or detect) and follow our attention and gestures. We let other individuals follow our gestures (declaratively), because we know the other individual would follow our gestures in return. We also know which gestures are valid for that purpose. As described above, previous studies in human have argued that following gaze and using social cues have a potentially innate and reflexive character (even this is still not clear). Does this mean that the production and utilization of social cues in a declarative manner are acquired a posteriori?

In regard to the production of pointing (as a social communicative gesture) in human infants, Moore and Corkum (1994) have suggested that "the initial use of protodeclaratives towards the end of the first year appears more likely to be the use of an object to elicit a particular form of adult behavior to 
the infant rather than to the object", such as laughter, smiles, and eye contact. Wellman (1993) and Barresi and Moore (1994) suggest that the production of pointing gestures appear in the second year. Wellman (1993) stated that in the second year infants point to objects in increasingly sophisticated ways. Specifically, Barresi and Moore (1994) note that pointing gestures may be used only in a self-other distinction at around 18 months. In any event, it is likely that this behavior undergoes significant developmental changes throughout this period. The claim that infants point to objects in different ways during the second year has often been made in the literature (e.g., Bates, 1979; Butterworth, 1991; Lempers, Flavell, \& Flavell, 1977). As described above the pointing gesture appears at around 12 months of age, however, pointing at 12 months may not be intended to draw adults' attention to objects but simply to elicit adult attention toward the infant (Moore \& Corkum, 1994; for a different interpretation see Liszkowski et. al., 2004). This interpretation can explain the results from previous studies about active (imperative) directing behavior in apes (e.g., Gomez, 1994) like argued above. Moreover, the sophisticated way of pointing that is accompanied by looking at the mother was observed in only half of the 15 months old subjects studied by Desrochers, Morissette, \& Ricard (1995). More advanced socio-cognitive skills (such as a theory of mind) develop gradually and significantly later in development (around the third and fourth year).

Is there a correlation between the production of pointing and solving the object-choice task? As mentioned above, this task is both cognitively and methodologically complex. When cues (such as gaze or pointing) were presented in a randomized order, 2.5 year-old human children were unable to use these cues to locate hidden toys (Barth, Call, \& Tomasello, 2004). Itakura and Tanaka (1998), however, used cues that gradually increased in complexity; from easy physical cues such as tapping on a desired object, to more difficult social cues such as pointing and head-orientation. Infants between 18 to 27 months performed well in this task. The disparity of these results suggests that performance hinges on the method used to present the stimuli (i.e., whether cues are presented in a random fashion or in step-by-step fashion). This implies that using the social gestures requires learning and is an ability acquired later on in development.

The ability to produce declarative pointing requires the knowledge that other individuals are similarly capable of producing declarative pointing and not only imperative pointing. If subjects cannot themselves produce the declarative pointing, it must be difficult to use pointing as a referential cue. Comprehension and use of social cues is not limited to following them reflexively. Infants must understand that another individual is pointing to a particular object declaratively (and intentionally), which suggests that some mental attribution is required to understand this behavior. 


\section{PRE-CUEING EFFECT IN GAZE FOLLOWING}

Previous studies with apes and monkeys suggest that subjects can follow others" gaze, but this behavior is an automatic POR (primitive orienting response), unrelated to the attribution of mental states (e.g., Povinelli et al., 1996 a, b; Emery et al, 1997). If subjects had continued looking at the previously attended object after the experimenter or conspecifics disappeared, then subjects must have learned that one object was inherently more important than the other. Such a result may have been used to argue for a more complex role in mental state attribution.

For the maintenance of joint attention episodes, remembering to which particular object another individual is attending to is a necessary component of social interactions. Eleven-months-old human infants continued looking at the object their mother looked at even when the mother stopped looking at it (Itakura, 2001). Three-month-old infants also turn their eyes to a given target more rapidly if the location of that target had been previously cued by an adult's gaze direction (Hood, Willen, \& Driver, 1998). This evidence may relate to the pre-cueing facilitation effect observed in studies with human adults (such as Posner's traditional target detection task [Posner, 1980]).

However, this pre-cueing effect has not been demonstrated in non-human primates. Fagot and Deruelle (2002) suggested that baboons do not spontaneously process eye-gaze direction but can learn to do so if the gaze has a predictive value (see General Introduction). Tomonaga (2004) also tested the facilitation effect with chimpanzees in the traditional detection task. In a series of experiments, chimpanzee subjects did not show the facilitation effect caused by gaze cues. This implies an essential difference between humans and chimpanzees (and maybe also monkeys).

Why does pre-cueing not affect the chimpanzee subjects" target detection performance? Chimpanzees can follow another individuals' gaze. However, this sequence does not need mental state attribution (e.g., $X$ wants to show $Y$ his gaze to share attention about object $Z$ ). It may not make a difference to chimpanzees whether $X$ is just looking at $Z$ for himself or whether $X$ is showing his looking behavior to (communicating with) $Y$. The latter case can be considered as declarative directing behavior. However, there is no replicable evidence of declarative directing behavior by chimpanzees. Among chimpanzees, there might be just the simple interpretation of $\mathrm{X}$ is just looking at $Z$ because $X$ wants to see it, which means they don't think (or don't understand) that $X$ wants to show $Z$ to $Y$ ). For humans, however, there is an essential difference between following other's intentional gaze $(X$ wants $Y$ to follow his gaze to lead $Y$ 's attention to $Z$ ) and following other's gaze (X just wants to see $Z$ ). Because chimpanzees may not have this declarative behavioral component which humans use in their daily social communication, they need to learn to use social cues (e.g., in object-choice tasks). This interpretation of the data may explain why chimpanzees (and other primates) do not show the pre-cueing effect, and need to learn the cues in object-choice tasks. In other words, they do not produce and understand the declarative nature of such behavior, because 
they do not have the declarative component and vice versa. This may imply that humans' reflexive orienting to gaze direction occurs based not only on the direction of gaze, but also on all potential components such as simple, imperative, and declarative gaze directing behaviors.

\section{PREREQUISITES FOR GAZE FOLLOWING}

The first appearance of triadic relationship has been treated as an important qualitative change in the development of human infants. The following components are necessary to establish a triadic relationship: infant, adult, and a particular object or event. Previous studies have investigated gaze following abilities in human infants and non-human primates. Particular objects have also been used as targets. Chapter 2 and 3 documented the development of gaze following to target objects in an infant chimpanzee. Several target objects elicited the infant's gaze following behavior (see Chapter 3). We also demonstrated that "expectancies" about the appearance of a target elicited more gaze following responses.

Chapter 4 investigated how the expectancy of a target that appeared inconsistently affects attention to gaze-direction cues in human adults. The results showed clear differences between the performances of two groups tested in trials with a consistently and inconsistently appearing target. In trials where the target appeared inconsistently, the subjects disengaged attention when no target appeared because they expected the trial to be a catch trial (no target).

Apes also performed differently in trials where targets appeared consistently or inconsistently. Okamoto-Barth, Call, \& Tomasello (unpublished data) manipulated the presence of a target in the gaze following task in all four great apes (chimpanzees, bonobos, orangutans, and gorillas). When there was no target, apes showed less following responses.

For humans' daily joint attention episodes, it is possible that a receiver of social attention cues has the expectancy and prediction that a sender may/must be looking at a particular object. Such expectancies and predictions facilitate social communication. However, when there is no particular object or event, the receiver would search for it or wonder what the sender is looking at. In this case, receivers might look back at the sender to gather more contextual information.

A behavior referred to as "checking back" typically accompanies gaze-following. This "checking back" behavior has been observed in adult chimpanzees in instances of apparent uncertainty (Call, Hare, \& Tomasello, 1998). However, as mentioned above, the chimpanzee infant in the present study did not show this behavior. We interpreted the absence of "checking back" in the infant chimpanzee we studied as evidence against "Triad relationship-based" joint attention (or "shared attention"). However, there may be an essential difference between "checking back" and "shared attention". Checking back could be completed without an understanding of mental states. But checking back cannot be accomplished without the ability to track gaze geometrically. A number of studies have demonstrated that chimpanzees can effectively track an 
individual's gaze geometrically, even when there is a distracter between the subject and the target (e.g., Povinelli \& Eddy 1996; Tomasello, Hare \& Agnetta, 1999). Yet, it does not follow from these results that subjects that track gaze are interpreting them mentalistically. After following the senders gaze, does the receiver need a terminal point (target object or event)? Although this is still an open question, it is clear that the presence or expectancy of a target affects the receiver's attention to a potential target location. For example, consider the preparation for new environmental information that was observed in human adults presented with a schematic face whose eyes were directed to a given location (Chapter 4). However, the use of this cue does not imply mental-state attribution.

It is possible that triadic relationships affect performance in the object-choice task. Barth, Call, \& Tomasello (2004) reported that 2.5-year-old children were more successful exploiting a pointing cue when they immediately followed the experimenter's cue. Although it is difficult to recreate natural triadic communications such as mutual gazing with infants mediating the object in the testing situation, the results reported here highlight the potential importance of triadic relationships in the object-choice task. Nine-month-old infants, however, also engage in triadic exchanges with others (Tomasello, 1999). When one considers the cognitive abilities of 9 -month olds as compared to those of 2-year olds one must wonder whether the understanding of the experimenter's declarative behavior is related to "full-fledged" triadic relationships.

\section{DIFFERENCE OR DIVERGENCE ?}

A sophisticated social-cognitive ability may not be an exclusive pre-requisite for gaze following, or learning to use another's attention cues to locate a food reward. In the daily lives of primates, the simple skill of gaze following already has a number of adaptive benefits. From an evolutionary perspective, it might not be thrifty to have an additional ability which includes attributing other individual's mental states. That is, the ability to attribute mental states may incur unnecessary costs. Nevertheless, the ability of gaze following characterizes us as primates, and this ability plays a role as a precursor of sophisticated social interaction. Although, some species of birds can differentiate between whether an approaching human is looking towards or away from them (Ristau, 1991), they do not follow human gaze. This limited use of gaze direction might work only for protecting themselves from predators.

Non-human primates do not show "active" joint attention, however. Triadic-based joint attentional states as a sophisticated socio-cognitive situation (like mental attribution) may be achieved only when chimpanzees can produce and understand active joint attention in a declarative fashion and not via an automatic POR or an imperative fashion.

In a number of recent studies with human infants early social-cognitive abilities, including most prominently joint attention and protodeclarative communication, have been posited as precursors to a 
full-fledged theory of mind. For example, Wellman (1993) and Gomez, Sarria and Tamarit (1993) have proposed accounts of easly social cognition focusing on such things as infants' understanding of the desires or goals of others and the attention of others as evidenced by their protodeclarative behavior. It should also be recognized that infants must understand the goal of others to go beyond simple gaze following and on to an appreciation of their attentional focus.

Tomasello (1995) argued that "although other primate species especially chimpanzees display impressive social intelligence in many ways of their daily lives, it is only humans who enter into joint attentional states with conspecifics, use symbols without special training, imitatively learn novel behaviors from conspecifics, intentionally teach their offspring, and in general, interact with other persons as intentional beings. It is thus at the level of the social cognition of 1- to 2-year-old children-not 3- to 4-year-old children-that we see the basis of the uniquely human forms of social cognition that underlie the evolution of many uniquely human competencies, including language and other cultural skills" (pp.126-127).

From infancy, chimpanzees are highly sensitive to gaze, and use eye contact to discern affective states. Moreover, gaze following develops in humans and chimpanzees similarly. However, there are a number of differences in how humans and chimpanzees process eye gaze. Chimpanzees follows other's gaze sensitively as social signals, but do not use their own gaze as social signals (e.g., Tomasello, 2000). They can be a receiver of social gaze, but not an intentional sender of it. Unlike human infants who eventually develop an ability to attribute mental states to others, chimpanzees never reach this cognitive milestone. As a result, mother chimpanzees never exhibit active showing or teaching to their offspring, for instance (e.g., Sousa, Okamoto, \& Matsuzawa, 2003). Is the lack of several social interactive behaviors in chimpanzees as compared to humans, a "divergence" or an "essential difference"?

Considering the similarities it could be said that the inconsistency of the social-cognitive ability between human and chimpanzee infants may be regarded as an example of divergence. However, once we consider a plethora of the different results from comparative studies between adult chimpanzees and human infants (or adults), there must be an essential difference between their social-cognitive abilities. As the necessary abilities become more complex, the differences between humans and chimpanzees become more pronounced. Considering the negative results of facilitation effects by pre-cueing of gaze stimuli in adult chimpanzees (Tomonaga, 2004), it seems to be more likely that each species" ability is essentially different and not just divergence of development or a different output of the same ability. If there is an essential difference due to a lack of declarative communication, would a subsequent development of sophisticated "human-like" social-cognitive abilities (such as theory of mind) not occur in chimpanzees? In this regard, if chimpanzees have a simple rule such as 'follow the other's gaze reflexively', then they may not need to understand gaze in terms of mental states for their daily social lives and environments. A growing number of studies suggest that while chimpanzees and 
humans use gaze in similar ways, humans may be unique in their propensity to interpret behaviors, including gaze, in a mentalistic fashion. Adhering meaning to others" behavior at any given time may characterize us as human beings.

\section{REFERENCES}

Anderson, J. R., Montant, M, \& Schmitt, D., (1996). Rhesus monkeys fail to use gaze direction as an experimentergiven cue in an object-choice task. Behavioral Processes, 37, 47-55.

Anderson, J. R., Sallaberry, P., \& Barbier, H. (1995). Use of experimenter-given cues during object-choice tasks by capuchin monkeys. Animal Behaviour, $49,201-208$.

Barresi, f, \& Moore, C. (1994). Sharing a oerspective precedes the understanding of that perspective. Behowioral and Brain Sciences, 16,513-514.

Barth, J., Call, J, \& Tomasello, M. (2004). Understanding of social cues in an object-choice task. A comparative study with 2,5-year old children and great apes. XIVth Biennial International Conference on Infant Studies. Chicago, Hllinois,

Barth, J., Reaux, J. E., \& Povinelli, D. J. (2005). Chimpanzees' (Pan troglodytes) use of gaze cues in object-choice tasks: different methods yield different results. Animal Cognition, 8, 84-92.

Bates, E. (1979). Intention, conversations, and symbols. In E. Bates, L.. Benigni, Bretherton, L. Camaioni, \& V. Volterra, (Eds.), The emergence of symbols (pp. 33-42). New York: Academic Press.

Butterworth, G. (1991). The ontogeny and phylogeny of joint visual attention. In A. Whiten (Ed.), Natural theories of mind: Evolution, development, and simulation of everyday mindreading (pp. 223-232). Oxford, England: Blackwell.

Butterworth, G., \& Jarrett, N. (1991). What minds have in common is space: spatial mechanisms serving joint visual attention in infancy. British Jowmal of Developmental Psychology, 9, 55-72.

Boesch, C. (1991). Teaching among wild chimpanzees. Animal Behaviour, 41, 530-532.

Call, J., Hare, B. A., \& Tomasello, M. (1998). Chimpanzee gaze following in an object-choice task. Animal Cognition, 1, 89-99.

Carpenter, M., Nagell, K., \& Tomasello, M. (1998). Social cognition, joint attention, and communicative competence from 9 to 15 months of age. Monographs of the Society for Research in Child Development 63.

Desrochers, S., Morissette, P., \& Ricard, M. (1995). Two perspective on pointing in infancy. In C. Moore \& P. J. Dunham (Eds.). Joint Attention: Its origins and role in developwent. (pp. 85-102). Hillsdale, NJ: Lawrence Erlbaum Associates, Inc.

Emery N N. J. (2000). The eyes have it: the neuroethology, function and evolution of social gaze. Neuroscience and Biobehavioral Reviers, 24, 581-604.

Emery, N. J., Lorincz, E. N., Perrett, D. I., Oram, M, W., \& Baker, C. 1. (1997). Gaze following and joint attention in rhesus monkeys (Macaca mulatta). Jownal of Comparative Psychology, 111, 286-293.

Fagot, J., \& Deruelle, C. (2002). Perception of pictorial eye gaze by baboons (Papio papio). Joumal of Experimental Psychology. Amimal Behowior Processes, 28, 298-308.

Gomex, J. C. (1990). The emergence of intentional communication as a problem-solving strategy in the gorilla. In: Parker S. T., Gibson, K. R. (Eds.), 'Language' and Intelligence in Monkeys and Apes: Comparative developmental approaches (pp. 333-355). Cambridge: Cambridge University Press.

Gomer, J. C., Sarria, E., \& Tamarit, J. (1993). The comparative study of early communication and 
theories of mind. In: S. Baron-Colnen, H. Tager-Flusberg, 2 . Cohen (Eds.), Understanding other minds (pp. 397-426). Oxford, England: Oxford Universiy Press.

Hood, B. M., Willen, J. D., \& Driver, J. (1998). Adwit's eyes trigger shifis of wistal attention in human infants. Psychological Science, 9, $1311-134$.

Itakura, S. (2001). Attention repeated events in infants: effects of joint attention ws. stimulius change. Animal Cogwition, 4, 281-284.

Itakura, S., \& Anderson, J. R. (1996). Learning to wse experimenter-given cties during an object-choice task by a capuchin monkey. Cahiers de Psychologie cognime, 15, 103-112.

ftakura, S., \& Tanaka, M. (1998). Use of experimenter-given cues during object0choice tasks by chimpanzees (Pan troglodytes), and Orangutan (Pongo pygmaeus), and human infants (Homo sapiens). Jourmal of Comparane Psychology, 112, 119-126.

Kummer, H., Anzenberger, G, \& Hemelrijk, C. K. (1996). Hiding and perspective-taking in long-tailled macaques (Macaca fascicularis). Journal of Comparative Psycholog, 110, 97-102.

Lempers, J. D. Flawell, E. R., \& Flavell, J. H. (1977). The development in very young children of tacit knowledge concerning visual perception. Genetic Psychology Monographs, 95, 3-53.

Liszkowski, U., Carpenter, M., Henning, A., Striano T., \& Tomasello, M. (2004). Twelve-month-olds point to share attention and interest. Developmental sictence, 7. 297-307.

Miklosi, A., Polgardi, R., Topal, J., \& Csanyi, V., (1998). Use of experimenter-given cues in dogs. Animal Cognition, $1,113-121$.

Moore, C., \& Corkum, V. (1994). Social understanding at the end of the first year of life. Developmental Review.

Okamoto-Barth, S., Call, J., \& Tomasello, M. Gaze following under visual obstruction conditions by great apes.

Okamoto, S., Tomonaga, M., Ishii, $\mathbb{K}$., \& Matsuzawa, T. (2002). Use of experimenter-given cues by chimpanzee infants. The XIXth Congress of the International Primatological Society. Beijing, China. (Abstracts, p.334-335).

Posner, M. 1. (1980) Orienting of attention. Quarterly Journal of Experimental Psychology, 32, $3-25$.

Povinelli, D.J., Bierschwale, D.T., \& Cech, C.G. (1999). Comprehension of seeing as a referential act in young children, but not juvenile chimpanzees. British Joumal of Developmental Psychology, 17, 37-60.

Povinelli, D. J., \& Eddy, T. J. (1996a). Factors influencing young chimpanzees" (Pan troglodytes) recognition of attention, Journal of Comparative Psychology, $110,336-345$.

Povinelli, D. J., \& Eddy, T. J. (1996b). Chimpanzees: joint visual attention. Psychological Science, $7,129-135$.

Povinelli, D. J., Bering, J. M., \& Giambrone, S. (2003). Chimpanzees" "Pointing": Another efror of the argument by analogy? In S. Kita (Ed.), Pointivg: Where language, culture, and cognition meet (pp. 35-68), London: Lawrence Erlbaum Associates.

Ristau, C. A. (1991). Before mindreading: attention, purpose and deception in birds? Iri: A. Whiten (Ed.), Natural Theories of Mind (pp. 209-222), Ox ford: Blackwell.

Rochat, P. (2001). The wofant s world. Cambridge, MA: Harward University Press.

Russell, C. L., Bard, K. A. \& Adamson, L. B. (1997). Social referencing by young chimpanzees (Pan troglodytes). Joumal of Comprarative Psychology, $111,185-193$.

Sousa, C., Okamoto, $S_{,}$\& Matswzawa, T. (2003). Behavioural development in a matching-to-sample task and token use by an infant chimpanzec reared by his mother. Animal Cognition, 6, 259-267.

Tomasello, M. (1995). Joint attention as social cognition. In C. Moore \& P.J. Dumham (edss.), Joint 


\section{2}

artention: Its origins and wide in development (pp. 103-130). Hillsdale, NI: Erlbaum.

Tomasello, M. (1999). The cultural origins of human cogmition. Harvard University Press: London.

Tomasello, M. (2000). Two Hypothesis about primate cognition. In C. Heyes \& L. Huber (eds.), The Evolution of cognition (pp. 165-184). Cambridge, MA. The MIT Press.

Tomonaga, M. (2004). Percepitual Basis of Social Cognition. Comparative-Cognitive. Unpublished research repont of grant-inwaid for scientific research 2001-2003. (Japanese text)

Tomonaga, M., Myowa-Yamakoshi, M, Mizuno, Y, Okamoto, S., Yamaguchi, M. K., Kasugi, D., Bard, K. A. Tanalka, M, \& Matsuzawa, T. (in press). Chimpanzee social cognition in early life: Comparative-developmental perspective. In E. A. Wasserman \& T. R. Zentall (Eds.), Comparative cognition Experimental explorations of animal intelligence. Oxford University Press: New York.

Wellman, H. M. (1993). Early understanding of mind: The normal case. In S. Baron-Cohen, H. Tager-Flusberg, \& D. Cohen (Eds.), Understanding other minds: Perspectives from cuwism (pp. 10-39). Oxford, England: Basil Blackwell.

Whiten, A. (1996). When does smart behavior-reading become mind-reading? hn: Carruthers P, Smith P. K. (Eds), Theories of theories of mind (pp. 277-292). Cambridge: Cambridge University Press.

Whiten, $A_{1}$, \& Byme, R. W. (1988). The manipulation of attention in primate tactile deception. In: Byme R. W., Whiten A. (Eds.), Machiavellian Intelligence: Social expertise and the evolution of intellect in monkeys, apes and humans (pp. 211-223). Oxford: Oxford University press. 


\section{SUMMARY}

Gaze is defined as looking steadily, intently, and with fixed attention at someone or something. Humans are highly sensitive to the gaze of others. For instance, humans use gaze to signal turns in conversations and to communicate interpersonal attitudes. Human and non-human primates have the ability to perceive eye gaze and other attention cues and use gaze information in their social interactions. Gaze shift and visual processing are important means for signaling social information and are related to the development of mental state attribution (e.g., a theory of mind) in humans.

This dissertation focused on gaze processing in humans and chimpanzees. A series of longitudinal studies with an infant chimpanzee investigated the development of gaze processing. Chapter $I$ focused on the visual interaction between mother and infant chimpanzee. Chapter 2 and 3 focused on the emergence and development of gaze following in an infant chimpanzee. Moreover, Chapter 4 measured eye movements of human adults when exposed to eye-like stimuli in the traditional cueing paradign. This experiment controlled for the presence of a target and investigated how expectancy of a target (or the absence of a target) affects attention to the gaze direction cue.

A series of longitudinal studies with an infant chimpanzee (Chapter 1,2, and 3) found similarities and essential differences between chimpanzee and human infants. In regard to similarities, the chimpanzee infant showed a behavioral sequence of typical "secure-base" behavior. Moreover, the looking at mother/infant increased when body contact decreased or when the distance between them increased. Secondly, by 13 months of age, the infant showed reliable following responses to the object that was indicated by the various cues, including glancing alone. At last, from 21 months of age, the infant started to look back at the target behind him. Although there are some developmental differences about the onset of each "level" of gaze following, on the surface, the development of gaze following in human and chimpanzee infants appears to be highly similar.

There is, however, an essential difference between chimpanzee and human infant. The chimpanzee subject did not look back at the experimenter once he began to follow her sociall (gaze) cue to the target. This behavior is a common occurrence in the social interactions of human mothers and their infants.

In Chapter 4 human adults were tested to investigate whether human adults' expectation of a target affects attention to the gaze direction cue of a line drawing face. Specifically, does a longer SOA (stimulus onset asynchrony) result in decreased expectation of the appearance of a target? The analysis of the eye movements confirmed that the subjects' eye fixation really remained at the fixation point. The results suggest that subjects loose focus of attention when no target appears because they expect the trial to be a trial without a 
target (catch trial). In the catch group, the delay in response time was significant in the valid condition as compared to the invalid condition at the longest SOA (1005 $\mathrm{ms}$ ). This result suggests that, during longer SOAs, the subjects disengage their attentional focus as they cease to expect the occurrence of the target, thus inhibiting attention to the location of the target when it does appear.

The anticipation (or expectancy) of target stimuli was also manipulated in Chapter 3. The results from both studies suggest that the presence or absence of a target and the property of the target (e.g., identical or more attractive moving one) affect the subjects' attention to the cued location.

In the general discussion, differences between humans and non-human primates are discussed. To summarize, although the ability to perceive gaze in various social contexts has been reported for monkeys and apes, the use of gaze within a mentalistic context appears to be uniquely human. The ability to follow another individual's gaze to specific objects, events, and individuals in the environment is accomplished by some species of macaques and apes, suggesting that eye gaze may be an important and complex component of learning about the environment from conspecifics, which does not require a sophisticated mental attribution mechanism. 


\section{SAMENVATTING}

'Gaze' of 'kijken naar' is gedefinieerd als het met strakke blik en aandachtig naar iemand of iets voor enige tijd blijven kijken. Mensen zijn er zeer gevoelig voor als anderen naar hen kijken. Zij, en andere primaten, kunnen informatie over kijkrichting en andere aandachtscues van een ander individu waarnemen en gebruiken die in hun sociale interacties. Veranderingen in kijkrichting en het visueel verwerken daarvan zijn van groot belang voor de onderlinge communicatie; ze houden ook verband met de ontwikkeling van het vermogen om aan een ander een mentale toestand toe te schrijven zoals een "Theory of Mind'.

Dit proefschrift handelt over hoe mensen en chimpansees omgaan met kijken. In een serie longitudinale studies met een babychimpansee werd de ontwikkeling onderzocht van het reageren op oogbewegingen. Hoofdstuk I behandelt de visuele communicatie over en weer tussen een chimpanseemoeder en haar baby. Hoofdstukken 2 en 3 behandelen het optreden van en de ontwikkeling in het volgen van de kijkrichting door een babychimpansee. In hoofdstuk 4 werden de oogbewegingen van volwassenen gemeten tijdens de presentatie van schematische oogstimuli in het traditionele, "Posner cueing paradigma'. In deze studie werden ook de effecten van de aan- of afwezigheid van doelstimuli gemeten.

In een reeks longitudinale studies met een babychimpansee (Hoofdstukken 1, 2, en 3) werden zowel parallellen met de ontwikkeling van kinderen gevonden als ook essentiële verschillen. Wat de overeenkomsten betreft, babychimpansees vertonen in hun gedrag een typische "secure-base" sequentie. Verder nam het onderlinge kijkgedrag toe naarmate er minder lichamelijk contact bestond tussen kind en moeder en de onderlinge afstand toenam. Op de tweede plaats begon de chimpansee op de leeftijd van 13 maanden de kijkrichting van de experimentator nauwkeurig te volgen en de blik te richten op dezelfde objecten in de omgeving. En op de derde plaats, de chimpansee begon op de leeftijd van 21 maanden de blik van de experimentator ook te volgen naar objecten die zich achter zijn rug bevonden ('omkijken'). Hoewel er enkele verschillen in ontwikkeling bestaan met betrekking tot het optreden van de verschillende 'niveaus' van het volgen van de kijkrichting, lijkt de ontwikkeling bij chimpansee- en mensenkinderen globaal op dezelfde wijze te verlopen.

Er is echter een essentieel verschil tussen chimpansee- en mensenkinderen. De chimpansee keek, nadat hij zich had omgedraaid om de kijkrichting van de experimentator te volgen, niet terug naar haar zodra hij haar sociale cue (kijkrichting) naar het doel begon te volgen. Dit is in de sociale communicatie over en weer tussen moeder en kind bij de mens een zeer gebruikelijk gedrag.

In hoofdstuk 4 werd bij volwassen mensen onderzocht hoe de verwachting van een doelstimulus van invloed is op de aandacht voor de 
kijkrichtingscue in een tekening van een gezicht. Meer in het bijzonder was de vraag of een langere SOA (stimulus onset asynchrony) leidt tot een geringere verwachting dat de doelstimulus zal verschijnen? Analyse van de oogbewegingen bevestigde dat de subjecten inderdaad hun ogen op het fixatiepunt gericht hielden. De resultaten suggereren ook dat de proefpersonen als er geen doelstimulus verschijnt hun aandacht laten verslappen, omdat ze verwachten dat het een trial zonder doelstimuli is (catch-trial). In de "çatch"-groep was de verlenging van de responstijd significant voor de grootste SOA (1005 ms) in de conditie ("valid') waarin cue- en doelstimuli corresponderen maar niet in de conditie waarin dat niet het geval is ('invalid'). Dit gegeven suggereert dat de aandacht van de subjecten verslapt tijdens de langere SOA's omdat ze niet langer verwachten dat de doelstimulus zal verschijnen waardoor àls de doelstimulus verschijnt, de aandacht geînhibeerd wordt voor de locatie waar hij verschijnt.

Het anticiperen van doelstimuli werd ook gemanipuleerd in de studie in hoofdstuk 3. De resultaten van beide studies suggereren dat de aan- of afwezigheid van een doelstimulus en de eigenschappen van de doelstimulus (bijv. identiek of een aantrekkelijker bewegende) de aandacht van het subject beînvloeden in de richting van de cue.

In de algemene discussie werden verschillen tussen mensen en apen/mensapen besproken. Samenvattend kan geconcludeerd worden dat alhoewel voor verschillende sociale contexten gevonden is dat apen en mensapen de kijkrichting kunnen waarnemen, het gebruik daarvan in een mentalistische een uniek menselijk vermogen lijkt. Voor enkele soorten makaken en mensapen is vastgesteld dat ze in staat zijn om de kijkrichting van een ander individu naar bepaalde objecten, gebeurtenissen of individuen in hun omgeving te volgen, hetgeen suggereert dat oogbewegingen een belangrijke component vormen met betrekking tot het van soortgenoten leren over de omgeving, waarvoor geen ingewikkeld mentaal attributiemechanisme nodig is. 


\section{DANKWOORD}

I wish to express my thanks to $\mathrm{K}$. Ishii for giving me the opportunity to study psychology at Nagoya University. I learned a lot of important things about psychology and animal behavior at the animal psychology laboratory (doubutsu-sha). Thanks are also due to all members of the laboratory.

I am very grateful to $T$. Matsuzawa, $M$. Tomonaga, and $M$. Tanaka for giving me the opportunity to work with them at the Primate Research Institute, Kyoto University. I wish to express my appreciation to T. Matsuzawa for igniting my interest in chimpanzees. I appreciated his tender toughness, humor and generousness. $M$. Tomonaga supervised me for all studies with chimpanzees from the beginning. He patiently took the time to discuss with me about chimpanzees' cognition. He was always open for trying and discussed new ideas and methods. M. Tanaka always helped and supported me with my experiments. Especially, he always saved me about mechanical problems with PC tasks. Thanks are also due to M. Myowa, Y. Mizuno, N. Nakashima, T. Imura, M. Uozumi, M. Hayashi, A. Ueno, T. Ochiai, C. Sousa, S. Hirata, C. Douke, and the other members of the Language and Intelligence Section for their support of the research project. I also thank to M. Sakai for taking care of all office procedure. Especially I thank N. Maeda, K. Kumazaki, A. Kato, J. Suzuki, S. Goto, C. Hashimoto, and K. Matsubayashi for their daily care of the chimpanzees. I am also grateful to all chimpanzees in PRI. Especially, Ayumu and Ai participated in most of my studies. I appreciate their wonderful cooperation very much.

I wish to express my thanks to all teachers, children and their mothers of Kosumosu-en (the Day-Service Center for the Children with Disabilities of Inuyama City) for letting me join them and learn from them.

I also wish to express my appreciation to N. Kawai, Graduate School of Information Science, Nagoya University for giving me the opportunity to work with him at his laboratory. He always gave me useful advice, and reliable responses. He also patiently took the time to help me with my study, equipments and analysis etc. I also thank all members of the Cognitive Informatics Unit for letting me work at their laboratory.

I am very grateful to $M$. Tomasello and J. Call for giving me the opportunity to work with them at the Max Planck Institute for Evolutionary Anthropology. Working with the four great ape species was really a great and unique experience. Thanks are also due to the colleagues, the staff at the institute, and the keepers at the Wolfgang Köhler Primate Research Center.

W. Raaijmakers has been an excellent co-promoter since I transferred to Universiteit Maastricht. He always helped and supported me a lot with my promotion, our workshop, and many other things. I also really enjoyed talk with him about many other things. I wish to express my appreciation to R. Goebel for supporting me as an external Ph.D student at Universiteit Maastricht. His passion for his work has inspired me and II am grateful for his enthusiasm about my research ideas. 
108

I wish to express my thanks to $F$. Subiaul and $J_{\nu}$ Vonk, Cognitive Evolution Group, University of Louisiana at Lafayette for giving me many helpful suggestions. I also thank J. Sharp for all his help. I am grateful to D. Povinelli for his support.

I am very grateful to J. Barth for his help, support and understanding as a husband and scientist. He always gives me critical comments and useful advice on my studies.

In closing, I would like to dedicate this dissertation to my parents. Without their support, help and deep understanding nothing would have been possible. 


\section{CURRICULUM VITAE}

After graduating in 1995 (BA, Education, Aichi Prefectural University), Sanae Okamoto worked at the patent law office for several years. She got interested in primates and psychology in summer, 1999. In the April of 2000, she entered the master course in psychology at Nagoya University. From the end of July 2000, she started to work on her interest in primate social cognition at the Primate Research Institute, Kyoto University as a cooperative researcher until 2004. In 2002, she received her MA in Psychology at Nagoya University. From 2002 to 2003, she also participated in the observation of Autistic children at the Day-Service Center for Children with Disabilities in Inuyama City, Japan. From 2003 to 2004, she worked at the Max Planck Institute for Evolutionary Anthropology, Leipzig, Germany as a guest researcher at the Department of Developmental and Comparative Psychology for studying social cognition in the four great ape species. In 2004 she joined the Faculty of Psychology, Universiteit Maastricht as an external Ph.D student. Since March, 2005, she is a research director at the Cognitive Evolution Group, University of Louisiana at Lafayette. 


\section{PUBLICATIONS}

Okamoto, S, Tomonaga, M, Ishii, K, Kawai, N, Tanaka, M, \& Matsuzawa, T. (2002). An infant chimpanzee (Pan troglodyres) follows human gaze. Animal Cognition 5, 107-114.

Sousa, C, Okamoto, S, \& Matsuzawa, T. (2003). Behavioural development in a matching-to-sample task and token use by an infant chimpanzee reared by his mother. Animal Cognition. 6, 259-267.

Okamoto, S., Tanaka, M., \& Tomonaga, M. (2004). Looking Back: The "Representational mechanism" of Joint Attention in an infant chimpanzee

(Pan troglodytes). Japanese Psychological Research 46, 236-245.

Tomonaga, M., Tanaka, M., Matsuzawa, T., Myowa-Yamakoshi, M., Kosugi, D., Mizuno, Y., Okamoto, S., Yamaguchi, M. K., \& Bard, K. A. (2004). Development of social cognition in infant chimpanzees (Pan troglodytes): Face recognition, smiling, mutual gaze, gaze following, and the lack of triadic interactions. Japanese Psychological Research, 46, 227-235.

Okamoto, S., \& Matsuzawa, T. (2002). Infant chimpanzees and "Pointing". Science Journal KAGAKU, 4, 398-399.

Sousa, C., Okamoto, S., \& Matsuzawa, T. (2002). Behavioural development in a matching-to-sample task and token use by an infant chimpanzee reared by his mother. Science Journal KAGAKU, 10, 1056-1057.

\section{BOOK CHAPTER}

Okamoto, S., Tomonaga, M., \& Ishii, K. (2003). Understanding and using of another individual's gaze and gestures. In: Tomonaga, M., Tanaka, M., \& Matsuzawa, T. (Eds.), Cognitive and behavioral development in chimpanzees: A comparative approach. Kyoto University Press: Kyoto. pp. 199-210.

Sousa, C., Okamoto, S., \& Matsuzawa, T. (2003). Behavioural development in a matching-to-sample task and token use by an infant chimpanzee reared by his mother. In: Tomonaga, M., Tanaka, M., \& Matsuzawa, T. (Eds.), Cognitive and behavioral development in chimpanzees: A comparative approach. Kyoto University Press: Kyoto. pp.271-276.

Tomonaga, M., Myowa-Yamakoshi, M., Okamoto, S., \& Bard, K. A. (in press). Development of gaze recognition in chimpanzees (Pan troglodytes). In: Fujita, K. \& Itakura, S. (Eds.), Diversity of Cognition: Evolution, Development, Domestication, and Pathology. Kyoto University Press: Kyoto.

Tomonaga, M., Myowa-Yamakoshi, M., Mizuno, Y., Okamoto, S., Yamaguchi, M. K., Kosugi, D., Bard, K. A., Tanaka, M., \& Matsuzawa, T. (in press). Chimpanzee social cognition in early life: Comparative-developmental perspective. In E. A. Wasserman \& T. R. Zentall (Eds.), Comparative cognition: Experimental explorations of animal intelligence. Oxford University Press: New York. 


\section{Submitted manuscripts}

Okamoto-Barth, S., \& Kawai, N. The role of attention in the facilitation effect and Another "Inhibition of Return"

Okamoto-Barth, S., Kawai, N., Tanaka, M., \& Tomonaga, M. Looking compensates for the distance between mother and infant chimpanzee.

\section{Manuscripts in preparation}

Okamoto-Barth, S., Tanaka, M., Tomonaga, M. \& Matsuzawa, T. Use of experimenter-given cues in object-choice tasks by infant chimpanzees.

Okamoto-Barth, S., Call, J., \& Tomasello, M. Gaze following by great apes under visual obstruction conditions.

Okamoto-Barth, S., \& Call, J. Spatial localization after changes in position by great apes and human children.

\section{MEETINGS}

\section{Oral Presentations}

Okamoto, S., Tomonaga, M., Ishii, K., Myowa-Yamakoshi, M., Tanaka, M., \& Matsuzawa, T. (2002, February). Use of experimenter-given cues during object-choice tasks by chimpanzee infants. The 2nd International Symposium on Comparative Cognitive Science, "Social transmission of knowledge". Kyoto and Inuyama, Japan. (Program and Abstracts, p.46).

Tomonaga, M., Okamoto, S., Myowa-Yamakoshi, M., \& Yamaguchi, M. (2002, February). Recognition of face and gaze in infant chimpanzees (Pan troglodytes). The 2nd International Symposium on Comparative Cognitive Science, "Social transmission of knowledge". Kyoto and Inuyama, Japan. (Program and Abstracts, p.66).

\section{Poster presentations}

Okamoto, S., Tomonaga, M., Ishii, K., \& Matsuzawa, T. (2002, August). Use of experimenter-given cues by chimpanzee infants. The XIX th Congress of the International Primatological Society. Beijing, China. (Abstracts, p.334-335).

Sousa, C., Okamoto, S., \& Matsuzawa, T. (2002, August). Cognitive development of an infant chimpanzee. The XIXth Congress of the International Primatological Society. Beijing, China. (Abstracts, p.56).

Okamoto, S., Tanaka, M., \& Tomonaga, M. (2002, November). Looking back: The "representational mechanism" of joint attention in an infant chimpanzee (Pan troglodytes). COE21 International Symposium, "Evolution of the Apes and the Origin of the Human Beings". Inuyama, Japan. (Program and Abstracts, p.40).

Tomonaga, M., Myowa-Yamakoshi, M., Yamaguchi K. M., Okamoto, S., Kosugi, D., \& Bard, A. K. (2002, November). Developmental changes in the recognition of gaze in infant chimpanzees (Pan troglodyres). COE International Symposium, "Evolution of the Apes and the Origin of the Human Beings". Imuyama, Japan. (Program and Abstracts, p.26). 
Okamoto, S., Tanaka, M., \& Tomonaga, M. (2003, July). Development of joint attention in an infant chimpanzee (Pan troglodytes). COE International Symposium, "Evolution and Development of Cognition". Kyoto, Japan. (Abstracts, p.49)

Okamoto, S., \& Kawai, N. Facilitation effects by the direction of the gaze of a line drawing face. (2003, September). COE21 International Symposium, "Diversity of Cognition. Evolution, Development, Domestication, and Pathology". Kyoto, Japan. (Abstracts, p.27)

Okamoto-Barth, S., Tanaka, M., Tomonaga, M., \& Matsuzawa, T. (2003, Novemver). Development of joint attention in an infant chimpanzee. Netherlands society of behavioral biology program annual meeting. Dalfsen, Netherlands.

Okamoto-Barth, S., Tanaka, M., Tomonaga, M., \& Matsuzawa, T. (2004, May). Development of joint attention in an infant chimpanzee. $14^{\text {th }}$ Biennial international conference on infant studies. Chicago, USA. 